
\title{
Atwioce
}

Review

Archive for

Organic Chemistry
Arkivoc 2019, part iv, 0-0 to be inserted by editorial office

\section{Fluorinated aminoglycosides}

\section{Oscar M. Saavedra a and Miguel A. Vilchis-Reyes ${ }^{b}$}

a NuChem Therapeutics Inc, 6100 Royalmount Ave Montreal, Quebec, Canada H4P 2R2

${ }^{b}$ Basic Sciences Department, Universidad Juárez Autónoma de Tabasco, Km. 1 Carretera Cunduacán-Jalpa 86690,Tabasco, México

Email:oscar.saavedra@nuchemtherapeutics.com, miguel.vilchis@ujat.mx

\section{Dedicated to Prof. Stephen Hanessian in honour his scientific contributions to aminoglycoside chemistry}

Received 04-01-2019

Accepted 05-29-2019

Published on line 06-08-2019

\begin{abstract}
Aminoglycosides (AGs) are natural or semisynthetic antibiotics that are inherently toxic, and their use is limited by the widespread presence of AG-resistant bacteria. However, AGs are still valued members of the antibiotic arsenal, particularly against Gram-negative bacteria. The efficiency and clinical value of this class of antibiotics have motivated the exploration of strategies to overcome or evade both the antimicrobial resistance and toxicity. The incorporation of a fluorine atom into AGs has attracted attention as a potential strategy to solve these problematics. This review provides an overview of the research on fluorinates aminoglycosides, their synthesis and, when available, their antimicrobial activity, relative toxicity toward mice or human cells and physicochemical properties.
\end{abstract}

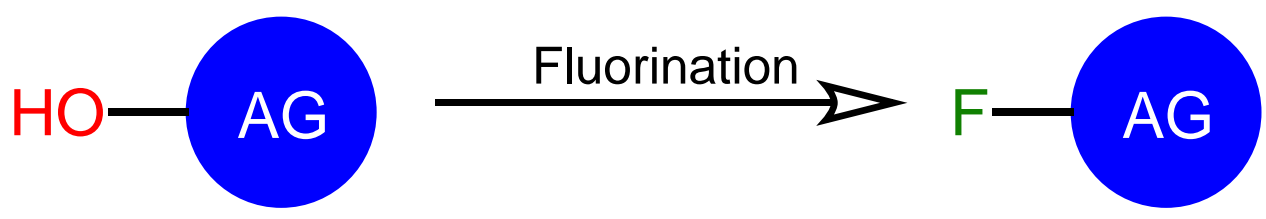

- Aminoglycoside fluorination strategies

- Modification of antimicrobial potency

- Reversal of aminoglycoside resistance

- Modulation of host-toxicity

Keywords: Fluorinated aminoglycosides, deoxyfluorination, toxicity modulation, evasion of antimicrobial resistance. 


\section{Table of Contents}

1. Introduction

2. Fluorinated Monosubstituted Aminocyclitol AGs

2.1. Fluorinated derivatives of sporaricin A (9)

2.2. Fluorinated analogues of neamine (19) and paromamine (20)

2.2.1. Synthesis of $6^{\prime}$-deoxy-6'-fluoroparomamine (23)

2.2.2. Synthesis of $4^{\prime}$ deoxy-4'-fluoro analogues of neamine (19)

2.2.3. Synthesis of $4^{\prime}$-deoxy-4', $4^{\prime}$-difluoroneamine (40)

2.3. Synthes is of $\alpha$-linked 2', 3 '-dideoxy-2'-fluoro-pseudo-disaccharides

2.4. Fluorination of apramycin (47)

3. Fluorinated 4,6-Disubstituted 2-Deoxystreptamine AGs

3.1. Fluorinated 4,6-disubstituted 2-deoxystreptamine AGs

3.1.1. Synthesis of fluorinated sisomicin analogues by mutasynthesis or mutational biosynthesis

3.1.2. Synthesis of 5-deoxy-5-fluoro and 5-deoxy-5-epi-5-fluoro derivatives of sisomicin (65), netilmicin (66) and verdamicin (67)

3.1.3. Synthesis of the 5-deoxy-5-fluoro- and 5-deoxy-5,5-difluoro-derivatives of netilmicin (66)

3.1.4. Synthesis of 6'-deamino-6'-fluorosisomicin (87)

3.2. Fluorination of gentamicin

3.3. Synthesis of fluorinated derivatives of the kanamycin family

3.3.1. Synthesis of 4 "'-deoxy-4"-epi-4"'-fluorokanamycin A (100)

3.3.2. Synthesis of 5-deoxy-4"'-epi-5-fluoro- (103), 6"-deoxy-6"-fluoro- (106) and 5,6"-dideoxy-5epi-5,6"-difluorokanamycin A (107)

3.3.3. Synthesis of $4^{\prime \prime}, 6^{\prime \prime}$-dideoxy-4"-epi-4",6"-difluoro- (110), 4",6"-dideoxy-4"-epi-4"-fluoro(113) and 6"-deoxy-4"'-epi-6"-fluorokanamycin A (116)

3.3.4. Synthesis of $4^{\prime \prime}$-deoxy-4"-fluorokanamycin $A$ (120)

3.3.5. Synthesis of $3^{\prime}, 4^{\prime}, 6^{\prime}$-trideoxy-6'-fluoro- and 1-N-HABA-3', $4^{\prime}, 6^{\prime}$-trideoxy-6'-fluorokanamycin $C$

3.3.6. Synthesis of $6^{\prime}$-C-(fluoromethyl)kanamycin $C(130 \mathrm{a} / \mathrm{b})$ and $6^{\prime}-C$-(fluoromethyl)arbekacin (131)

3.3.7. Synthesis of $3^{\prime}$-deoxy-3'-fluorokanamycin $A(\mathbf{1 4 0})$ and $3^{\prime}, 4^{\prime}$-dideoxy-3'-fluorokanamycin $A$ (144)

3.3.8. Synthesis of $3^{\prime}$-deoxy-3'-fluorokanamycin A (151) via a nucleophilic oxirane opening

3.3.9. Synthesis of $2^{\prime}, 3^{\prime}$-dideoxy-2'-fluorokanamycin $A(158)$

3.3.10. Synthesis of $3^{\prime}$-deoxy-3'-fluoro (163) and $3^{\prime}, 4^{\prime}$-dideoxy-3'-fluoro (165) analogues of kanamycin B (91)

3.3.11. Synthesis of $4^{\prime}$-deoxy-4'-fluorokanamycin A (176)

3.3.12. Synthesis of $4^{\prime}$-deoxy-4'-fluorokanamycin B (182)

3.3.13. Synthesis of 5-deoxy-5-fluoro derivatives of kanamycin B (91), tobramycin (2), and dibekacin (3)

3.3.14. Synthesis of 1-N-HABA-5-deoxy-5-fluoro analogues of kanamycin B (91), tobramycin (2), arbekacin (93)

3.3.15. 5-Deoxy-5-epi- derivatives of amikacin (4), tobramycin (2), dibekacin (3), 1-N-HABA tobramycin, and arbekacin (93) 
3.3.16. Synthesis of 2"-amino-5,2"-dideoxy-5-epi-5-fluorodibekacin (208) and 2"-amino-5,2"'dideoxy-5,2"-diepi-5-fluorodibekacin (210)

3.3.17. Synthesis of 5-deoxy-5,2"-diepi-5-fluorodibekacin (216), 5-deoxy-5-epi-5-fluoro-2"-hydroxy dibekacin (218) and 5-deoxy-5-epi-5-fluoro-2"'-hydroxyarbekacin (219)

3.3.18. Synthesis of $4^{\prime}$-deoxy-4', $4^{\prime}$-difluorokanamycin A (223)

3.3.19. Synthesis of $6^{\prime \prime}$-deoxy-6",6"-difluorokanamycin A (227)

4. Fluorinated 4,5-Disubstituted 2-Deoxystreptamine AGs

4.1. Synthesis of 5"-deoxy-5"-fluorolividomycin B (234)

4.2. Fluorination of paromomycin (7) and neomycin (8)

4.2.1. Synthesis of $6^{\prime}$-deoxy-6'-fluoroparomomycin (238)

4.2.2. Synthesis of $4^{\prime}$-deoxy-4'-epi-4'-fluoro- (241), 4'-deoxy-4'-fluoro- (243), and 1-N-HABA-4'deoxy-4'-epi-4'-fluoroneomycin B (246)

5. AGs with Fluorinated $\omega$-Amino Acid Lateral Chains at Position 1

5.1. Synthesis of amikacin analogues with a $\omega$-amino- $\alpha$-fluoroalkanoyl side chain

5.2. Synthesis of $1-N-[(2 R, 3 R)-$ and $1-N-[(2 R, 3 R)-4$-amino-3-fluoro-2-hydroxybutanoyl] derivatives of kanamycin A

5.3. Synthesis of $1-N-\left[\left(2^{\prime \prime \prime} S, 4^{\prime \prime \prime} S\right)\right.$ and $\left(2^{\prime \prime \prime} S, 4^{\prime \prime \prime} R\right)$-5-amino-4-fluoro-2-hydroxypentanoyl] derivatives of dibekacin

5.4. Synthesis of $3^{\prime \prime \prime \prime}$-fluorinated $1-N-\left(4^{\prime \prime \prime \prime}\right.$-amino-2"'”-hydroxybutanoyl)-3", 4 "', $3^{\prime \prime \prime}, 4^{\prime \prime \prime}$-tetradeoxy neomycin B analogues

6. Conclusions

\section{Introduction}

Aminoglycosides (AGs) are a class of clinically important, potent and broad-spectrum antibiotics. ${ }^{1}$ They bind to the decoding A-site of the $16 \mathrm{~S}$ ribosomal $\mathrm{RNA}^{2-4}$ and interfere with protein synthesis, ${ }^{3-5}$ which gives these types of molecules broad bactericidal effects. Examples of clinically used AGs include the natural products kanamycin A (1), tobramycin (2), and the gentamycin complex (gentamycin C2 (6) shown) as well as semisynthetic AGs amikacin (4) and dibekacin (3). ${ }^{6}$ Other important AGs include paromomycin (7), used for the treatment of leishmaniosis and dysenteric amoebiasis, ${ }^{7-8}$ and neomycin B (8), used in topical ointments ${ }^{9}$ (Figure 1).

The extensive use of AGs as antibiotics has led to the emergence of resistant strains that express aminoglycoside-modifying enzymes (AMEs). ${ }^{1}$, 6, 10-12 AMEs catalyse modifications of the functional groups of AGs, rendering clinically important AGs inactive. AMEs include enzymes such as $N$-acetyltransferases (AACs), $O$-phosphotransferases (APHs) and $O$-adenyltransferases (ANTs). It is possible to avoid the action of AMEs by the suitable synthetic modification of the AG. Semisynthetic dibekacin (3), ${ }^{13}$ which lacks the $3^{\prime}$ and $4^{\prime} \mathrm{OH}$ moieties, is not deactivated by APH (3') and ANT (4') enzymes that render kanamycin (1) inactive. A similar result can be obtained by deoxyfluorination. Semisynthetic AG $3^{\prime}, 4^{\prime}$-dideoxy-3'-fluorokanamycin $A(144)$, ${ }^{14}$ is not deactivated by APH (3') or ANT (4') enzymes. The introduction of a fluorine atom in the structure of an AG has another advantage: it can modulate the electron density of neighbouring nitrogen atoms, reducing their basicity (vide infra).

In addition to resistance, another limitation on the use of AGs as drugs is their high nephrotoxicity ${ }^{15}$ and ototoxicity. ${ }^{16-19}$ The correlation between the acute toxicity and basicity of AGs has been established, ${ }^{20}$ and the 
introduction of an electronegative fluorine atom allows the modulation of the $\mathrm{p} K_{\mathrm{a}}$ of a neighbouring nitrogen. ${ }^{21-22}$
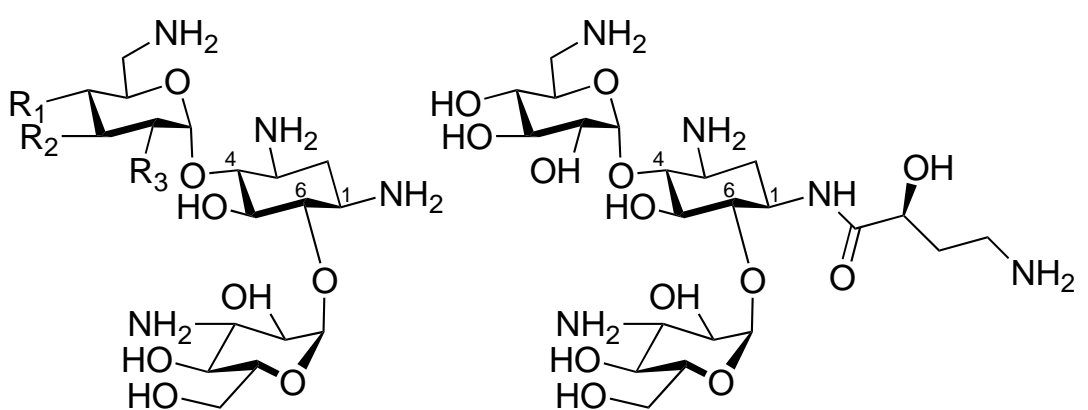

$$
\begin{array}{ll}
1 \text { kanamycin } A R_{1}=R_{2}=R_{3}=O H \\
\text { 2 tobramycin } & R_{1}=O H, R_{2}=H, R_{3}=N_{2} \\
\text { 3 dibekacin } & R_{1}=R_{2}=H, R_{3}=N_{2}
\end{array}
$$

4 amikacin

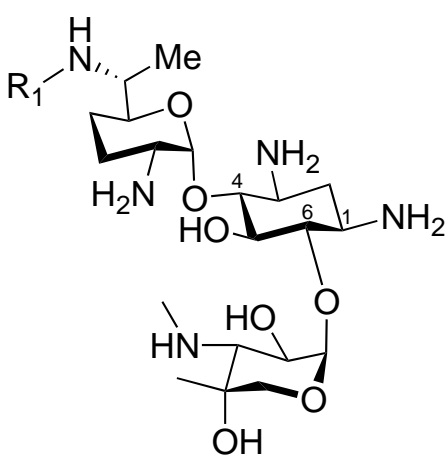

5 gentamycin $\mathrm{C}_{1} \mathrm{R}_{1}=\mathrm{Me}$ 6 gentamycin $\mathrm{C}_{2} \mathrm{R}_{1}=\mathrm{H}$

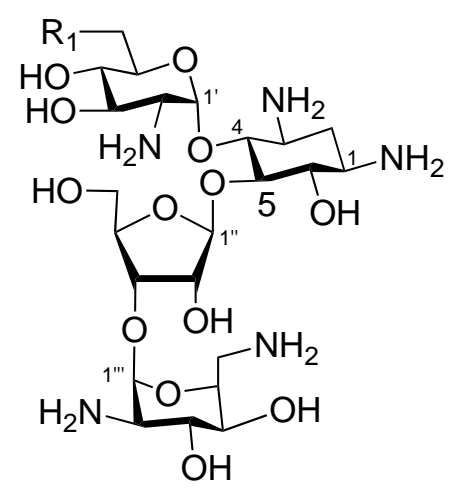

7 paromomycin $\mathrm{R}_{1}=\mathrm{OH}$

8 neomycin $\mathrm{B} \quad \mathrm{R}_{1}=\mathrm{NH}_{2}$

Figure 1. Clinically important AGs.

Fluorinated AGs are of interest to provide antibiotics with improved antibacterial activity, ${ }^{23}$ better resistance to inactivation by bacterial enzymes, ${ }^{24-25}$ and lower toxicity. ${ }^{26-28}$ To date, the primary synthetic tool for preparing fluorinated derivatives of AGs has been deoxyfluorination using fluorinating agents, particularly DAST, or by nucleophilic displacement using a fluoride salt (organic or inorganic) ${ }^{29}$. The principal obstacle to fluorination of aminoglycosides is obtaining an appropriately protected molecule in which only the target group is free to transform; this process may require several well-planned protection-deprotection sequences. ${ }^{29}$ Sometimes, the outcome of deoxyfluorination is difficult to predict a priori, ${ }^{30}$ and several steps are required to achieve the desired substitution pattern, obtaining a single fluorinated AG derivative can be considered a scientific feat in and of itself.

The first reports related to fluorinated AGs appeared in the literature in the $1970 \mathrm{~s} .{ }^{31-32}$ Since then, the topic has been of particular interest, and several studies were published between 1980 and 1998. Recently, this field has attracted new interest. ${ }^{33-36}$ Our aim is to briefly review the synthetic procedures used to obtain fluorinated AGs described in the literature. When available, we also comment on the biological data and physicochemical parameters of the fluorinated AG. 


\section{Fluorinated Monosubstituted Aminocyclitol AGs}

\subsection{Fluorinated derivatives of sporaricin $A(9)^{37-38}$}

The structures of sporaricins $A$ and $B(\mathbf{9}$ and $\mathbf{1 0})$ are shown in Figure 2.

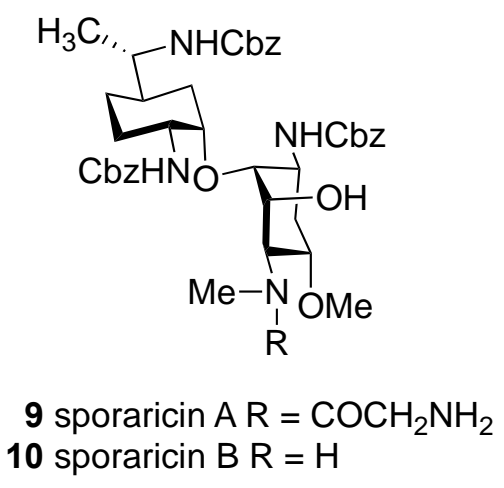

Figure 2. Sporaricin A and sporaricin B.

The treatment of a suitable protected sporaricin B analogue (11) with diethylaminosulfur trifluoride (DAST) at low temperature resulted in deoxyfluorination with inversion of the configuration (Scheme 1), the use of DAST for deoxyfluorination has been reviewed. ${ }^{39-41}$ Selective hydrolysis of the cyclic carbamate with $\mathrm{Ba}(\mathrm{OH})_{2}$ followed by $\mathrm{N}$-acylation with $\mathrm{Cbz}$ glycine $\mathrm{N}$-hydroxysuccinimide gave 12 in an overall yield of $25 \%$. Removal of the $\mathrm{N}$-Cbz protecting group by hydrogenolysis provided 3-demethoxy-3-epi-3-fluorosporaricin A (16). Treatment of $\mathbf{1 1}$ with pyridinium chlorochromate (PCC) gave the 3-oxo derivative (13) in excellent yield. The Pfitzner-Moffatt oxidation can also be used, although the yields are lower.

The reduction of the carbonyl exclusively afforded the axial alcohol, and subsequent deoxyfluorination using DAST yielded compound (14). Global deprotection afforded 3-fluoro-3-demethoxy sporaricin A (17). The reaction of 13 with DAST afforded the C-3 difluorinated analogue (15), which after deprotection, afforded 18. 


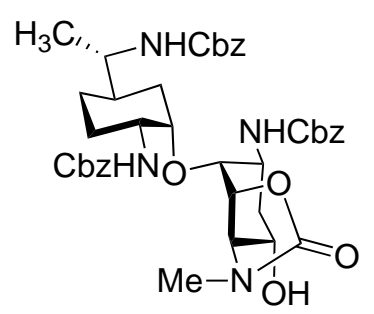

11

PCC, $\mathrm{CH}_{2} \mathrm{Cl}_{2}$

reflux, $3 \mathrm{~h}$

$90 \%$

$\mathrm{H}_{3} \mathrm{C}$, $\mathrm{NHCbz}$

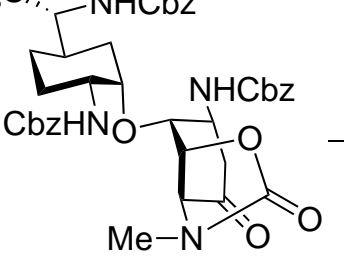

13

$\mathrm{H}_{3} \mathrm{C}_{\text {, }}-\mathrm{NHCbz}$

1. DAST, $\mathrm{CH}_{2} \mathrm{Cl}_{2},-15^{\circ} \mathrm{C}$

2. $\mathrm{Ba}(\mathrm{OH})_{2}$ aq., $80{ }^{\circ} \mathrm{C}$

3. N-Cbz-Gly-OSu, $\mathrm{Et}_{3} \mathrm{~N}$, THF, 2 days

$25 \%$

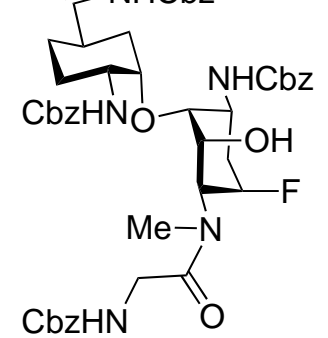

12

$\mathrm{H}_{3} \mathrm{C}$

1. $\mathrm{MeOH}, \mathrm{NaBH}_{4}$

2. DAST, $\mathrm{CH}_{2} \mathrm{Cl}_{2}$

$\begin{array}{ll}\text { DAST, } \mathrm{CH}_{2} \mathrm{Cl}_{2} & \mathrm{H}_{3} \mathrm{C} \text {, } \\ -15^{\circ} \mathrm{CH} \text { to rt } & \mathrm{NHCbz}\end{array}$

$72 \%$
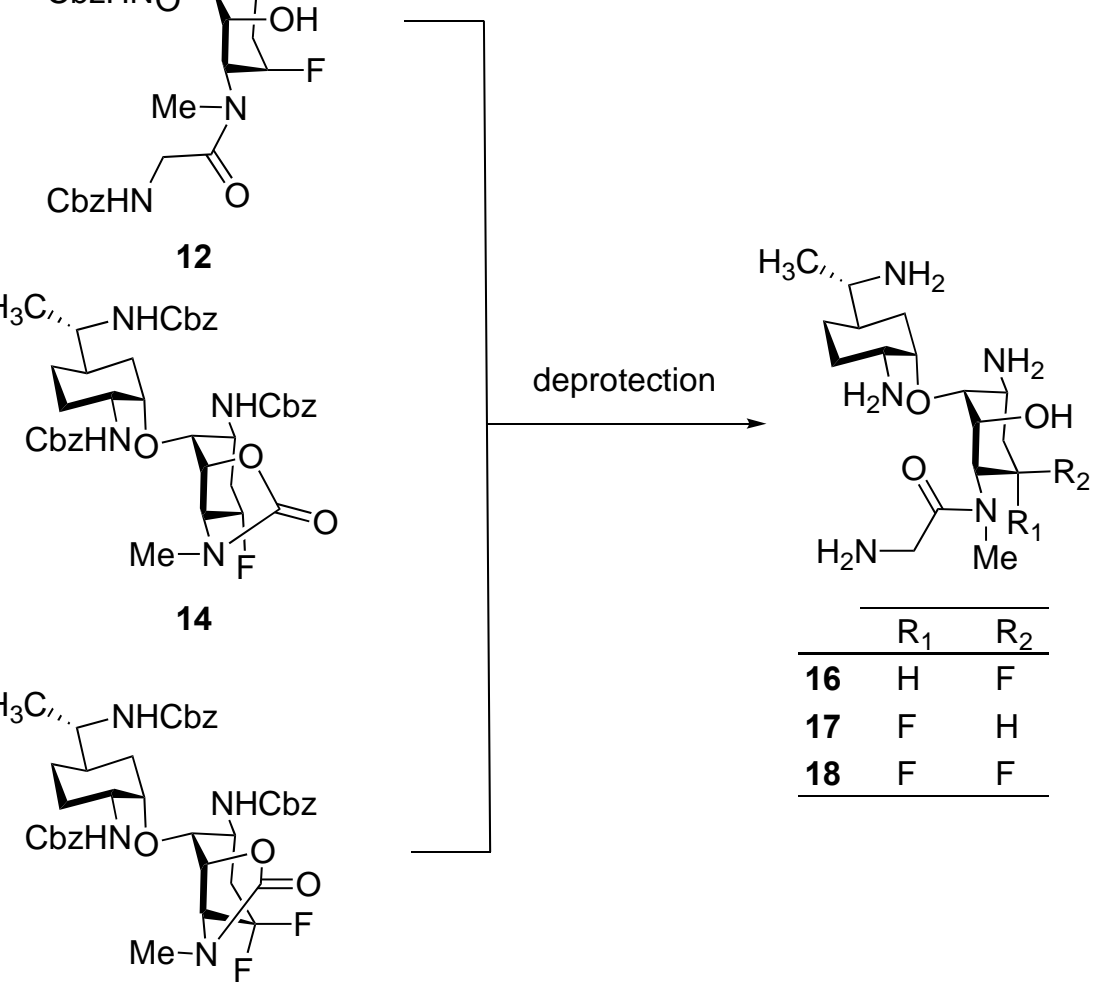

15

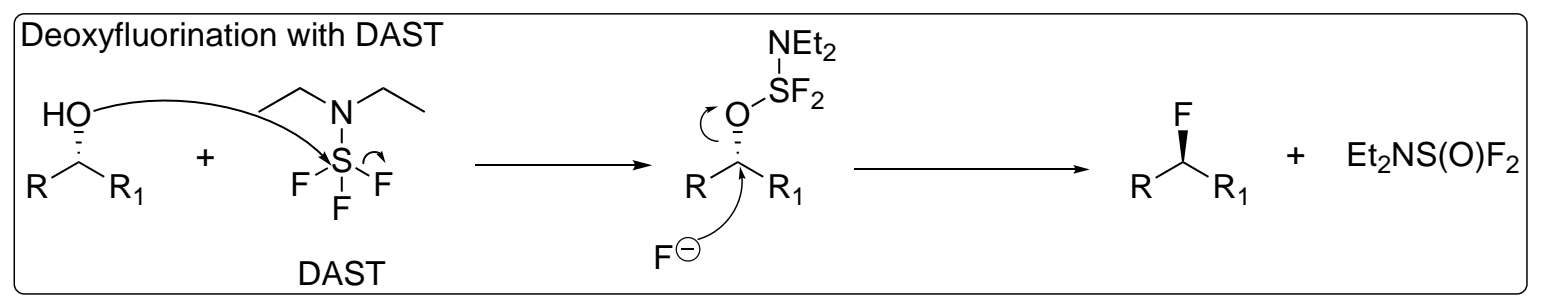

Scheme 1. Synthesis of 3-demethoxy-3-epi-3-fluorosporaricin A (16), 3-demethoxy-3-fluorosporaricin A (17) and 3-demethoxy-3,3-difluorosporaricin A (18).

Compounds 16, 17 and 18 were tested together with sporaricin A (9) against a panel of clinically important bacteria. The order of their antibacterial activity was $17>$ sporaricin A (9) $>16>18$. The fluorinated analogues $(\mathbf{1 6}, 17$ and 18 ) were less toxic than the parent compound, sporaricin $A(9)$, with difluorinated analogue (18) being approximately two-fold less toxic than sporaricin A (9) in acute toxicity studies on mice. ${ }^{37}$

\subsection{Fluorinated analogues of neamine (19) and paromamine (20)}

The chemical structure of neamine (19) and paromamine (20) are displayed in Figure 3. 


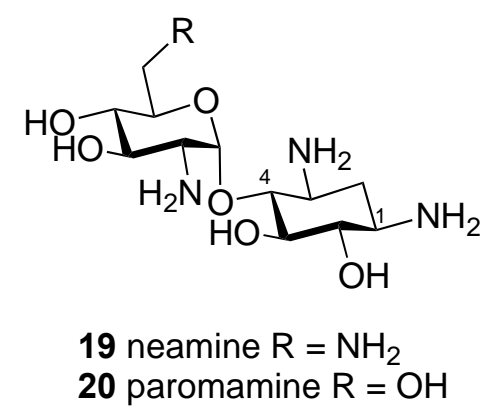

Figure 3. Neamine and paromamine.

2.2.1. Synthesis of $6^{\prime}$-deoxy-6'-fluoroparomamine (23). ${ }^{39}$ The synthesis of the title compound (23) was performed with the aim of generating a high affinity ligand to perform ligand-based competitive binding NMR studies. ${ }^{42}$ A suitably protected paromamine analogue (21) was reacted with tert-butyldimethylsilyl chloride (TBSCl) and then subjected to per-O-acetylation, affording 22 after cleavage of the silyl protecting group with $\mathrm{HF}$ and pyridine (Scheme 2). The reaction of $\mathbf{2 2}$ with DAST, followed by cleavage of the protecting groups yielded 23 in $64 \%$ yield.
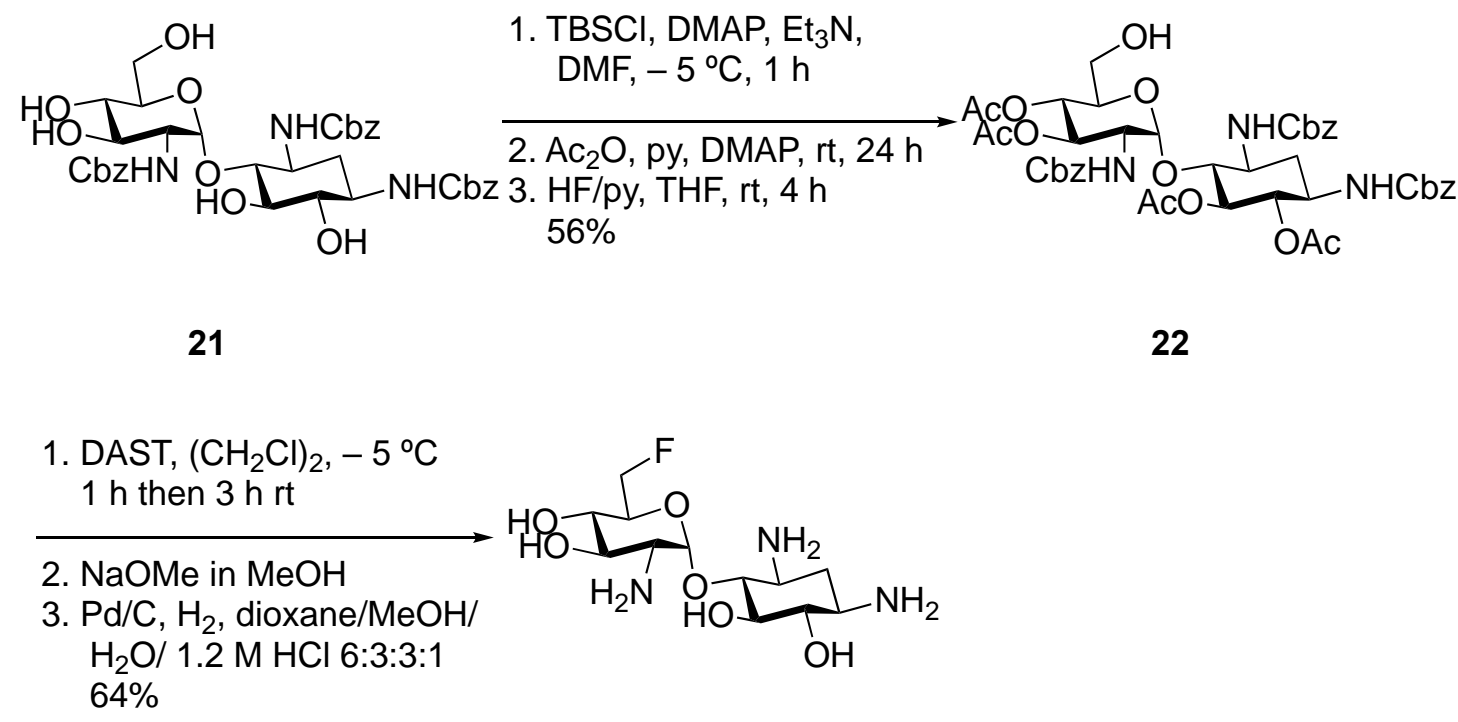

Scheme 2. Synthesis of $6^{\prime}$-deoxy-6'-fluoroparomamine (23).

Compound (23) proved to be a good reporter for monitoring the binding of A-site rRNA ligands. Taking advantage of the chemical-shift variations in their ${ }^{19} \mathrm{~F}$ NMR spectra, the authors were able to determine the dissociation constants of paromomycin (7), neomycin (8), and neamine (19), and the obtained values were in good agreement with previous determinations. ${ }^{42}$

2.2.2. Synthesis of 4'deoxy-4'-fluoro analogues of neamine (19). ${ }^{43}$ Two syntheses were reported by Hanessian's group as part of a systematic study to obtain fluorinated analogues of neomycin B (8). ${ }^{25}$ In their first approach (Scheme 3), paromamine derivative (24) was used as the starting material, and their second approach (Scheme 4) used neamine derivative (32). The deoxyfluorination reaction was first studied using 6azido-3-O-benzyl-6-deoxy- $\alpha$-D-glucosamine pyranoside, a model compound that mimics ring I of neamine (19) (not shown). The reaction with DAST and the $S_{N} 2$ displacement of 4-sulfonate esters with fluoride anion were 
modelled. Treatment with DAST gave a complex mixture of products, making the approach from the 4sulfonate esters a more successful model. Both approaches were used in the synthesis of fluorinated neamine analogues. ${ }^{43}$

The per-O-benzylation of $\mathbf{2 4}$ using sodium hydride, benzyl bromide and tetrabutylammonium iodide (TBAI) as the catalyst, followed by cleavage of the benzylidene protecting group under acidic conditions, gave compound (25) (Scheme 3). The regioselective tosylation of the primary 6'-OH followed by azide displacement afforded 26. Unlike the monosaccharide model, the reaction of compound $\mathbf{2 6}$ with DAST in dichloromethane afforded a separable mixture of $\mathbf{2 7}$ and $\mathbf{2 8}$ in 32\% and 33\% yields, respectively. Derivative (28), with retention of the configuration at C-4', was generated via neighbouring group participation by the C-3' benzyl ether through a 3',4'-oxiranium ring intermediate. Although the yields were reasonable, scale-up proved challenging, and the use of 4-sulfonate esters was explored. Formation of the triflate and displacement with fluoride using tetrabutylammonium fluoride (TBAF) provided 27. A Staudinger reduction of the azide groups followed by hydrogenolysis of the benzyl ethers gave 29. The treatment of 26 with $\mathrm{Tf}_{2} \mathrm{O}$ in $\mathrm{pyridine} / \mathrm{CH}_{2} \mathrm{Cl}_{2}$ followed by $S_{N} 2$ displacement with acetate and Zemplén deacetylation afforded a 4'-epi derivative (30). Compound $\mathbf{3 0}$ was treated with $\mathrm{Tf}_{2} \mathrm{O}$ and TBAF to give a $4^{\prime}$-deoxy-4'-fluorinated derivative (28). Compound $\mathbf{3 1}$ was obtained after removal of the protecting groups under standard conditions. ${ }^{43}$

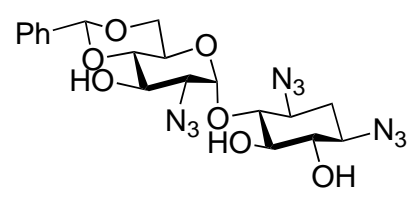

24

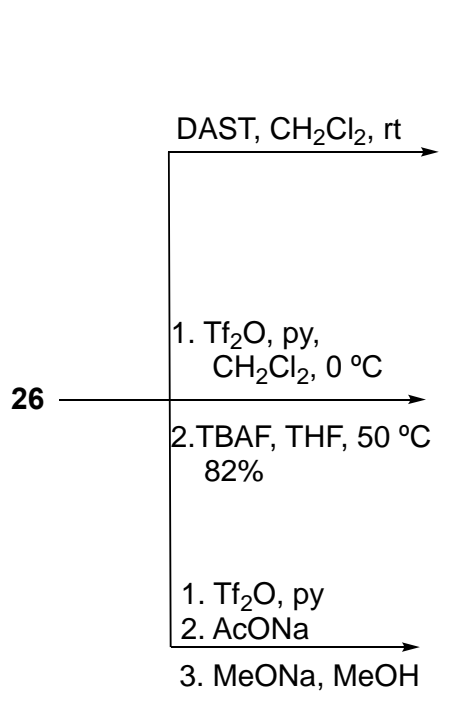

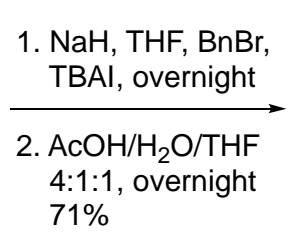

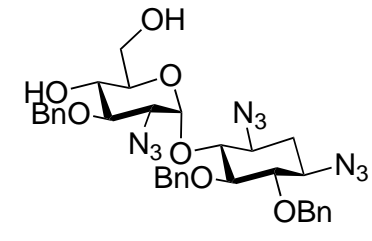

25
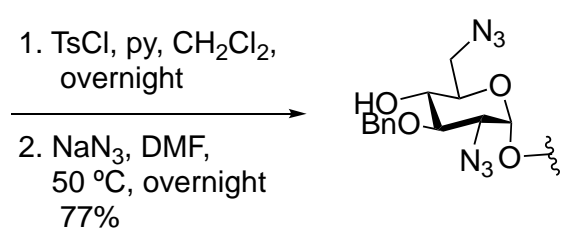

26

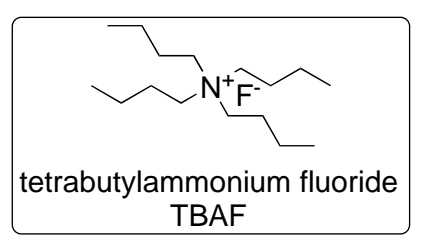

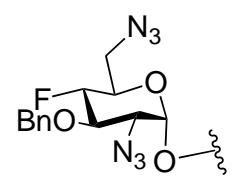

$27(32 \%)$

$28(33 \%)$
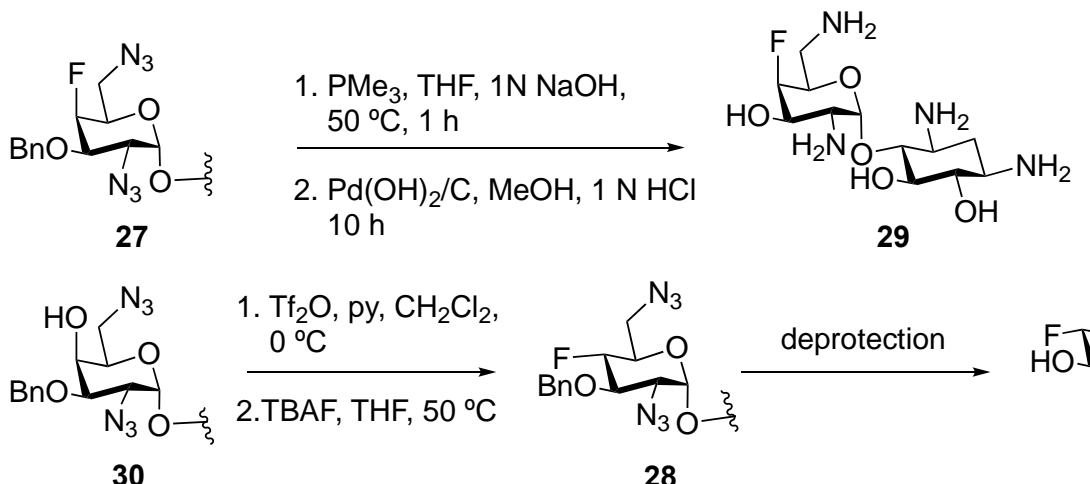

28

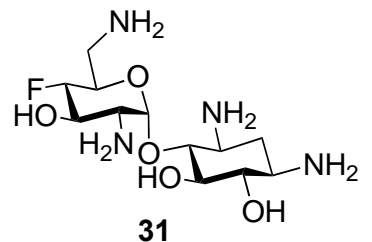

Scheme 3. First approach to the synthesis of $4^{\prime}$-deoxy-4'-epi-4'-fluoroneamine (29) and 4'-deoxy-4'fluoroneamine (31).

The second approach started from perazido neamine derivative 32 (Scheme 4). Treatment of 32 with triisopropylsilyl trifluoromethanesulfonate (TIPSOTf) followed by reaction with mesyl chloride (MsCl) and cleavage of the silyl protecting group with concomitant formation of the 3'-4'-oxirane moiety afforded epoxide (33) in 35\% yield. Treatment of 33 with TBAF gave 4'-deoxy-4'-fluoroglucosamine derivative (34) and vinyl 
azide 35. The vinyl azide is formed by syn elimination promoted by the basicity of the fluoride ion by a method that was previously reported in the literature. ${ }^{44}$ The deprotection of compound $\mathbf{3 4}$ gave $\mathbf{3 1}$ in $68 \%$ yield. The reaction of $\mathbf{3 2}$ with DAST in dichloromethane afforded two compounds: a 4'-deoxy-4'-epi-4'-fluoro neamine derivative (36) and compound $\mathbf{3 7}$, which was formed by ring contraction.

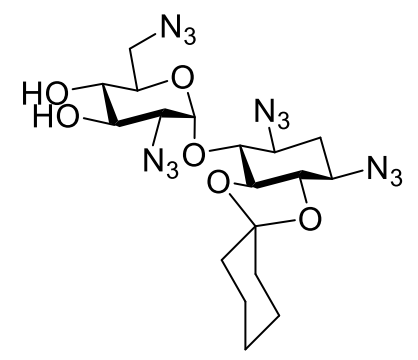

32
1. TIPSOTf, collidine,

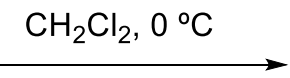

2. $\mathrm{MsCl}$, collidine, $\mathrm{rt}$,

3. TBAF, $\mathrm{CH}_{2} \mathrm{Cl}_{2}$ $\mathrm{rt}$, overnight $35 \%$

DAST, $\mathrm{CH}_{2} \mathrm{Cl}_{2}$,
rt,2 days

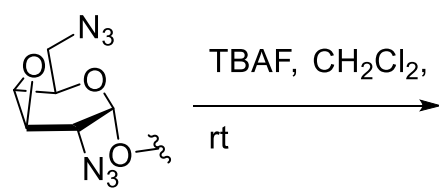

33
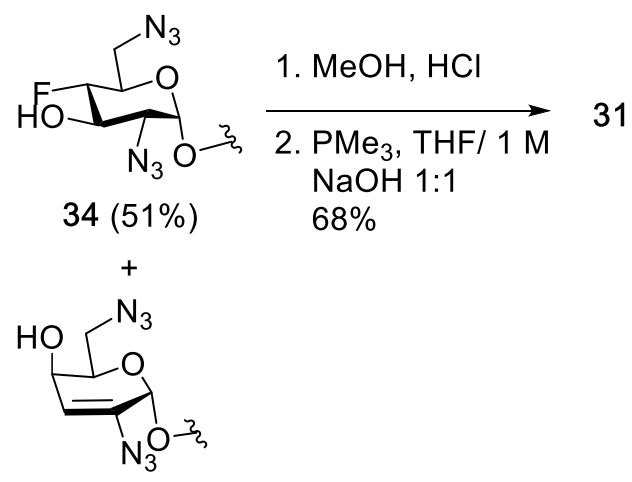

$35(28 \%)$

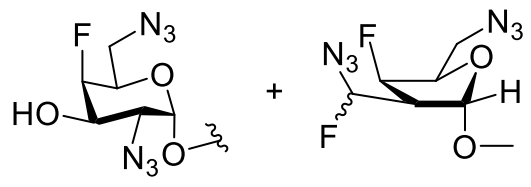

$36(34 \%)$

$37(22 \%)$

Scheme 4. Second approach to the synthesis of 4'-deoxy-4'-fluoroneamine (31).

Both compounds (29 and 31) were crystallized as complexes with the rRNA A-site, ${ }^{45-46}$ showing that these compounds effectively interact with the macromolecule.

2.2.3. Synthesis of $\mathbf{4}^{\prime}$-deoxy-4',4'-difluoroneamine (40).47 The treatment of suitable protected neamine derivative (38) with tert-butyldimethylsilyl chloride (TBSCl) and imidazole (Im) in DMF followed by oxidation of the 4'-OH group with DMSO-Ac $2 \mathrm{O}$ gave 39 (Scheme 5). Deoxyfluorination was achieved by treating 39 with Morpho-DAST, a more thermally stable version of DAST, 40, 48 and 4'-deoxy-4',4'-difluoroneamine (40) was obtained after removal of the protecting groups under standard deprotection conditions.
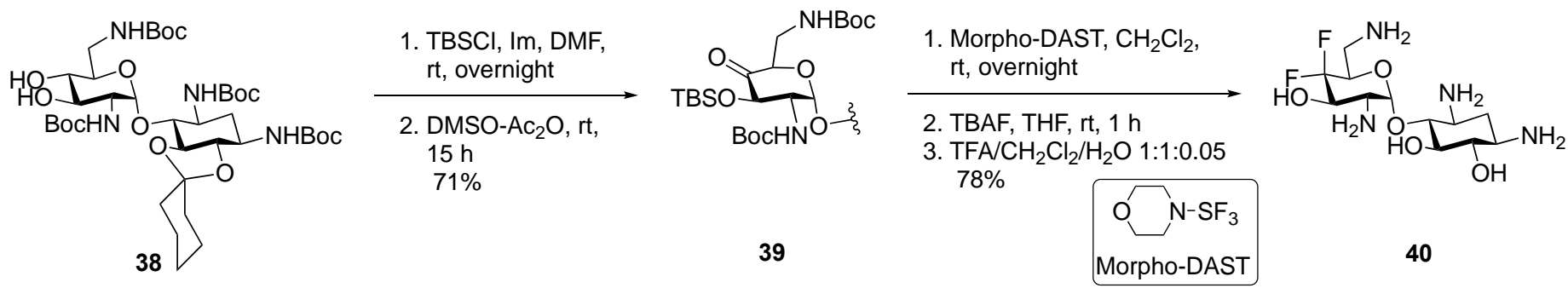

Scheme 5. Synthesis of 4'-deoxy-4',4'-difluoroneamine (40).

The kinetics of the reaction of Gram-negative $\mathrm{APH}\left(3^{\prime}\right)$ types I and II with neamine (19) and its 4'-deoxy4',4'-difluoro analogue (40) were evaluated, and the results showed that difluorination severely impairs the binding of the difluorinated analogue to the enzymes. The impairment was in the same range as that observed 
with the D198A mutant of the $\mathrm{APH}\left(3^{\prime}\right)$-la with $4^{\prime}$-deoxy-4', $4^{\prime}$-difluorokanamycin $\mathrm{A}$ (223) (refer to section 3.3.18), ${ }^{47}$ and these results were attributed to the reduction of the nucleophilicity of the $4^{\prime}-\mathrm{OH}$ due to the presence of the electronegative atoms.

\subsection{Synthesis of $\alpha$-linked 2',3'-dideoxy-2'-fluoro-pseudo-disaccharides ${ }^{31}$}

Compounds 44 and 46 were obtained by glycosylation of the previously fluorinated derivative 3,4,6-tri-Oacetyl-2-deoxy-2-fluoroglycal $\mathbf{4 1}$, which is accessible from tri-O-acetylglycal, ${ }^{49-50}$ with cyclitol derivatives $\mathbf{4 2}$ and 45, respectively (Scheme 6). The glycosylation reaction between $\mathbf{4 1}$ and $\mathbf{4 2}$ afforded a mixture of the $\alpha$ and $\beta$ anomers. The $\alpha$ anomer (43) was obtained in 58\% yield, and the $\beta$ anomer was obtained in $28 \%$ yield. Compound $\mathbf{4 4}$ was obtained after displacement of the tosyl groups with sodium azide, hydrolysis of the ester protecting groups and hydrogenation with Pt. A similar procedure was used to obtain 46. Both aminocyclitol derivatives were synthesized as possible precursors of more complex AGs by mutasynthesis. ${ }^{31}$

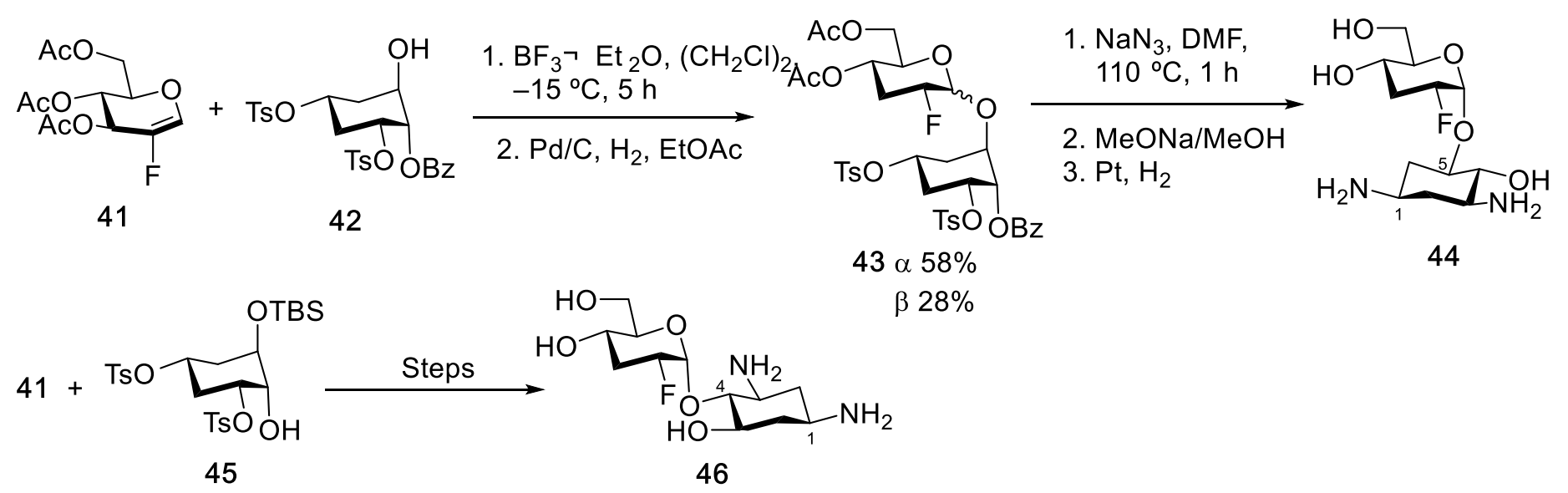

Scheme 6. Synthesis of fluorinated pseudo saccharides $\mathbf{4 4}$ and $\mathbf{4 6 .}$

\subsection{Fluorination of apramycin $(47)^{34}$}

Apramycin (47, Figure 4) is a structurally unique monosubstituted aminocyclitol AG, which currently is only approved for veterinary use. ${ }^{51}$

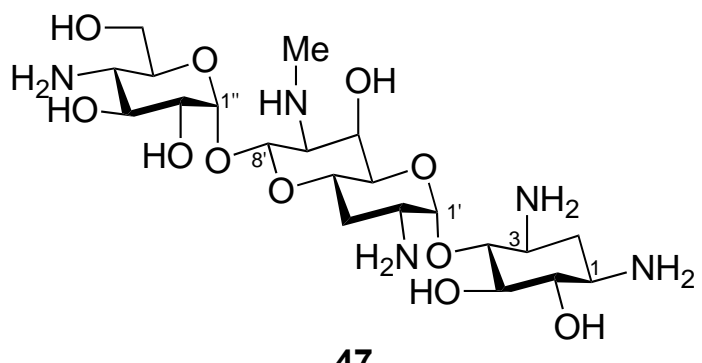

Figure 4. Apramycin (47).

The synthesis of several fluorinated apramycin analogues (48 - 55) has been reported in the patent literature (Figure 5). ${ }^{34}$ Two of the reported syntheses are discussed next (vide infra). 


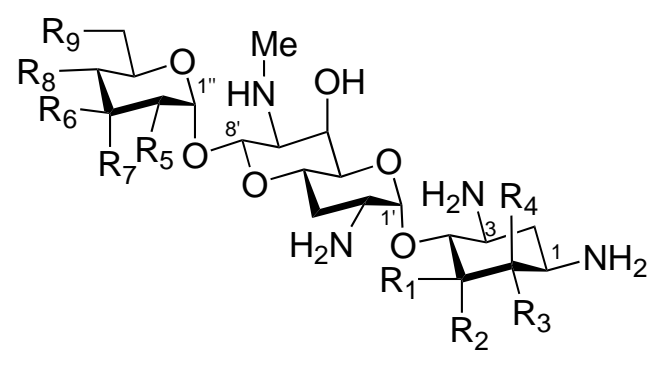

\begin{tabular}{llllllllll}
\cline { 2 - 8 } & $\mathrm{R}_{1}$ & $\mathrm{R}_{2}$ & $\mathrm{R}_{3}$ & $\mathrm{R}_{4}$ & $\mathrm{R}_{5}$ & $\mathrm{R}_{6}$ & $\mathrm{R}_{7}$ & $\mathrm{R}_{8}$ & $\mathrm{R}_{9}$ \\
\hline $\mathbf{4 8}$ & $\mathrm{H}$ & $\mathrm{F}$ & $\mathrm{OH}$ & $\mathrm{H}$ & $\mathrm{OH}$ & $\mathrm{OH} H$ & $\mathrm{H} H_{2}$ & $\mathrm{OH}$ \\
$\mathbf{4 9}$ & $\mathrm{H}$ & $\mathrm{F}$ & $\mathrm{OH}$ & $\mathrm{H}$ & $\mathrm{H}$ & $\mathrm{H}$ & $\mathrm{OH}$ & $\mathrm{NH}_{2}$ & $\mathrm{OH}$ \\
$\mathbf{5 0}$ & $\mathrm{H}$ & $\mathrm{F}$ & $\mathrm{OH}$ & $\mathrm{H}$ & $\mathrm{OH}$ & $\mathrm{H}$ & $\mathrm{H}$ & $\mathrm{NH}_{2}$ & $\mathrm{OH}$ \\
$\mathbf{5 1}$ & $\mathrm{H}$ & $\mathrm{F}$ & $\mathrm{H}$ & $\mathrm{NH}_{2}$ & $\mathrm{OH}$ & $\mathrm{OH} \mathrm{H}$ & $\mathrm{NH}_{2}$ & $\mathrm{OH}$ \\
$\mathbf{5 2}$ & $\mathrm{H}$ & $\mathrm{F}$ & $\mathrm{OH}$ & $\mathrm{H}$ & $\mathrm{OH}$ & $\mathrm{OH} \mathrm{H}$ & $\mathrm{NH}(\mathrm{CNH}) \mathrm{NH}_{2}$ & $\mathrm{OH}$ \\
$\mathbf{5 3}$ & $\mathrm{H}$ & $\mathrm{F}$ & $\mathrm{OH}$ & $\mathrm{H}$ & $\mathrm{OH}$ & $\mathrm{H}$ & $\mathrm{H}$ & $\mathrm{NH}(\mathrm{CNH}) \mathrm{NH}_{2}$ & $\mathrm{OH}$ \\
$\mathbf{5 4}$ & $\mathrm{F}$ & $\mathrm{H}$ & $\mathrm{H}$ & $\mathrm{H}$ & $\mathrm{OH}$ & $\mathrm{OH} \mathrm{H}$ & $\mathrm{NH}_{2}$ & $\mathrm{OH}$ \\
$\mathbf{5 5}$ & $\mathrm{OH}$ & $\mathrm{H}$ & $\mathrm{OH}$ & $\mathrm{H}$ & $\mathrm{OH}$ & $\mathrm{OH} \mathrm{H}$ & $\mathrm{NH}_{2}$ & $\mathrm{~F}$ \\
\hline
\end{tabular}

Figure 5. 5-Deoxy-5-epi-5-fluoroapramycin (48), 5,2"-dideoxy-5,3"-di-epi-5-fluoroapramycin (49), 5,3"dideoxy-5-epi-5-fluoroapramycin (50), 6-amino-5,6-dideoxy-5,6-di-epi-5-fluoroapramycin (51), 4"'-deamino-5deoxy-5-epi-5-fluoro-4"-guanidinoapramycin (52), 4"-deamino-5,3"'-dideoxy-5-epi-5-fluoro-4"guanidinoapramycin (53), 5,6-dideoxy-5-fluoroapramycin (54) and 6"'-deoxy-6"'-fluoroapramycin (55).

The synthesis of 5-deoxy-5-epi-5-fluoroapramycin $(\mathbf{4 8})^{34}$ started from suitably protected apramycin derivative 56. ${ }^{52}$ The reaction of $\mathbf{5 6}$ with $\mathrm{Boc}_{2} \mathrm{O}$ and triethylamine (TEA) afforded $\mathbf{5 7}$, which was further reacted with benzoyl chloride $(\mathrm{BzCl})$ to give $\mathbf{5 8}$ (Scheme 7). Treatment of $\mathbf{5 8}$ with DAST gave two products, the 5-epi derivative (59) and the desired 5-deoxy-5-fluoro-5-epi derivative (60), in 58\% and 32\% yields, respectively. Compound (60) was deprotected under standard conditions, affording 48 (Figure 5).

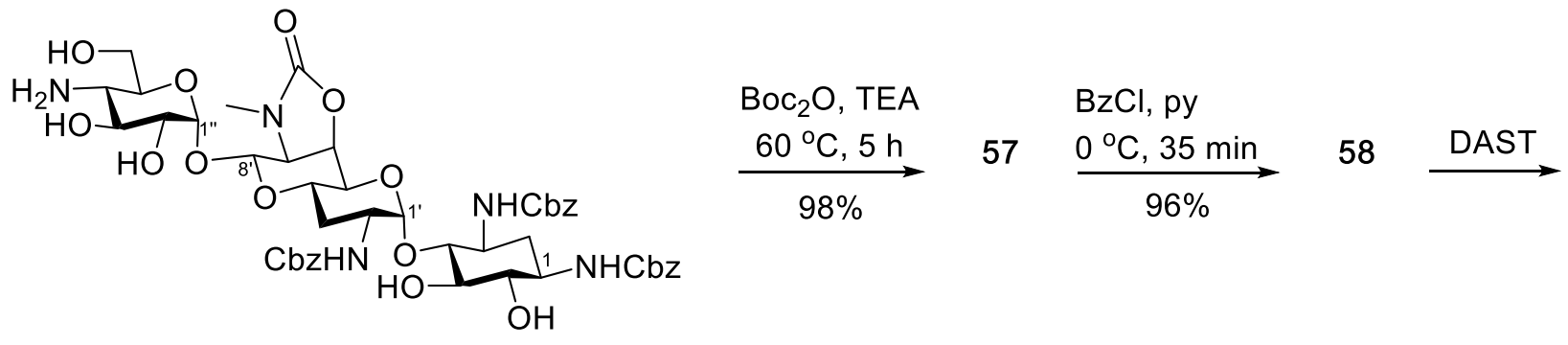

56

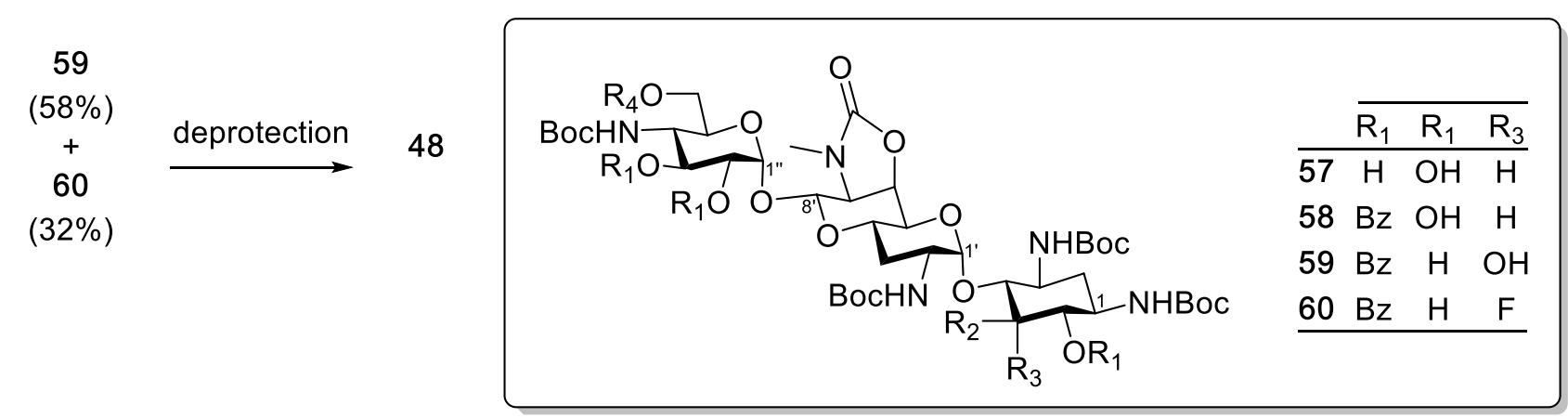

Scheme 7. Synthesis of 5-deoxy-5-epi-5-fluoroapramycin (48).

The synthesis of 6 "'-deoxy-6"-fluoroapramycin $(55)^{34}$ started from the $\mathrm{N}$-Cbz apramycin derivative (61). Treatment of $\mathbf{6 1}$ with 1,1-dimethylcyclohexane and $p$-toluenesulfonic acid ( $p$-TsOH) gave $\mathbf{6 2}$ in excellent yield (Scheme 8). Treatment of $\mathbf{6 2}$ under the conditions described by Vasella et al. ${ }^{52}$ afforded 63 , which was reacted 
with DAST to afford the 6"-deoxy-6"-fluoro derivative (64). Compound 64 was further deprotected under standard conditions to afford 55 (Figure 5).

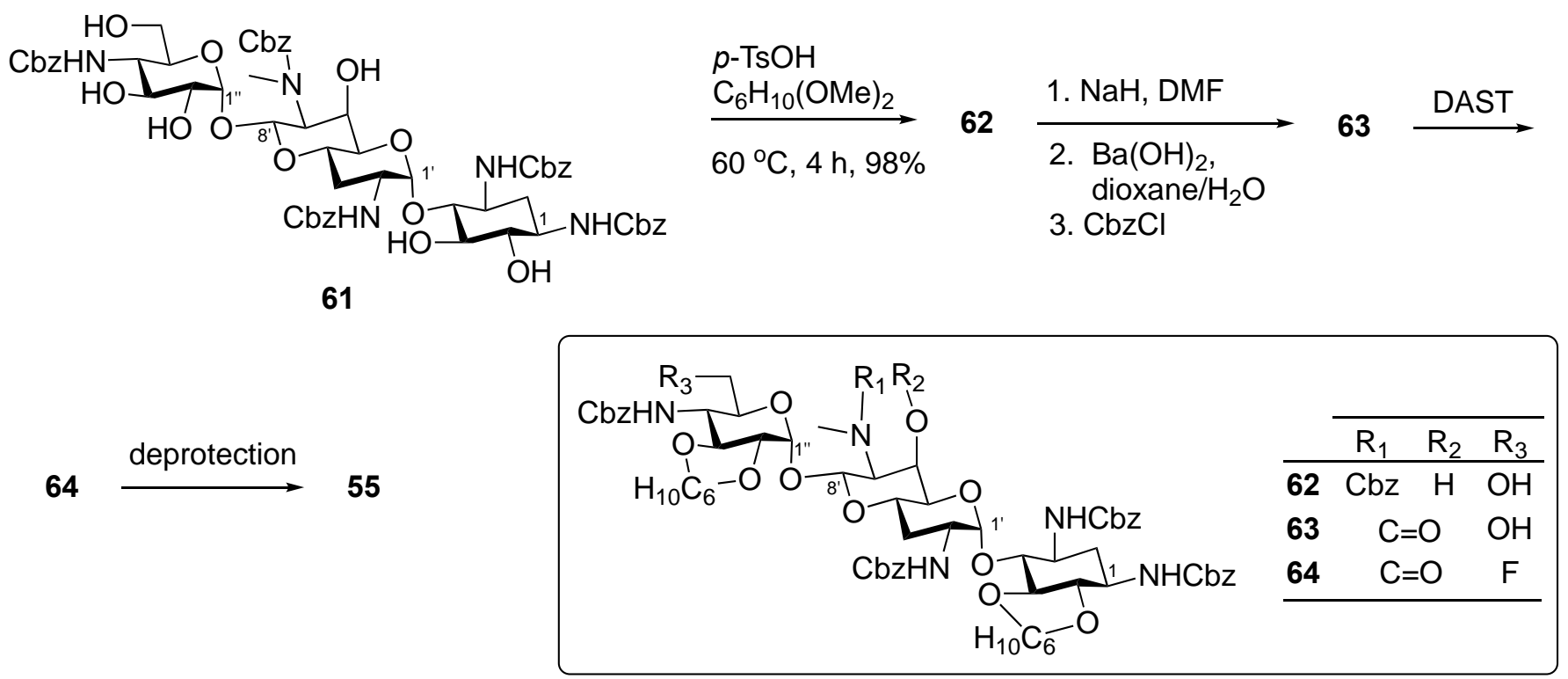

Scheme 8. Synthesis of 6"-deoxy-6"'-fluoroapramycin (55).

Compounds (48 - 55) were tested against Gram-positive and Gram-negative bacteria and showed activity against Pseudomonas aeruginosa, Klebsiella pneumoniae and Staphylococcus aureus strains, which are resistant or show low sensitivity to amikacin (4), arbekacin (93, Figure 9) and gentamycin.

\section{Fluorinated 4,6-Disubstituted 2-Deoxystreptamine AGs}

\subsection{Fluorinated 4,6-disubstituted 2-deoxystreptamine AGs}

The structure of 4,6-disubstituted 2-deoxystreptamine AGs sisomicin (65), netilmicina (66), and verdamycin (67) are depicted in Figure 6.

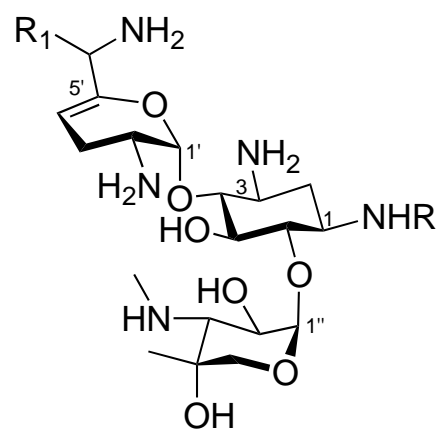

65 sisomicin $\mathrm{R}=\mathrm{H}, \mathrm{R}_{1}=\mathrm{H}$ 66 netilmicin $\mathrm{R}=\mathrm{CH}_{2} \mathrm{CH}_{3}, \mathrm{R}_{1}=\mathrm{H}$ 67 verdamycin, $\mathrm{R}=\mathrm{H}, \mathrm{R}_{1}=\mathrm{Me}$

Figure 6. Sisomicin (65), netilmicin (66) and verdamicin (67). 
3.1.1. Synthesis of fluorinated sisomicin analogues by mutasynthesis or mutational biosynthesis. ${ }^{32}$ The first attempts toward fluorinated 4,6-disubstituted 2-deoxystreptamine aminoglycosides involved mutasynthesis or mutational biosynthesis. The process consists of selecting a microorganism, called an idiotroph, that is unable to synthesize a natural product without a mutasynthon. This precursor has to be supplemented to the microorganism for the synthesis to be successful. The most accessible mutasynthon used for generating structurally diverse AGs has been the aminocyclitol ring, particularly the 2-deoxystreptamine moiety (69) (Figure 7)..$^{32}$

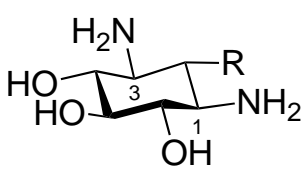

68 streptamine $\mathrm{R}=\mathrm{OH}$

69 2-deoxystreptamine $\mathrm{R}=\mathrm{H}$

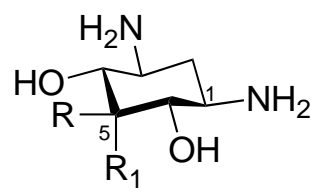

$70 \mathrm{R}=\mathrm{FR}_{1}=\mathrm{H}$

$71 \mathrm{R}=\mathrm{HR}_{1}=\mathrm{F}$

Figure 7. Streptamine derivatives.

Feeding fluorinated 2-deoxystreptamine analogues $\mathbf{7 0}$ or $\mathbf{7 1}$ to Micronospora inyuyensis strain 1550F afforded sisomicin derivatives $\mathbf{7 2}$ and $\mathbf{7 3}$ (Figure 8). The structures of the fluorinated sisomicin derivatives were confirmed by semisynthesis. The mutasynthetic approach was abandoned due to poor incorporation of the fluorinated mutasynthons (70 and $\mathbf{7 1}$ ) by the idiotroph M. inyoensis. ${ }^{32}$

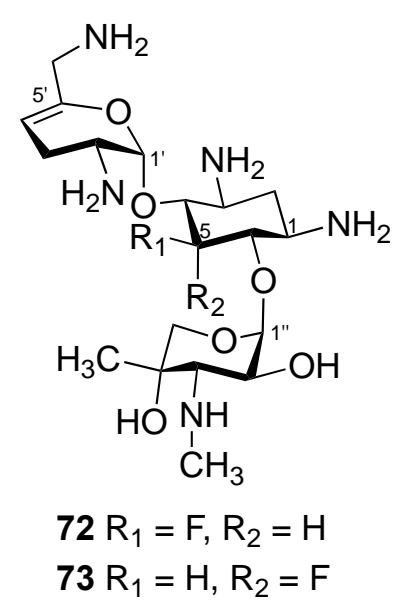

Figure 8. 5-deoxy-5-fluorosisomicin (72) and 5-deoxy-5-epi-5-fluorosisomicin (73).

3.1.2. Synthesis of 5-deoxy-5-fluoro and 5-deoxy-5-epi-5-fluoro derivatives of sisomicin (65), netilmicin (66) and verdamicin (67). ${ }^{53}$ The synthesis of 5-deoxy-5-fluoro-5-epi sisomicin (73) is shown in Scheme 9. The fully $\mathrm{N}$-Cbz-protected AG derivative was obtained by first reacting sisomicin (65) with benzyloxycarbonyl chloride $(\mathrm{Cbz}-\mathrm{Cl})$, and subsequent simultaneous pentacyclic carbamate formation promoted by sodium hydride and selective esterification with benzoyl chloride afforded intermediate $\mathbf{7 4}$. Treatment of $\mathbf{7 4}$ with methanesulfonyl chloride followed by a reaction with a fluoride salt ( $\mathrm{Li}, \mathrm{Na}$ and $\mathrm{K}$ ) was unsuccessful. However, the reaction of 74 with DAST in dichloromethane at $-78{ }^{\circ} \mathrm{C}$ led to complete clean inversion, generating exclusively the 5deoxy-5-fluoro-5-epi derivative. Then, cleavage of the protecting groups afforded 5-deoxy-5-fluoro-5-epi sisomicin (73). The patent ${ }^{53}$ also describes the synthesis of 5-deoxy-5-fluorosisomicin (72) (Figure 5), 5-deoxy- 
5-fluoro-5-epi verdamicin (75), 5-deoxy-5-fluoro-5-epi netilmicin (76) and 5-deoxy-5-fluoro-epi tobramycin (77) using a similar protocol.

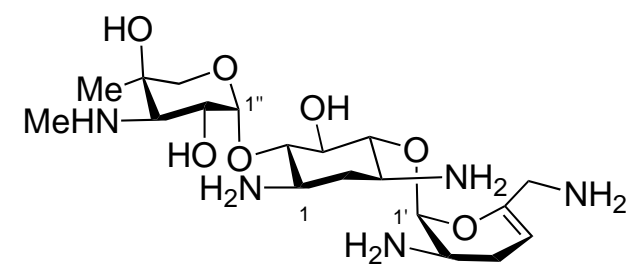

65

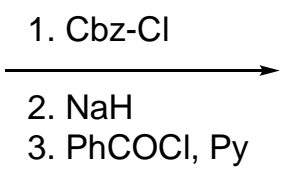

3. $\mathrm{PhCOCl}, \mathrm{Py}$

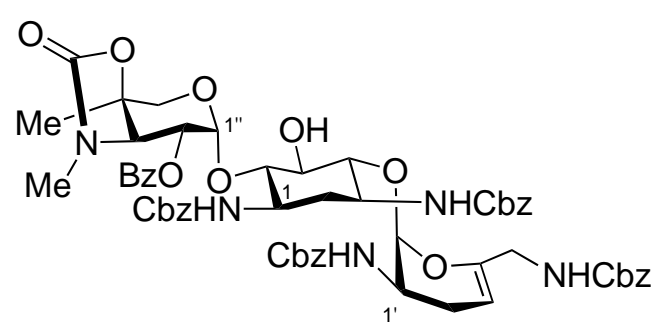

74

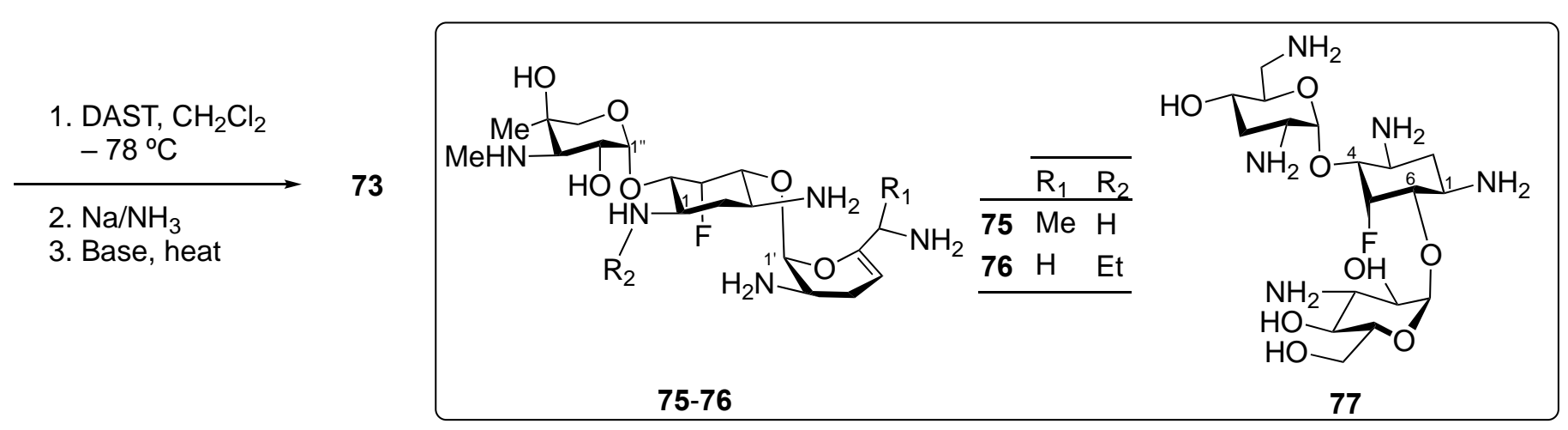

Scheme 9. 5-Deoxy-5-epi-5-fluorosisomicin (73), 5-deoxy-5-epi-5-fluoroverdamicin (75), 5-deoxy-5-epi-5fluoronetilmicin (76) and 5-deoxy-5-epi-5-fluorotobramacyn (77).

Both isomers (72 and 73) exhibited good antibacterial potency against aminoglycoside-susceptible and aminoglycoside-resistant bacteria, with $\mathbf{7 2}$ being the more potent of the two. In general, both fluorinated derivatives (72 and 73) were at least as potent as sisomicin (65) and slightly less potent than 5-epi-sisomicin, but they showed broader activities; ${ }^{53-55}$ toxicity studies with 5-deoxy-5-epi-5-fluorosisomicin (73) revealed that this derivative was less toxic toward mice than was sisomicin (65) (LD 50 of $160 \mathrm{mg} / \mathrm{kg} \mathrm{vs} 30 \mathrm{mg} / \mathrm{kg}$ via i.v.). ${ }^{55}$

3.1.3. Synthesis of the 5-deoxy-5-fluoro- and 5-deoxy-5,5-difluoro-derivatives of netilmicin (66).56 Compounds (79 and 82) where synthesized in an effort to clarify the relationship between the deoxyfluorination and toxicity of the fluorinated AGs. Treatment of a suitably protected 5-epi netilmicin derivative (78) with DAST in dichloromethane followed by cleavage of the protecting groups under standard conditions afforded 5-deoxy-5-fluoronetilmicin (79) (Scheme 10). 


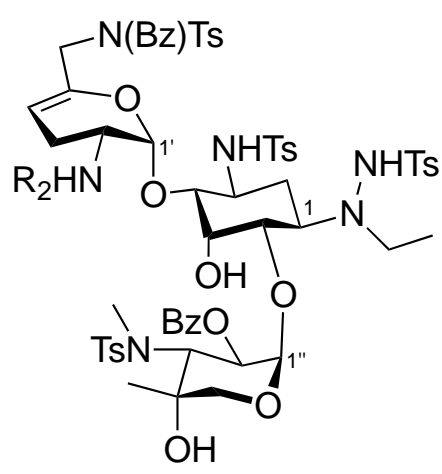

78

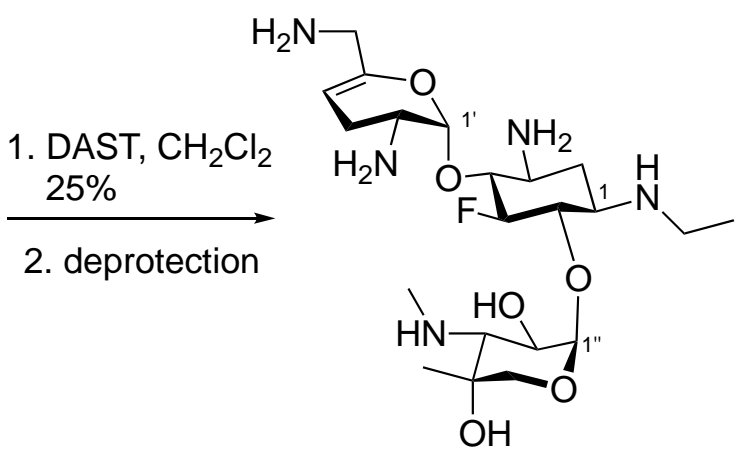

79

Scheme 10. Synthesis of 5-deoxy-5-fluoronetilmicin (79).

The reaction of $\mathbf{8 0}$ with $\mathrm{Ac}_{2} \mathrm{O}$ in DMSO followed by treatment with DAST afforded difluorinated analogue 81. 5-Deoxy-5,5-difluoronetilmicin (82) was obtained from $\mathbf{8 1}$ after cleavage of the protecting groups under standard conditions (Scheme 11).

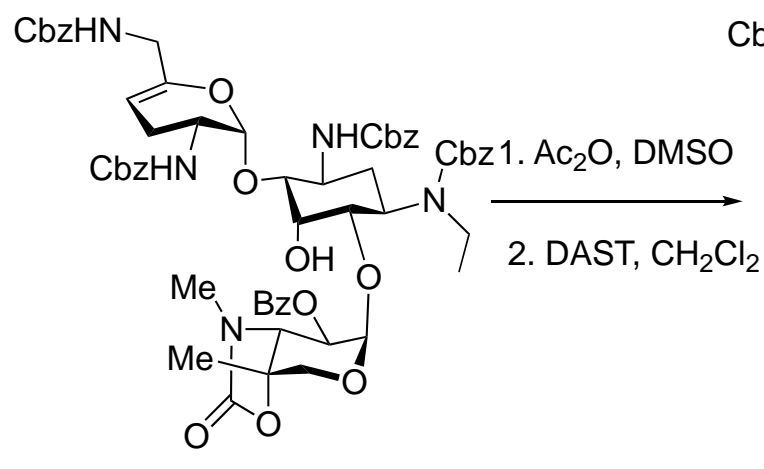

80

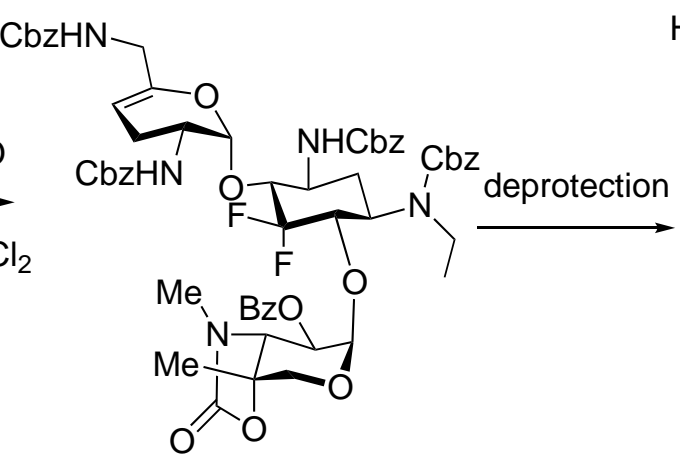

81

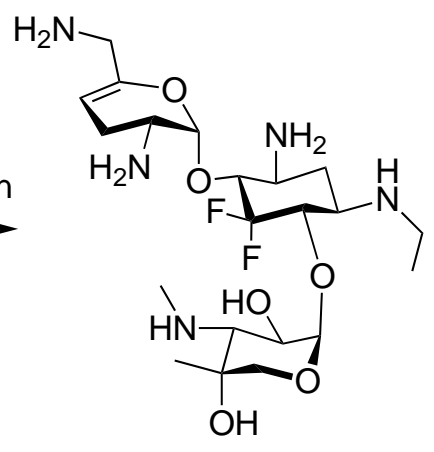

82

Scheme 11. Synthesis of 5-deoxy-5,5-difluoronetilmicin (82).

Fluorinated netilmicin derivatives (79 and 82) have antibacterial activities comparable to the parent compound. The mono fluorinated derivative (79) was slightly more potent than 5-deoxy-5,5-difluoronetilmicin (82). ${ }^{56}$ The effect of 5-deoxy-5-fluorination and 5-deoxy-5,5-difluorination on AGs' toxicity is discussed in Section 3.3.13.

3.1.4. Synthesis of $6^{\prime}$-deamino-6'-fluorosisomicin (87)..$^{33}$ The treatment of sisomicin (65) with triflyl azide and $\mathrm{CuSO}_{4}$ in methanol followed by the reaction with Fmoc-OSu afforded 83 (Scheme 12). The treatment of 83 under optimized selenium dioxide allylic oxidation conditions using selenium dioxide and dihydropyran (DHP) afforded a $6^{\prime}$-aldehyde intermediate (84) that was subsequently reduced to afford $1,3,2^{\prime} 6^{\prime}$-tetradeamino-6'hydroxy-1,3,2'-triazido-3"'-N-Fmoc sisomicin (85) using sodium borohydride in THF/MeOH as previously reported. ${ }^{57}$ Deoxyfluorination of $\mathbf{8 5}$ was accomplished with PhenoFluor $^{\circledR}$, a deoxyfluorinating agent that shows remarkable selectivity for substituting allylic alcohols with fluorine in the presence of unprotected secondary and tertiary alcohols, ${ }^{58}$ and the reaction afforded 86 in good yield. Final deprotection under Staudinger conditions afforded 87. 

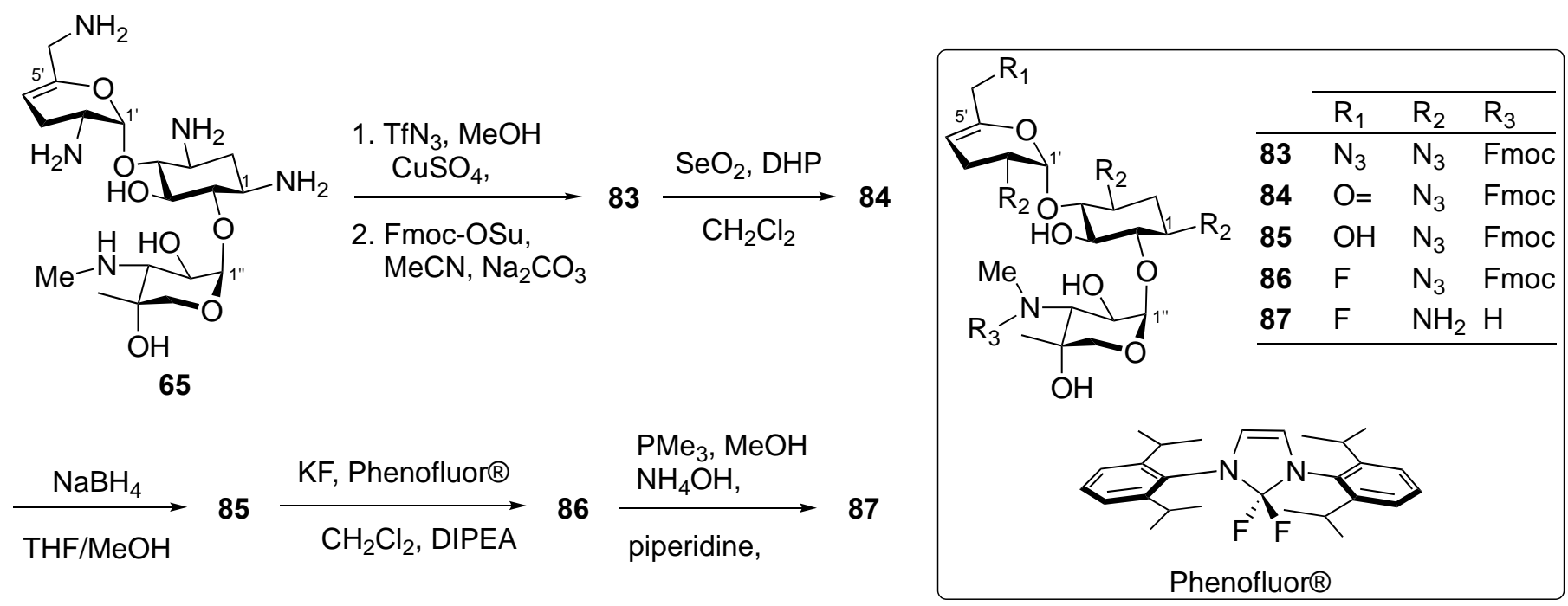

Scheme 12. Synthesis of 6'-deamino-6'-fluorosisomicin (87).

6'-Deamino-6'-fluorosisomicin (87) shows selective binding to the eukaryotic ribosome over the prokaryotic ribosome, supporting the presumption that substitution with fluoride at the C-6' position is detrimental to the antibacterial activity. ${ }^{33}$ Compound (87) does not show antibacterial activity against Escherichia coli or Staphylococcus aureus strains but shows antiparasitic activity against Tripanosoma brucei brucei, T. brucei rhodesiense, T. cruzi, Leishmania major, and Plasmodium falciparum. Outstandingly, sisomicin (65) possesses both antibacterial and antiparasitic activity, being approximately three-fold more potent against parasitic cells than $\mathbf{8 7}$, except for against $P$. falciparum, which showed some susceptibility only to the fluorinated derivative. These differences between the activities of sisomicin (65) and 6'-deamino-6'fluorosisomicin (87) are attributed to their interactions within the ribosomal A-site of bacteria and protozoa. A single nucleobase change from an adenine in position 1408 in the bacterial ribosome to guanine in the protozoal ribosome A-sites seems to be responsible for the selectivity shown by $\mathbf{8 7}$. Fluorine can only function as a $\mathrm{H}$-bond acceptor and is unable to form a stable interaction with adenine, while ring I of the $A G$ can interact with guanine through the $C-6^{\prime}$ fluorine, and the oxygen at $C-5^{\prime}$ that forms part of the pyranoside ring and the $\mathrm{OH}$ at $\mathrm{C}-1^{\prime}$ can form a characteristic stable pseudo base-pair. Additionally, their cytotoxic activities toward HeLa cells were determined, and both sisomicin (65) and 6'-Deamino-6'-fluorosisomicin (87) are toxic in the hundreds of micromolar range, with $\mathbf{8 7}$ being at least 20 -fold more toxic in vitro toward protozoan cells than toward human cells. ${ }^{33}$

\subsection{Fluorination of gentamicin ${ }^{59}$}

Daum et al. claimed ${ }^{59}$ that the addition of 2,5-dideoxy-5-fluorostreptamine (70) into a fermentation culture of Micromonospora purpurea strain ATCC 31,119 yielded 5-deoxy-5-fluorogentamicins $C_{1}$ (88), $C_{2}$ (89) and $C_{1}$ a (90) according to the reported procedure, and the compounds were most likely obtained as their 5-deoxy-5fluoro-5-epi fluoro derivatives (Scheme 13). The compounds were chemically modified by the introduction of an $N-(S)-4-a m i n o-\alpha$-hydroxybutyryl (HABA) moiety in positions $1-N, 3-N$ and $2^{\prime}-N$; unfortunately, neither the yields nor the characterization data nor the results of antibacterial tests were reported for these compounds. 


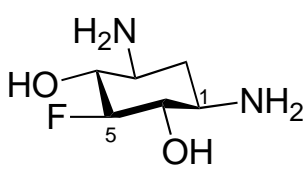

70
M. purpurea

ATCC 31, 119
$88 \mathrm{R}=\mathrm{CH}_{3} \mathrm{R}_{1}=\mathrm{CH}_{3}$

$89 \mathrm{R}=\mathrm{CH}_{3} \mathrm{R}_{1}=\mathrm{H}$

$90 \mathrm{R}=\mathrm{HR}_{1}=\mathrm{H}$

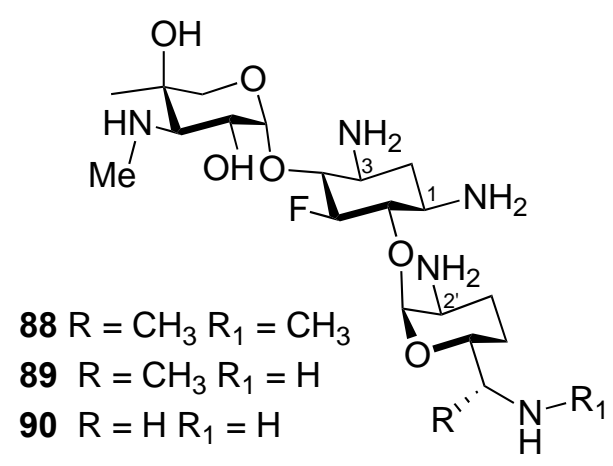

Scheme 13. Fluorinated derivatives of gentamicin.

\subsection{Synthesis of fluorinated derivatives of the kanamycin family}

The kanamycin family is an important class of 4,6-disubstituted 2-deoxystreptamine AGs that includes a series of important antibiotics, such as kanamycin A (1), kanamycin B (91), kanamycin C (92), tobramycin (2), dibekacin (3), amikacin (4) and arbekacin (93) (Figure 9).

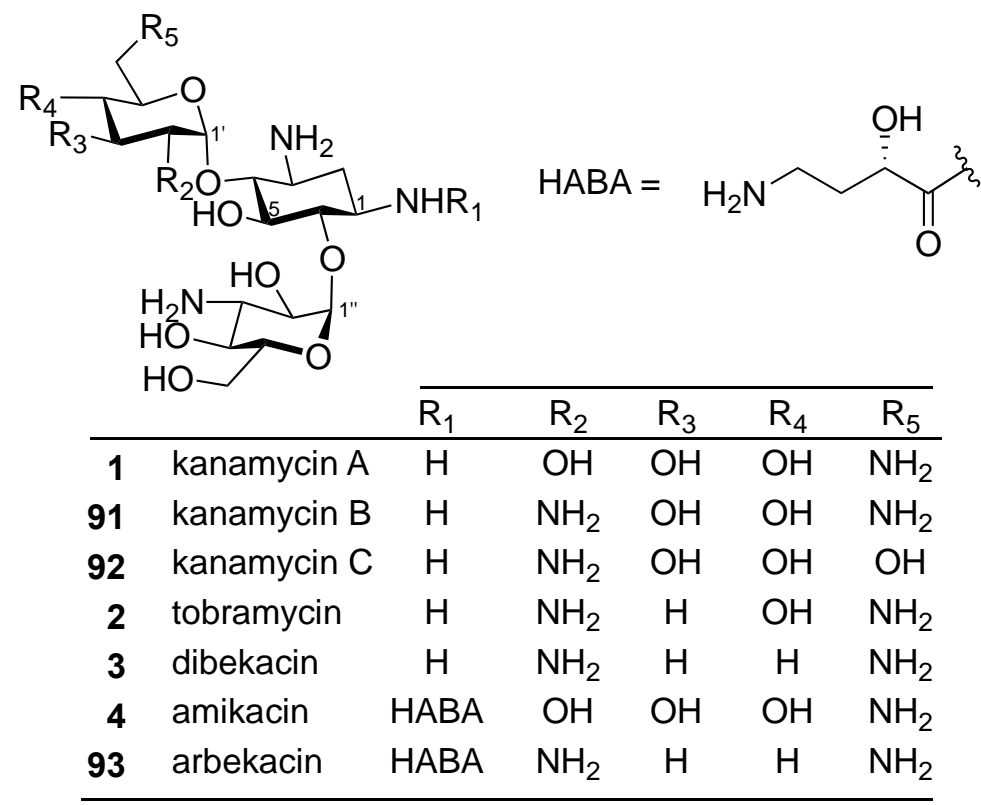

Figure 9. The kanamycin family of AGs.

3.3.1. Synthesis of 4"-deoxy-4"-epi-4"-fluorokanamycin A (100)..$^{60}$ The regioselective protection of the primary $\mathrm{OH}$ of $\mathbf{9 4}$ as a trityl ether followed by per-O-acetylation afforded compound 95 in $\mathbf{7 7 \%}$ yield (Scheme 14). Cleavage of the trityl protecting group with $\mathrm{BF}_{3} \cdot 2 \mathrm{MeOH}$ at room temperature afforded compound (96) in quantitative yield, ${ }^{61}$ and this compound was treated with a 1:1 mixture of pyridine in water to promote the acetyl migration from position 4" to position 6", providing 97. Alternatively, the slow addition of $0.1 \mathrm{~N} \mathrm{NaOH}$ in ethanol also promotes the migration of the acetyl group, but in a lower yield. The reaction of 97 with trifluoromethanesulfonic anhydride followed by treatment with tetrabutylammonium fluoride (TBAF) afforded 4"-deoxy-4"'-fluoro-4"-epi derivative (98) in 73\% yield. Oxazolidinone (99) was formed as a by-product (12\% yield) in this reaction. Both reactions proceeded with inversion of the configuration at C-4". The formation of 99 can be explained by nucleophilic attack of the $N$-Boc carbonyl on the C-4" triflate promoted by fluoride. ${ }^{62}$ 
The potential use of the $p$-bromobenzenesulfonyl (brosyl) ester as the leaving group at the C-4" oxygen of 97 was also examined (not shown). Unfortunately, the reaction of the 4"-brosyl derivative with TBAF resulted in a complex mixture of products that was not analysed. Reactions with other nucleophiles, however, resulted either in $\mathrm{S}_{\mathrm{N}} 2$ substitution products or elimination products, generating the $\mathrm{C}^{\prime \prime}$ "-C4"eno derivatives. Final cleavage of the protecting groups afforded 4 "'-deoxy-4"-epi-4"'-fluorokanamycin A (100).

3.3.2. Synthesis of 5-deoxy-4"-epi-5-fluoro- (103), 6"-deoxy-6"-fluoro- (106) and 5,6"-dideoxy-5-epi-5,6"difluorokanamycin A (107). ${ }^{63}$ The reaction of 97 with DAST did not afford the expected 5,4"-dideoxy-5,4" diepi-5,4"-difluorokanamycin A derivative but instead afforded 5-deoxy-5,4"-diepi-5-fluorokanamycin derivative 101 and the 5-deoxy-5-epi-5-fluoro derivative (102) (Scheme 15). The reaction intermediate (4"-O$\mathrm{SF}_{2}-\mathrm{NEt}_{2}$ ) undergoes neighbouring group attack from the carbonyl group of the Boc moiety at C-3" rather than attack by an external fluoride. The 101/102 ratio obtained depended on the reaction time with the formation of 102 being favoured at longer reaction times, which suggested that 101 was formed during work-up. Compounds 101 and 102 were deprotected using standard procedures to afford AGs (103 and 104).
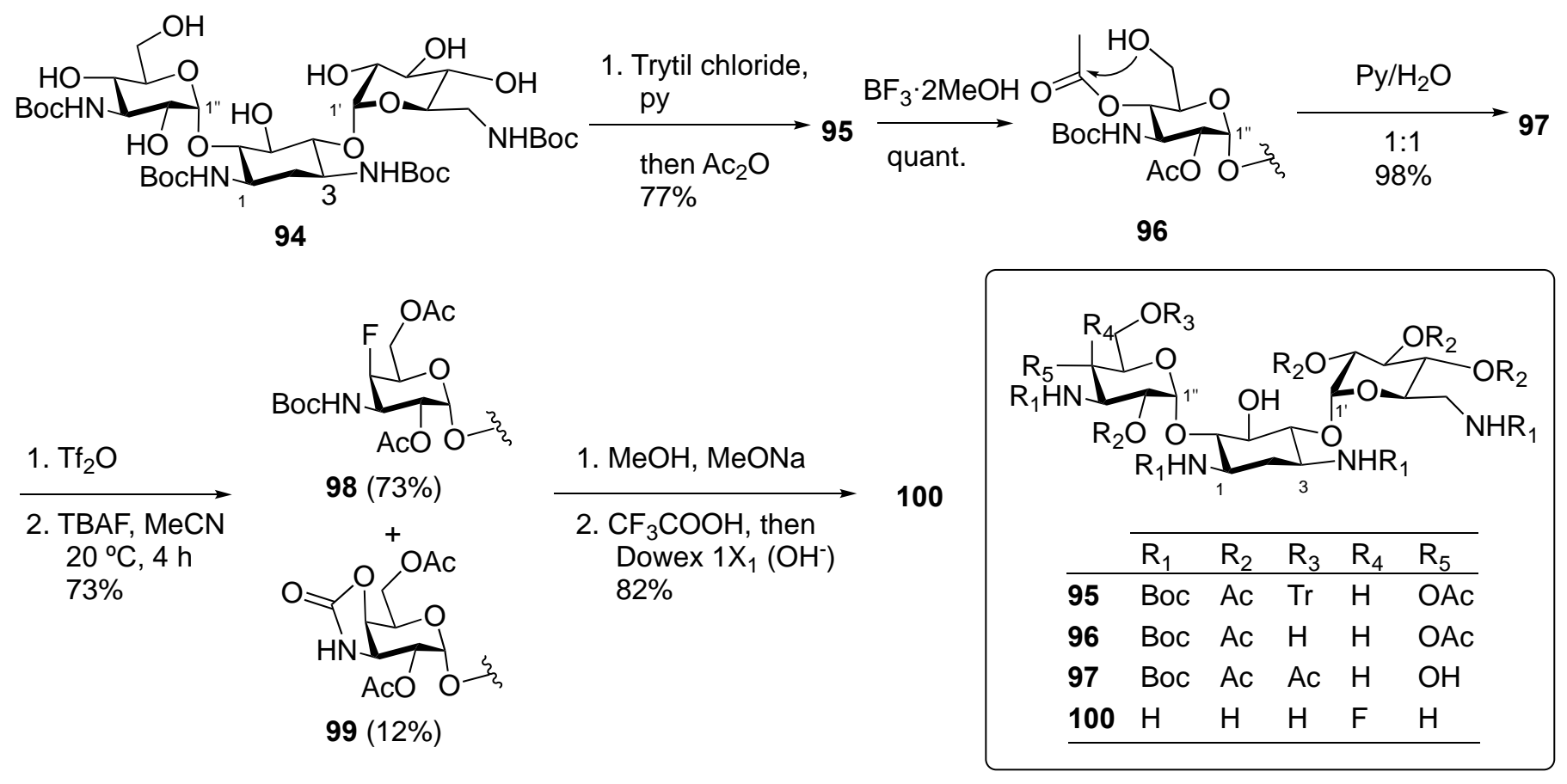

Scheme 14. Synthesis of 4"-deoxy-4"'-epi-4"'-fluorokanamycin A (100). 

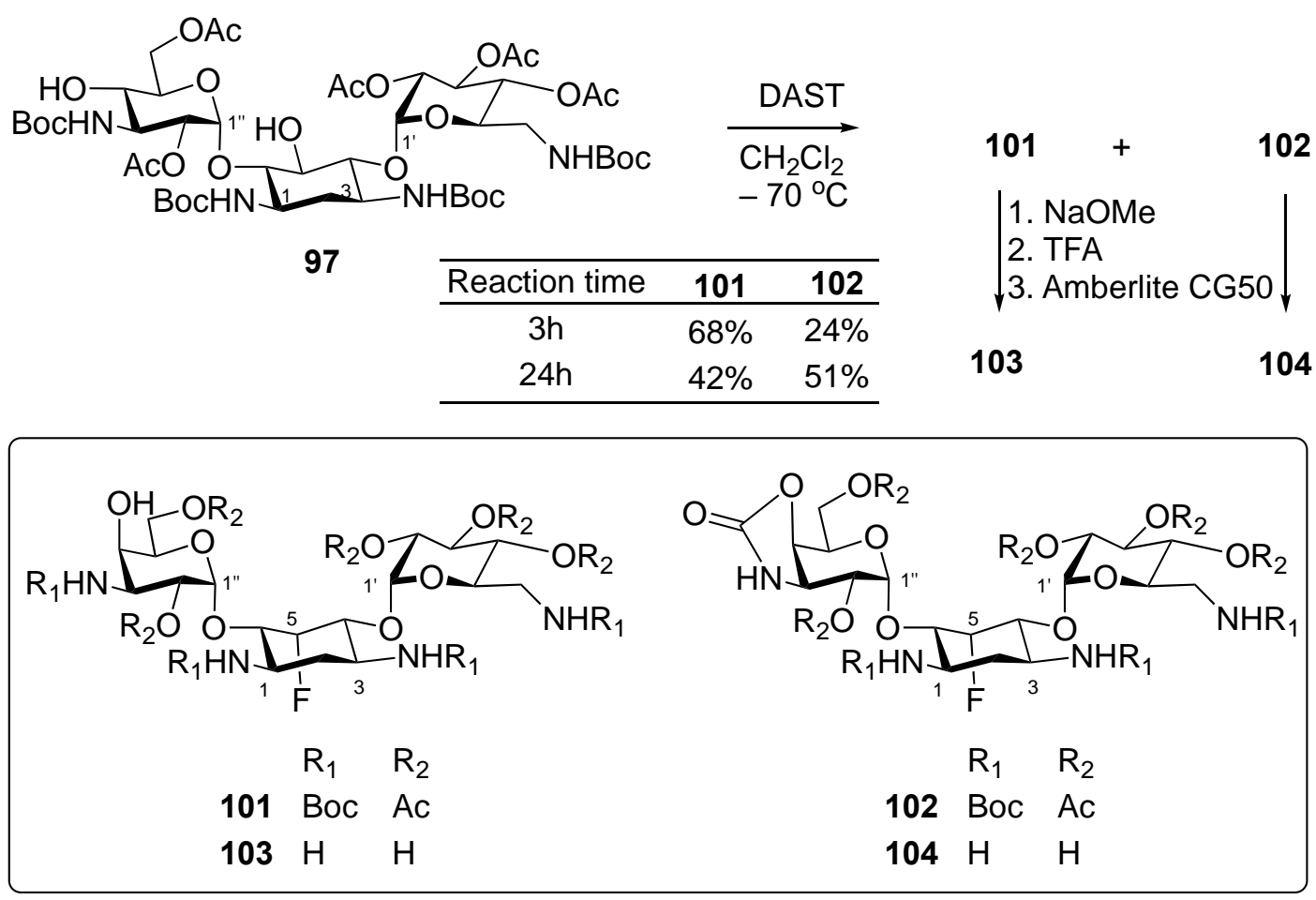

Scheme 15. Synthesis of 5-deoxy-4"'-epi-5-fluorokanamycin A (103).

Two more fluorinated derivatives were obtained from 96 as the starting material (Scheme 16). Triflate formation followed by displacement using TBAF afforded 105 in 76\% yield. Zemplén de-O-acetylation followed by treatment with trifluoroacetic acid gave 6"-deoxy-6"-fluorokanamycin A (106). The reaction of 105 with DAST followed by deprotection afforded 5,6"-dideoxy-5-epi-5,6"-difluorokanamycin derivative 107.
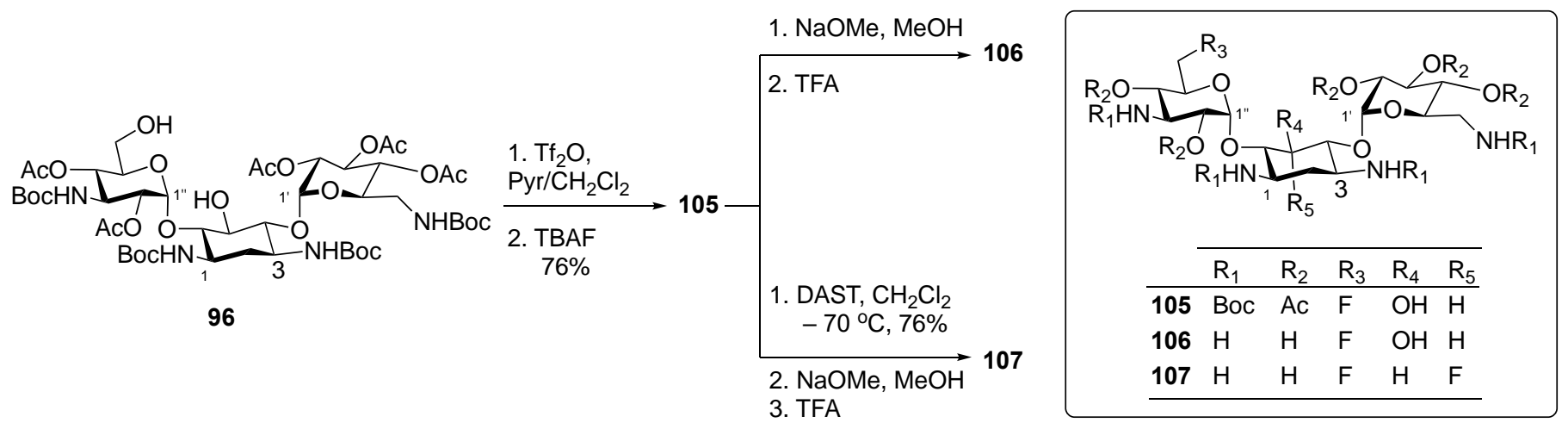

Scheme 16. Synthesis of 6"-deoxy-6"'-fluorokanamycin A (106) and 5,6"-dideoxy-5-epi-5,6"-difluorokanamycin A (107).

Compounds 100, 103, 104, 106, and 107 were tested against several bacterial strains, and with the exception of compound 104, all showed potencies comparable to kanamycin A (1). The p $K_{b}$ values of the $3^{\prime \prime}$ amino groups of $\mathbf{1 0 0}$ and kanamycin $\mathrm{A}(\mathbf{1})$ were calculated from the $\mathrm{pH}$ dependency of the chemical shift of $\mathrm{C}$ $2 "$ in the ${ }^{13} \mathrm{C}$ NMR spectrum. The obtained values were $\mathrm{p} K_{b} 7.4$ and $\mathrm{p} K_{b} 8.3$ for 100 and kanamycin $\mathrm{A}(\mathbf{1})$, respectively. The introduction of a fluorine atom in this series is compatible with their antibacterial activity and has a profound impact on the basicity of the amino groups near the introduced halogen. ${ }^{63}$ 
An alternative synthesis of $\mathbf{1 0 6}$ by the direct fluorination of tetra $\mathrm{N}$-benzyloxycarbonyl kanamycin A and 1$N$ acyl derivatives directly with DAST was reported in the literature, but only some NMR data of this compounds are discussed. ${ }^{64}$

3.3.3. Synthesis of 4",6"-dideoxy-4"-epi-4",6"-difluoro- (110), 4",6"-dideoxy-4"-epi-4"-fluoro- (113) and 6"deoxy-4"-epi-6"-fluorokanamycin A (116)65 The 4",6"-O-cyclohexylidene moiety of 108 was cleaved with lithium tetrafluoroborate in wet $\mathrm{MeCN},{ }^{66}$ affording 109 (Scheme 17). The reaction of 109 with triflic anhydride followed by treatment with TBAF in acetonitrile afforded a 4 ", 6" -dideoxy-4",6"-difluoro intermediate that after protecting group cleavage and purification by ion exchange chromatography afforded 110 . Selective $O-$ brosylation of 109 at position 6" followed by $O$-triflate formation afforded 111, a common intermediate in the synthesis of compounds $\mathbf{1 1 3}$ and 116. The reaction of $\mathbf{1 1 1}$ with TBAF in acetonitrile followed by treatment with tetrabutylammonium bromide (TBAB) afforded derivative $\mathbf{1 1 2}$. The 6"-bromo moiety was reduced with Raney nickel, and the protecting groups were removed under standard conditions, affording 113 . The reaction of $\mathbf{1 1 1}$ with sodium acetate in dimethylformamide proceeded with inversion at C-4", giving 114. Treatment of 114 with sodium methoxide to remove the acetates and with TBAF to introduce a fluorine atom at C $-6^{\prime \prime}$ gave 115, which was then deprotected using TFA to afford 116.

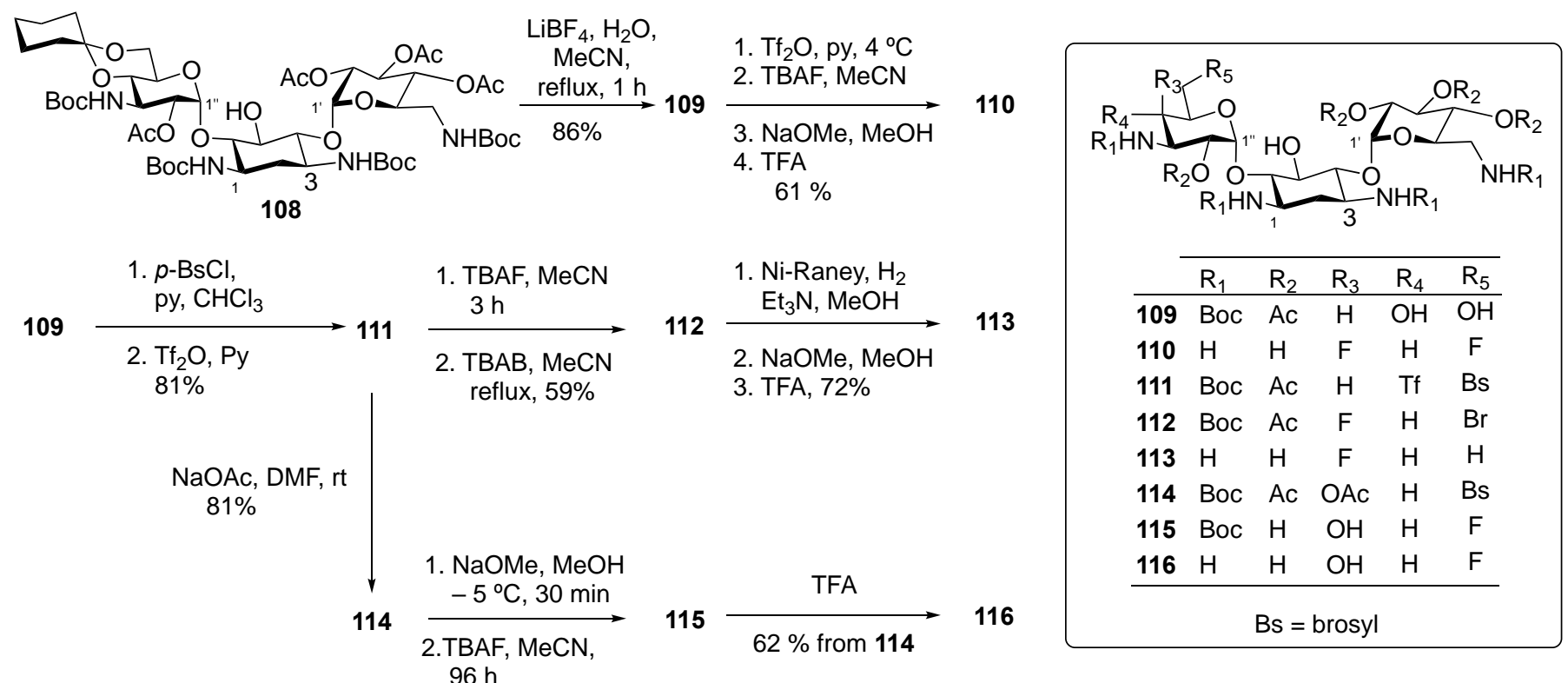

Scheme 17. Synthesis of 4",6"-dideoxy-4"-epi-4",6"-difluorokanamycin A (110), 4",6"-dideoxy-4"'-epi-4"'fluorokanamycin $A(\mathbf{1 1 3})$ and 6"-deoxy-4"'-epi-6"'-fluorokanamycin $A(\mathbf{1 1 6})$.

Compounds 100 (Scheme 14), 103 (Scheme 15), 110, 113, and 116 were tested against S. aureus, Streptococcus faecalis, P. aeruginosa, E. coli and Proteus mirabilis, and in general, their potencies were higher or similar to that of kanamycin A (1). It is known that kanamycin A (1) does not possess antibacterial activity against $P$. aeruginosa, but compounds with a fluorine atom at position C- 6 " presented a slight potency against this bacterial strain. ${ }^{65}$

3.3.4. Synthesis of 4"-deoxy-4"-fluorokanamycin A (120). ${ }^{67}$ The reaction of 97 with triflic anhydride in pyridine followed by treatment with $\mathrm{NaNO}_{2}$ in $\mathrm{DMF}^{68-69}$ afforded the $4^{\prime \prime}$-epi derivative (117) in good yield (Scheme 18). The attack of the ambident nitrite nucleophile produces the nitrite ester, which is then hydrolysed during routine work-up. The reaction of $\mathbf{1 1 7}$ with triflic anhydride followed by treatment with TBAF 
gave the desired compound (118) and derivative (119) as a by-product. The inseparable mixture was deprotected using standard conditions and afforded $\mathbf{1 2 0}$ after purification.

Fluorinated derivative (120) was less potent than its 4 "'-deoxy-4"-fluoro-4"-epi analogue (100) against different bacterial strains. ${ }^{67}$

3.3.5. Synthesis of $3^{\prime}, 4^{\prime}, 6^{\prime}$-trideoxy-6'-fluoro- and 1-N-HABA-3', $\mathbf{4}^{\prime}, 6^{\prime}$-trideoxy-6'-fluorokanamycin $\mathrm{C}^{\text {. }}{ }^{70}$ The reaction of unprotected triol $\mathbf{1 2 1}$ with DAST was fairly selective, giving the 6 "'-deoxyfluorinated analogue (122) in 71\% yield (Scheme 19). Compound 122 was then deprotected under standard conditions affording 123. Treatment of 123 with acetic acid-free zinc acetate in DMSO followed by Cbz-OSu gave 124. ${ }^{71}$ Compound 124 was reacted with ethyl trifluoroacetate in DMF, resulting in the selective introduction of a trifluoroacetamide moiety at $3^{\prime \prime}-\mathrm{N}$. First, a weak trifluoroacetyl ester is formed at 0-2", and subsequent migration of the trifluoroacetyl group to the neighbouring $3^{\prime \prime}-\mathrm{N}$ resulted in the more stable trifluoroacetamide. The HABA side chain was then installed using Cbz-protected HABA-OSu in $p$-dioxane, giving 125, which afforded the 1-N-[(S)4-amino-2-hydroxybutanoyl] (HABA) derivative (126) after a standard deprotection.

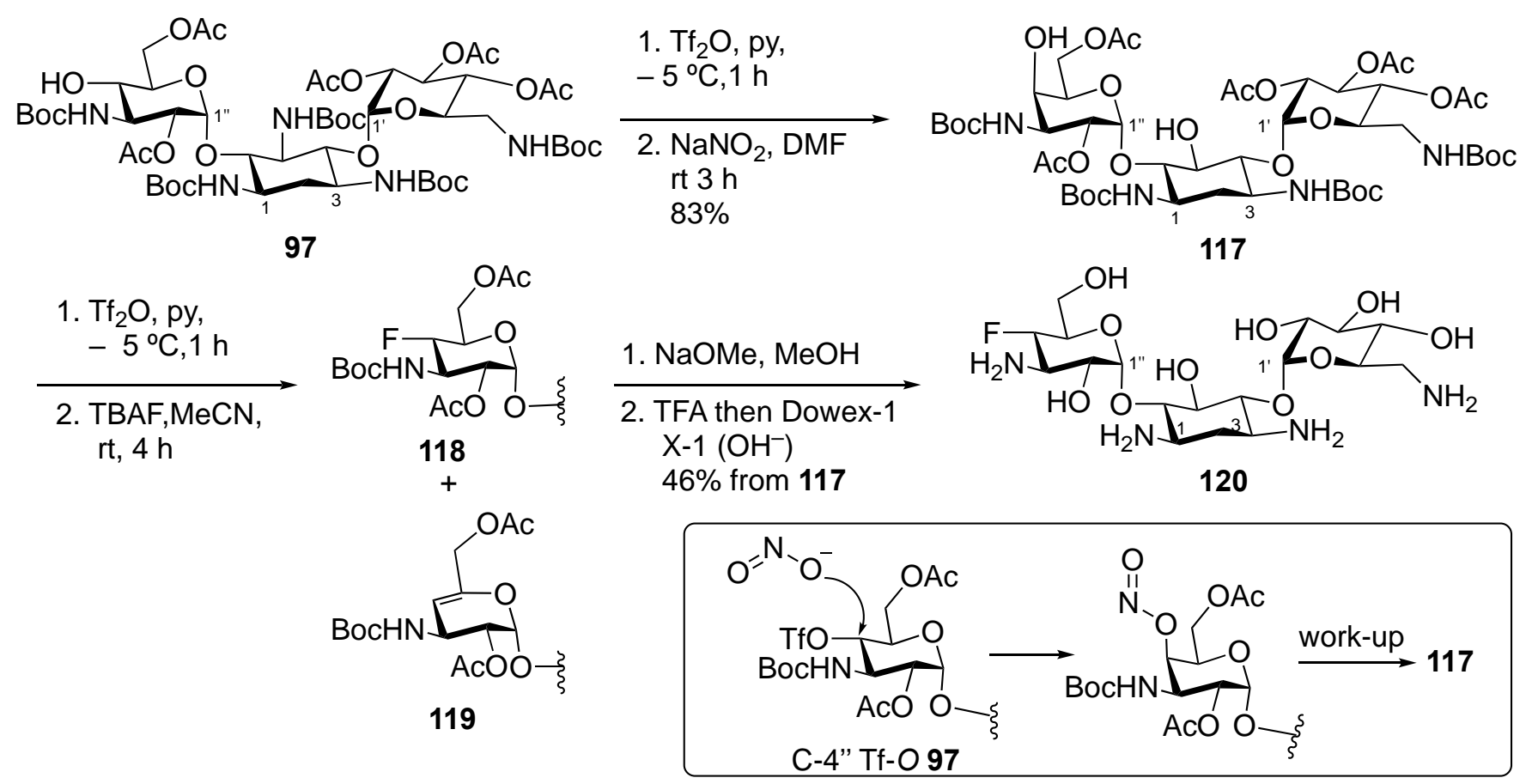

Scheme 18. Synthesis of 4"'-deoxy-4"'-fluorokanamycin A (120). 


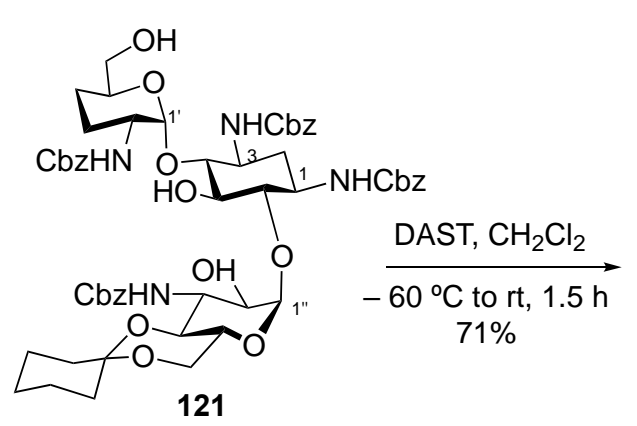

121

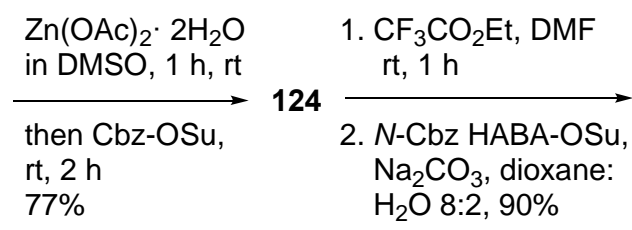

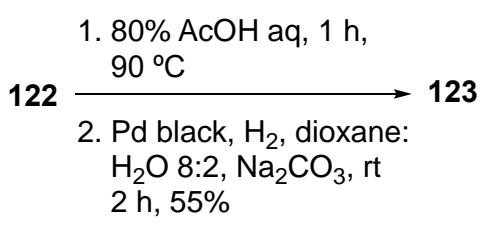

1. dioxane: $28 \%$ $\mathrm{NH}_{3} \mathrm{OH}$, r.t., $1 \mathrm{~h}$ 125

2. $\mathrm{Pd}, \mathrm{H}_{2}$, dioxane:
$\mathrm{H}_{2} \mathrm{O}: \mathrm{AcOH} 6: 3: 1$
$63 \%$

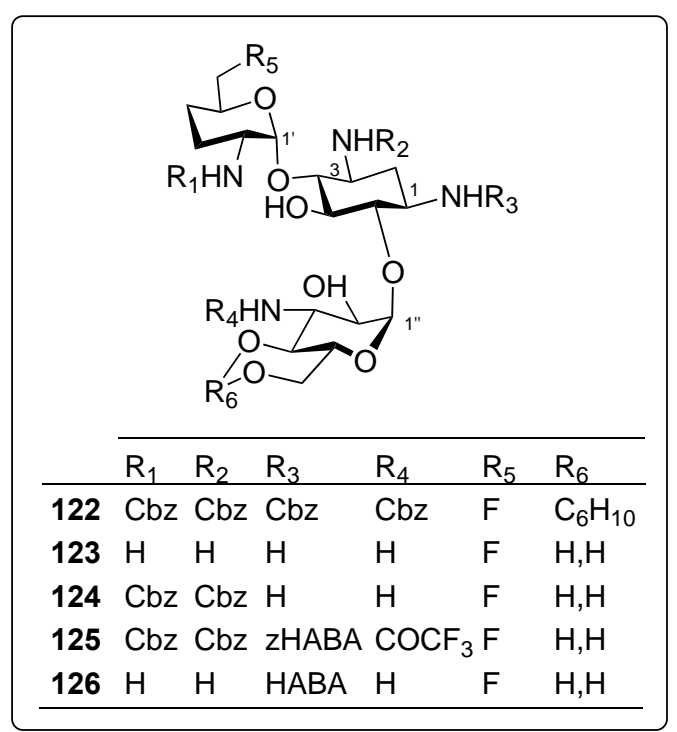

Scheme 19. Synthesis of $3^{\prime}, 4^{\prime}, 6^{\prime}$-trideoxy-6'-fluorokanamycin $\quad C \quad$ (123) and 1-N-[(S)-4-amino-2hydroxybutanoyl]-3', 4', 6'-trideoxy-6'-fluorokanamycin C (126).

Both compounds (123 and 126) possess very weak antibacterial potency. ${ }^{61}$

3.3.6. Synthesis of $6^{\prime}$ - $C$-(fluoromethyl)kanamycin $C(130 \mathrm{a} / \mathbf{b})$ and $6^{\prime}$ - $\boldsymbol{C}$-(fluoromethyl)arbekacin (131). ${ }^{70}$ The 6 '-oxo kanamycin $C$ derivative (127) was first alkylated with nitromethane and the nitro moiety was reduced with Adam's catalyst in a 25:5:1 mixture of $\mathrm{MeOH} /$ water/acetic acid. Final $\mathrm{N}$-tosylation afforded a separable diastereomeric mixture of $\mathbf{1 2 8 a}$ and $\mathbf{1 2 8 b}$ (Scheme 20). The isomers were separated and characterized, but the absolute stereochemistry at $C-6^{\prime}$ was not determined, and their syntheses were carried out using two parallel pathways. The reaction with 1,1-dimethoxycyclohexane and $p$-TsOH followed by phenylmethanesulfonyl chloride in pyridine and treatment with $\mathrm{KHF}_{2}$ in DMF gave 129a and 129b. Final cleavage of the protecting groups of $129 \mathrm{a}$ and $129 \mathrm{~b}$ afforded epimeric 6 '-C-(fluoromethyl)kanamycin $C$ 130a and $130 \mathrm{~b}$. The more active of the two isomers (130a) was $1-N$ acylated with a HABA under standard conditions, affording 6'-C-(fluoromethyl) arbekacin (131).

The antibacterial potencies of compounds 130a, 130b and 131 were generally lower than those of dibekacin (3) and arbekacin (93). Compound 131 was at least two-fold more active than 130a and 130b. It is theorized that the lack of activity of $\mathbf{1 2 3}$ and $\mathbf{1 2 6}$ is due to the absence of a hydrogen donor at C-6'; such a group is present in kanamycin C (92) and is vital for its interaction with the AG receptor. This explanation also satisfies the results obtained with compounds $130 \mathrm{a}, 130 \mathrm{~b}$ and 131 , which are active but to a lesser extent than their C-6' hydroxylated counterparts. Other AGs, such as gentamicin $C_{1}$ and $C_{2}(5$ and 6 , Figure 1$)$ that possess good antibacterial potency also have a methyl group at the C- $\sigma^{\prime}$ position, indicating the fluoromethyl group would not have an adverse steric effect. Instead, the electron-withdrawing character of the fluorine atom lowers the basicity of the C-6" amine group, decreasing its ability to form hydrogen bonds, and limiting the capacity of the molecule to bind its receptor. ${ }^{70}$ 


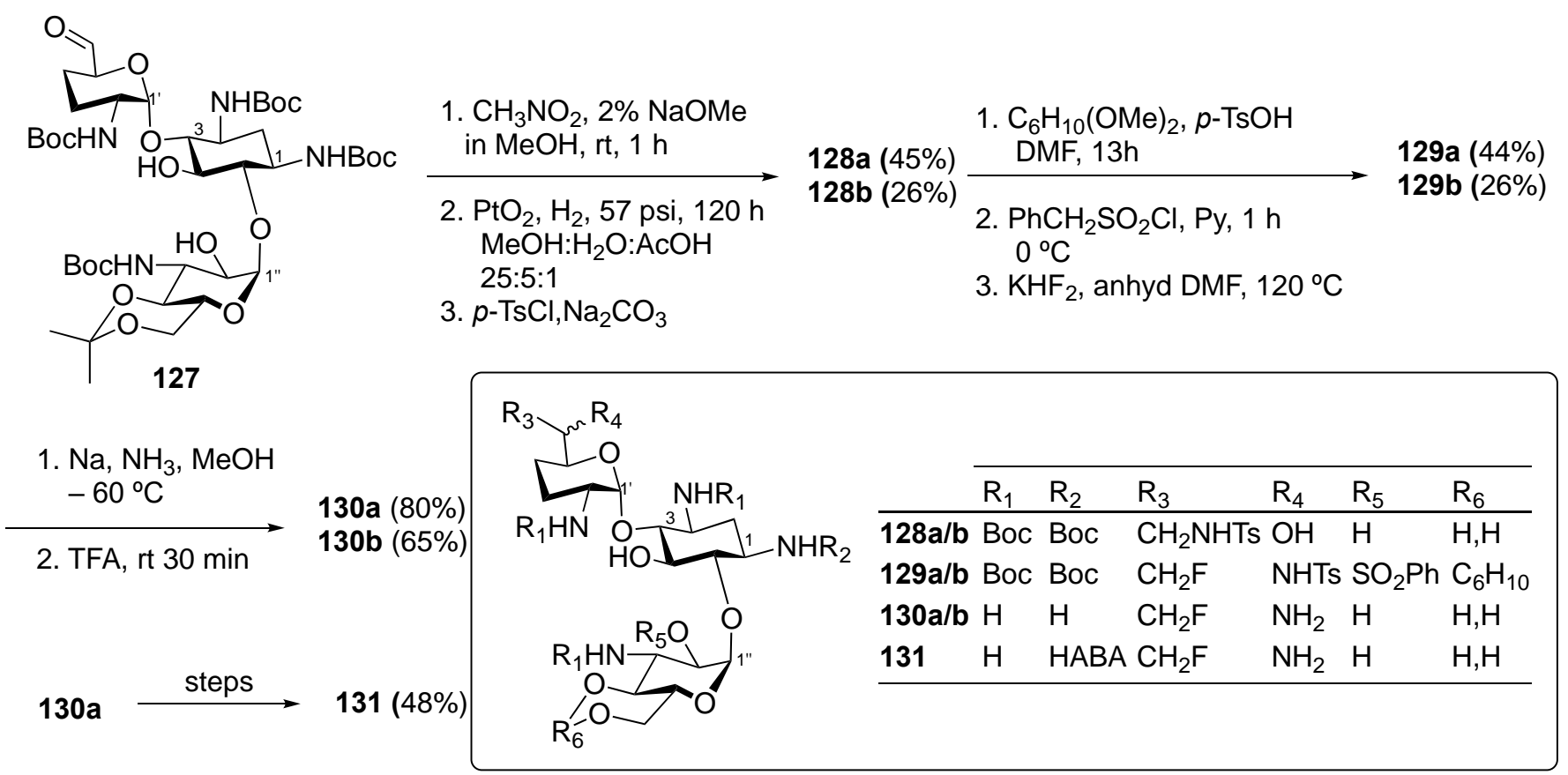

Scheme 20. Synthesis of $6^{\prime}-C$-(fluoromethyl)kanamycin $C(130 a / b)$ and 6'-C-(fluoromethyl)arbekacin (131).

3.3.7. Synthesis of 3'-deoxy-3'-fluorokanamycin A (140) ${ }^{14,24}$ and $3^{\prime}, 4^{\prime}$-dideoxy-3'-fluorokanamycin $A(144) .{ }^{14}$ 3'-Deoxy-3'-fluorokanamycin A derivative (140) was synthesized by the condensation of 6-azido-2,4-di-Obenzyl-3,6-dideoxy-3-fluoro- $\alpha$-D-glucopyranosyl bromide (135) and a protected derivative (138) of 6-O-(3amino-3-deoxy- $\alpha$-D-glucopyranosyl)-2-deoxystreptamine (136), in this approach the fluorine atom was introduced in an early stage of the synthesis (Scheme 21). The glycosyl donor (135) was synthesized from 3deoxy-3-fluoro-1,2-O-isopropylidene- $\alpha$-D-glucofuranose (132). Selective tosylation followed by $S_{N} 2$ displacement with sodium azide afforded 133. Methanolysis of the 1,2-O-acetonide followed by treatment with benzyl bromide in anhydrous DMF yielded 134 in excellent yield as a mixture of $\alpha$ and $\beta$ anomers. Treatment with acetic anhydride and catalytic sulfuric acid followed by exposure to $\mathrm{TiBr}_{4}$ afforded bromide 135. Glycosyl acceptor 138 was obtained from 6-O-(3-amino-3-deoxy- $\alpha$-D-glucopyranosyl)-2-deoxystreptamine (136). Sequential treatment with $p$-TsCl and sodium carbonate followed by 1,1-dimethylcyclohexane $\left(\mathrm{C}_{6} \mathrm{H}_{10}\left(\mathrm{OCH}_{3}\right)_{2}\right)$ and $p$-TsOH acid gave 137. The regioselective acetylation with 1-acetylimidazole (Aclm) in DMSO afforded 138 in $67 \%$ yield. The condensation of 135 and 138 in dichloromethane using mercury (II) cyanide as a promotor gave 139 in a $44 \%$ yield. The $\alpha$ anomer was the major product, and only traces of the $\beta$ anomer were observed. Compound (140) was obtained after deprotection and purification. ${ }^{14,24}$ 

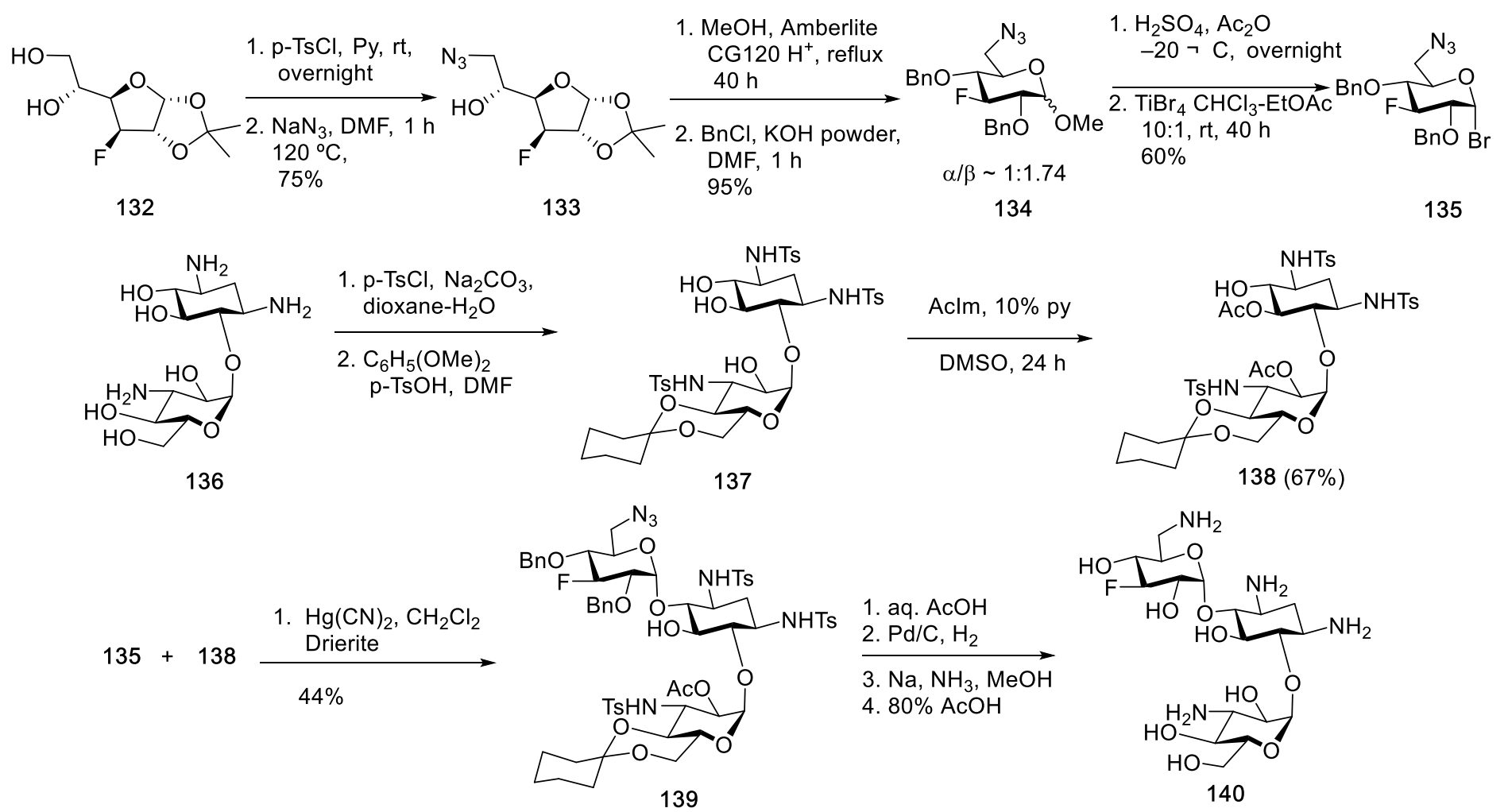

Scheme 21. Synthesis of 3'-deoxy-3'-fluorokanamycin A (140).

Treatment of 141 with Raney nickel reduced the 6'-azide, which was then protected as a tosylate. Peracetylation followed hydrogenolysis of the benzyl groups afforded 142 (Scheme 22). The treatment of 142 with sulfuryl chloride chemoselectively halogenation C-4' and afforded 143 in 92\% yield. The reduction of 143 under Birch conditions resulted in loss of both the chlorine and fluorine atoms and the formation of a $3^{\prime}, 4^{\prime}$ eno derivative (not shown). Tosyl deprotection was achieved by first reducing the 4' $\mathrm{Cl}$ moiety with tributyltin hydride and AIBN followed by reaction under Birch conditions to remove the tosyl groups. Compound 144 was obtained after cleavage of the remaining protecting groups under standard reaction conditions. ${ }^{14}$

As expected, compound (144) was active against resistant bacteria producing both APH( $\left.3^{\prime}\right)$ and ANT(4") AMEs. ${ }^{14}$

3.3.8. Synthesis of 3'-deoxy-3'-fluorokanamycin A (151) via a nucleophilic oxirane opening. ${ }^{72}$ The selectivity of the $\mathrm{N}$-acylation of AGs can be controlled by temporarily protecting vicinal amino groups as transition metal chelates and subsequently acylating of the unprotected groups. ${ }^{73-76}$ Using this approach, the treatment of kanamycin A (1) with zinc acetate in DMSO followed by the addition of Cbz-OSu allowed the selective introduction of a $\mathrm{Cbz}$ protecting group at $6^{\prime}-\mathrm{N}$ to afford 145 (Scheme 23). Subsequent treatment with Amberlite $\mathrm{CG}-50\left(\mathrm{H}^{+}\right)$ion exchange resin to remove the chelate, tosylation of the remaining amino moieties, $4^{\prime \prime}, 6^{\prime \prime}$-cyclohexylidene formation, followed by treatment with $\mathrm{NaH}$ in DMF to protect 4'-O as a cyclic carbamate afforded 146 in $67 \%$ overall yield. ${ }^{77}$ 

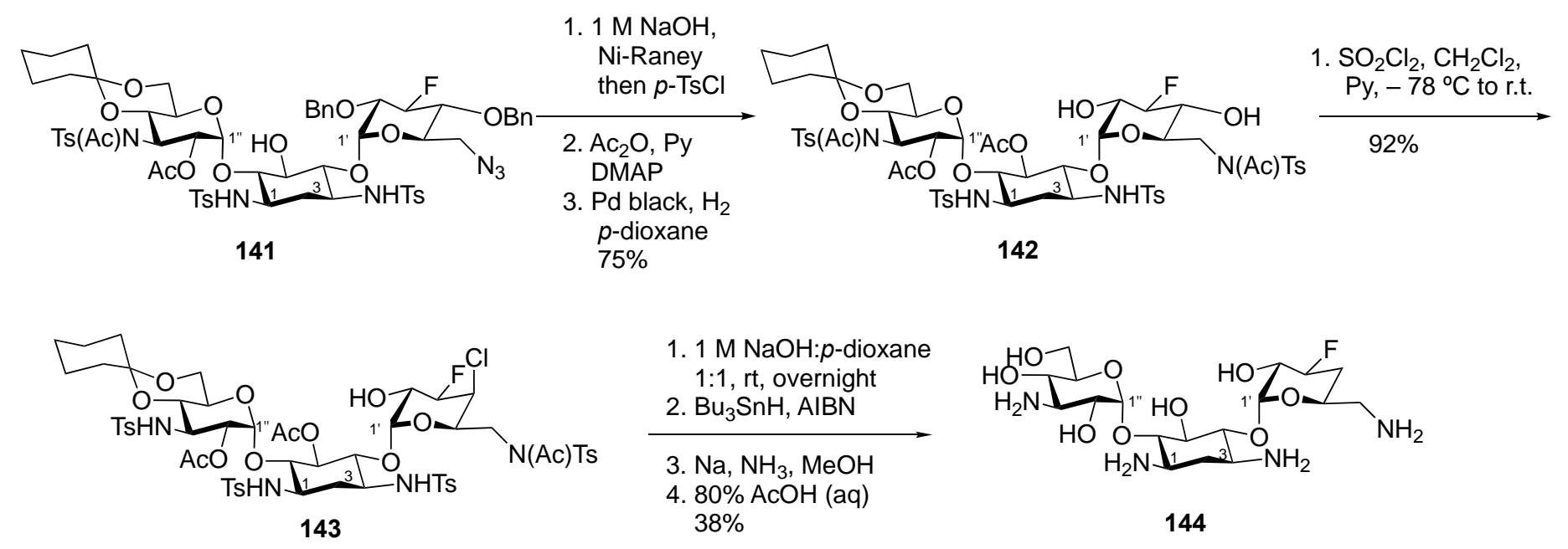

Scheme 22. 3', 4'-Dideoxy-3'-fluorokanamycin A (144).
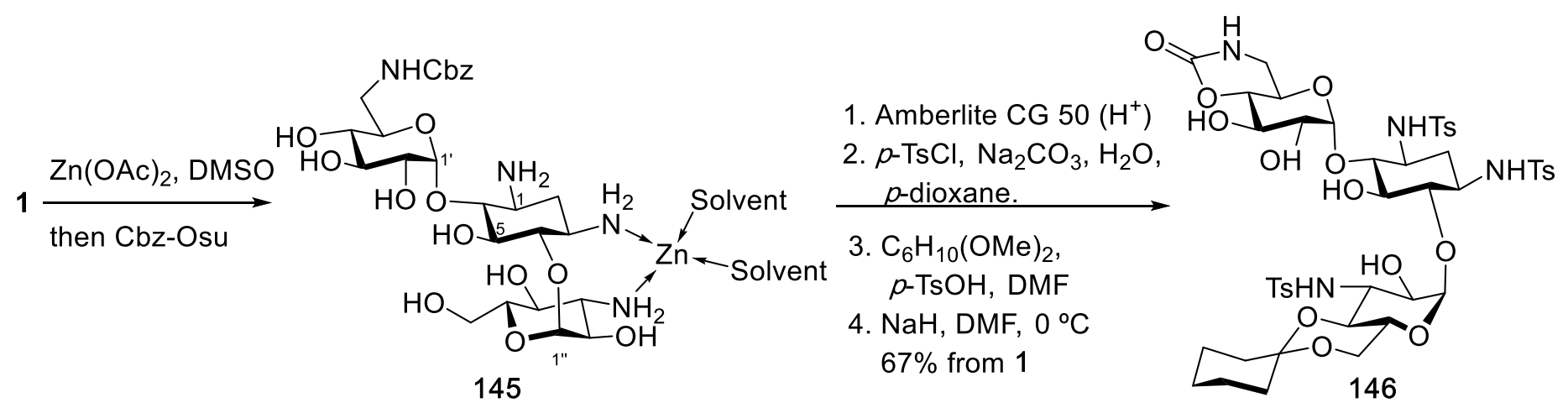

Scheme 23. Regiocontrol via chelation.

The selective $O$-acetylation of 146 with 1-acetylimidazole (Aclm) in a 1:10 mixture of pyridine-DMSO followed by treatment with benzylsulfonyl chloride in pyridine gave compound 147 (Scheme 24). The acetates were cleaved with a catalytic amount of sodium methoxide in methanol, and the 2', $3^{\prime}$-oxirane was formed upon treatment of the deacetylated product with a hot solution of $2 \%$ sodium methoxide in methanol, affording 148. Model experiments and molecular mechanics calculations were necessary to establish suitable conditions for maximizing the formation of the 3'-deoxy-3'fluoroglucose derivative (150) over the 2-deoxy-2fluoroaltrose derivative (149). Based on these optimization studies, a reaction with potassium hydrogen difluoride in ethylene glycol at $150{ }^{\circ} \mathrm{C}$ for $3.5 \mathrm{~h}$ was used to prepare 150 . Global deprotection afforded $151 .{ }^{72}$, 78

3'-Deoxy-3'-fluorokanamycin A (151) was tested against bacteria of the genera Staphylococcus, Micrococcus, Bacillus, Escherichia, Mycobacterium, Klebsiella, Shigella, Proteus, Serratia, Providencia and Pseudomonas. In general, the fluorinated derivatives exhibit greater antibacterial potency than tobramycin (2) against sensitive and resistant bacteria containing AMEs. ${ }^{24}$ 

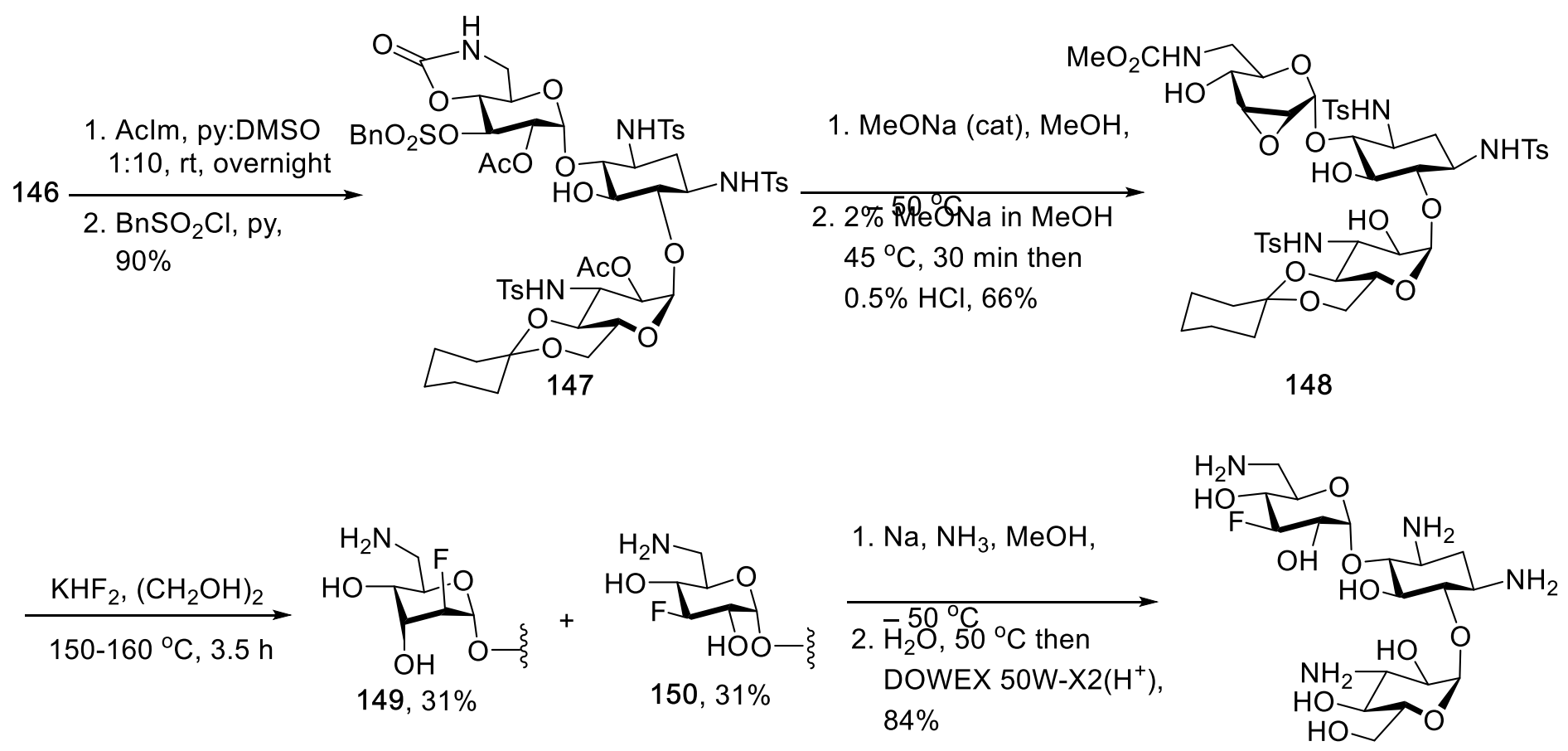

151

Scheme 24. Synthesis of $3^{\prime}$-deoxy-3'-fluorokanamycin A (151).

3.3.9. Synthesis of $\mathbf{2}^{\prime}, \mathbf{3}^{\prime}$-dideoxy-2'-fluorokanamycin A (158). ${ }^{\mathbf{7 9 - 8 0}}$ The glycosyl donor (157) was synthesized from methyl 4,6-O-benzilidene-3-chloro-3-deoxy- $\alpha$-D-allopyranoside (152) (Scheme 25). ${ }^{81}$ Compound 152 was treated with PCC and Drierite in dichloromethane, affording the corresponding $\alpha$-chloroketo derivative, which was then reduced with sodium dithionite to obtain the 2-oxo-ribo-hexapiranoside derivative (153). The reduction of $\mathbf{1 5 3}$ with lithium aluminium hydride afforded a 2:1 ratio of C-2 epimers. The desired compound (154) was obtained in $62 \%$ yield. The use of other reductants gave equimolar mixtures of axial and equatorial C-2 alcohols. The DAST-mediated deoxyfluorination proceeded with inversion of the configuration at C-2, affording 155 . The 4,6-O-benzylidene ring of 155 was regioselectively opened ${ }^{82-83}$ using $N$-bromosuccinimide (NBS), affording the 6-bromo 4-O-benzyl derivative, which was treated with sodium azide in DMF to generate the 6-azide derivative (156). Hydrolysis of the methyl glycoside moiety and bromination using thionyl bromide afforded glycosyl donor 157. The condensation of 157 with 138 using mercury (II) cyanide afforded a mixture of anomers, the $\alpha$-glycoside in $41 \%$ yield and the $\beta$-glycoside in $34 \%$ yield. The deprotection and reduction of the $6^{\prime}$-azido group afforded 158 as its $C-1^{\prime} \beta$ epimer 159.

Both epimers of 2',3'-Dideoxy-2'-fluorokanamycin A (158 and 159) were tested for their antibacterial activities; 159 was practically inactive, and 158 was only slightly less potent than tobramycin (2)..$^{79-80}$

3.3.10. Synthesis of 3'-deoxy-3'-fluoro (163) and 3',4'-dideoxy-3'-fluoro (165) analogues of kanamycin B (91). ${ }^{\mathbf{2 4}, \mathbf{8 4 - 8 5}}$ Treatment of $\mathbf{1 6 0}$ with 1-acetylimidazole (Aclm) in a 1:10 mixture of pyridine-DMSO gave selective 2 '-O-acetylation (Scheme 26). Treatment with benzenesulfonyl chloride allowed the introduction of a $3^{\prime}$-Obenzenesulfonyl moiety, which was then reacted with $0.5 \mathrm{M}$ aqueous $\mathrm{NaOH}$ to give the 2', $3^{\prime}$ - $\mathrm{N}$-tosylepimino derivative (161). The reaction of 161 with $\mathrm{KHF}_{2}$ in $\mathrm{DMF}$ at $150{ }^{\circ} \mathrm{C}$ for $2 \mathrm{~h}$ afforded the required common intermediate (162). The free $\mathrm{C}-4^{\prime} \mathrm{OH}$ of 161 seemed to stabilize the ${ }^{5} \mathrm{H}_{\mathrm{O}}$ conformation (half-chair with $\mathrm{C}-5$ up and the oxygen down) through hydrogen bonding, favouring fluoride attack at C-3' (Figure 10, 166). The final product (163) was obtained after deprotection under standard conditions. The selective 2"-O-acetylation of 162 using Aclm in a 1:10 mixture of pyridine-DMSO, followed by the introduction of a 4'-triflate moiety with 
triflic anhydride in pyridine and subsequent treatment with lithium chloride gave 164 . The reduction of $4^{\prime}$ - $\mathrm{Cl}$ with tributyltin hydride and AIBN followed by deprotection under standard conditions afforded 165.
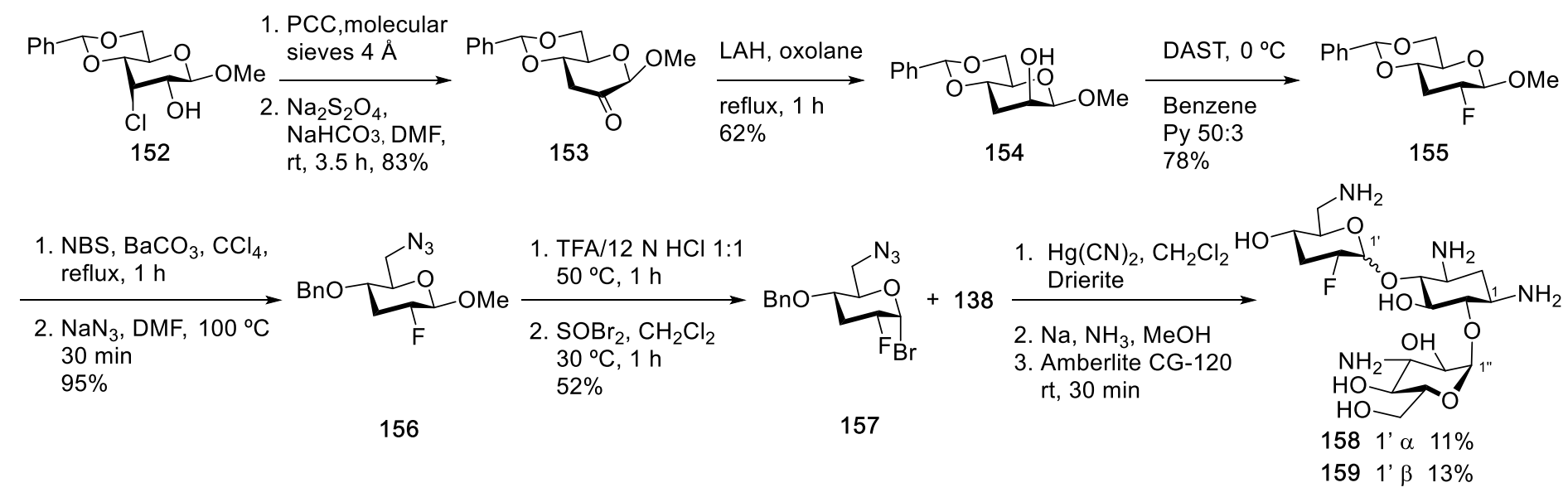

Scheme 25. Synthesis of 2',3'-dideoxy-2'-fluorokanamycin A (158).

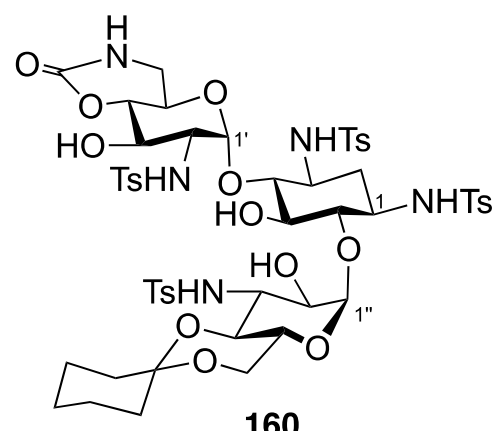

160
1. Aclm, Py:DMSO 1:9 overnight

2. $\mathrm{BnSO}_{2} \mathrm{Cl}, \mathrm{Py},-20^{\circ} \mathrm{C}$

3. $0.5 \mathrm{M} \mathrm{NaOH}, \mathrm{MeOH}$, rt, $4 \mathrm{~h}$ $90 \%$

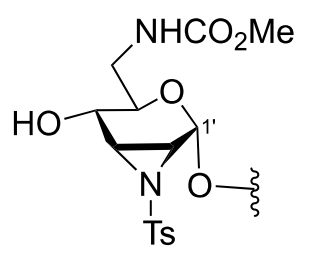

161
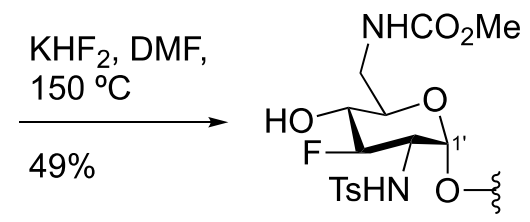

162
1. $\mathrm{Na}, \mathrm{NH}_{3}, \mathrm{MeOH}$ $-50^{\circ} \mathrm{C}$

2. $\mathrm{H}_{2} \mathrm{O}$ (basic), $80^{\circ} \mathrm{C}$

3. DOWEX 50-X2 $\left(\mathrm{H}^{+}\right)$ rt, overnight, $42 \%$

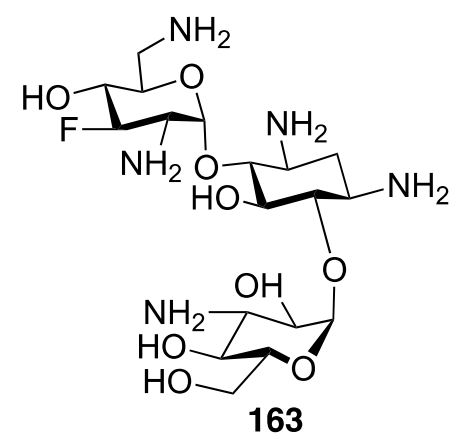

163

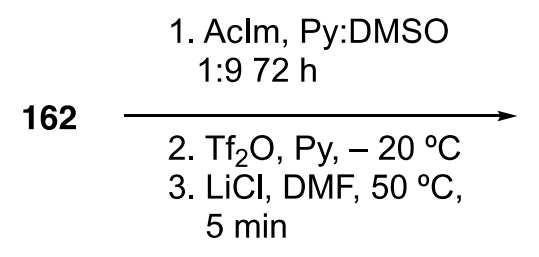

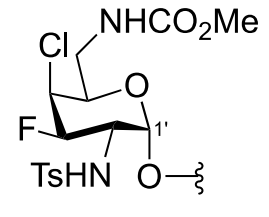

164

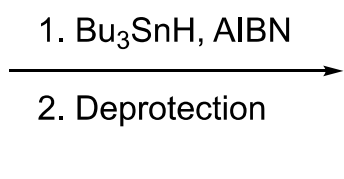

2. Deprotection

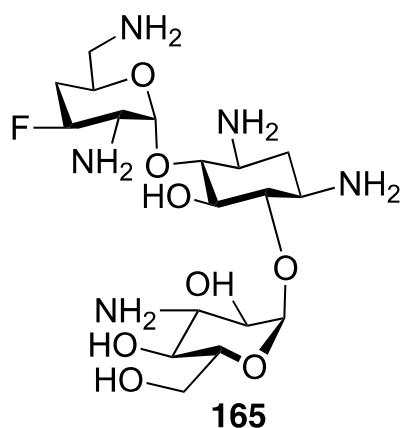

Scheme 26. Synthesis of 3'-deoxy-3'-fluorokanamycin B (163) and 3',4'-dideoxy-3'-fluorokanamycin B (165). 
Both compounds (163 and 165) showed antibacterial activity, and the potencies of 163 were similar to those of tobramycin (2), ${ }^{24}$ while 165 was active against bacteria producing $3^{\prime}$ and $4^{\prime}$ AMEs. ${ }^{84}$

The stereochemical outcome of the attack of 2,3-( $N$-tosylepimino)- $\alpha$-D-allopyranosides (166) by a fluoride nucleophile depends on the initial conformation (Figure 10). The attack can occur at position C-2, affording an altroside derivative (167), or at position C-3, affording a glucoside derivative (168). Model studies ${ }^{84}$ with 2,3( $N$-tosylepimino)- $\alpha$-D-allopyranosides (166) revealed that while the attack to form 168 is irreversible, the altroside (167) is in equilibrium with the 2,3-(N-tosylepimino)- $\alpha$-D-allopyranoside (166) despite the high $C-F$ bond energy. When the derivative is rigid, for example, when an acetal is formed at C-4 and C-6 OH, compounds 167 and 168 can be isolated, but at longer reaction times, the only fluorinated product detected is 168. When derivative (166) is flexible, only 168 is isolated regardless of the reaction times. It is postulated that the attack at position $\mathrm{C}-3$ occurs when $\mathbf{1 6 6}$ adopts a ${ }^{5} \mathrm{H}_{\mathrm{o}}$ conformation, which is stabilized by the acidic $\mathrm{KHF}_{2}$ and the solvent, instead of the ${ }^{\mathrm{O}} \mathrm{H}_{5}$ (half-chair with the oxygen up and $\mathrm{C}-5$ down) conformation that favours the attack at C-2 following the Fürst-Plattner rule; this creates a torsionally stable transition state despite the stereoelectronic effects of the lone pair on the pyranoside oxygen. ${ }^{86}$ If a nucleophile is present at C-6 (e.g., $\mathrm{OH}$ ), it could open the $N$-tosylepimino ring at $\mathrm{C}-3$ to form the 3,6-anhydroglucose derivative (169). ${ }^{84}$

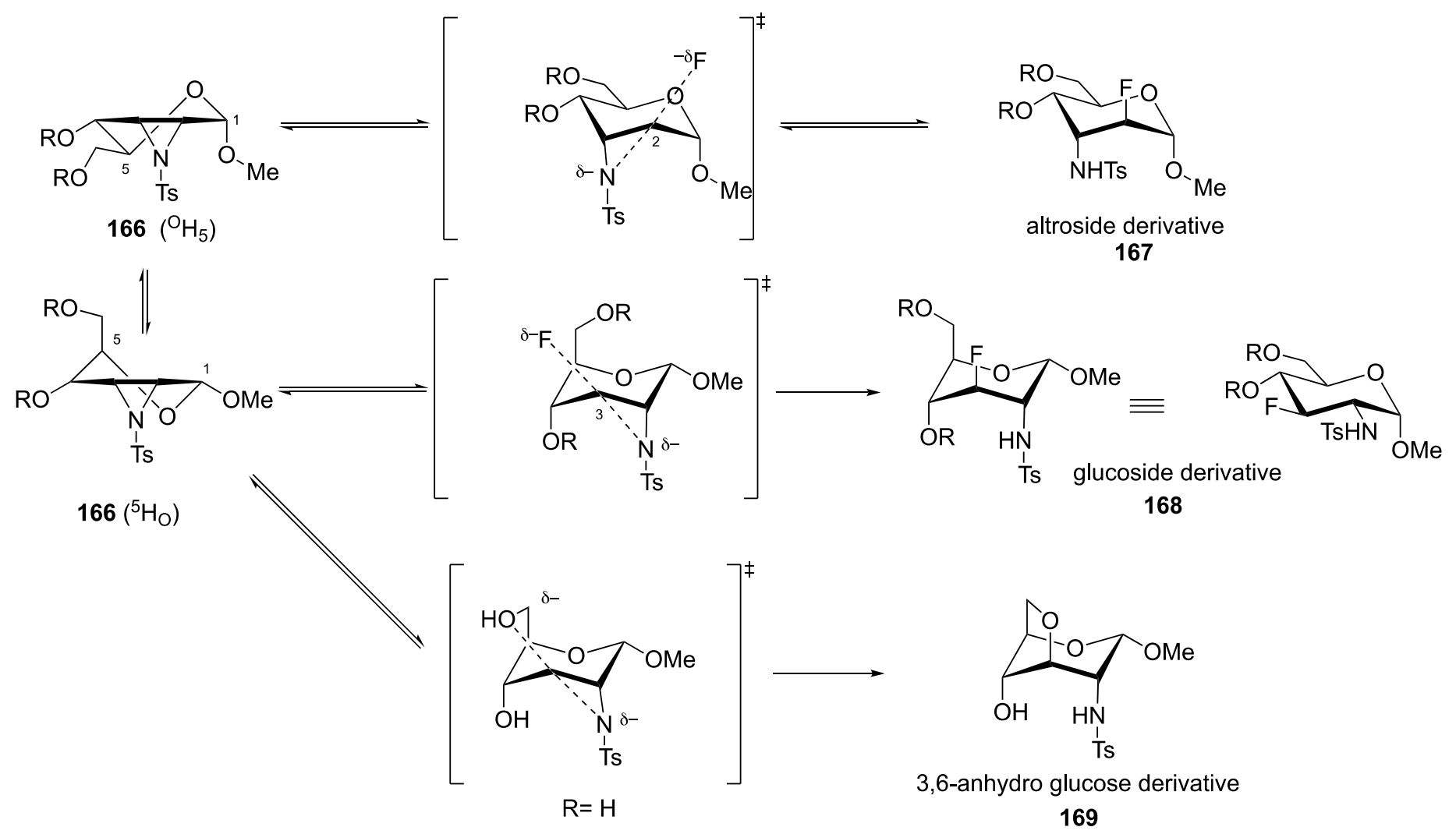

Figure 10. Stereochemical outcome of the attack of 2,3-(N-tosylepimino)- $\alpha$-D-allopyranosides by a fluoride nucleophile.

3.3.11. Synthesis of $4^{\prime}$-deoxy-4'-fluorokanamycin A (176). ${ }^{87}$ The C-5 configuration of $170^{88}$ was inverted at C4 ' by the SN2 displacement of the previously formed triflate with sodium nitrite in DMF, affording 171 in a low yield (Scheme 27). The treatment of 171 with DAST resulted in the formation of an unexpected product (172). The formation of this compound was postulated to occur via a 1,2-hydride shift in which the hydrogen at C-3' displaced the anti $-\mathrm{O}-\mathrm{SF}_{2}-\mathrm{NEt}_{2}$ leaving group at $\mathrm{C}-4^{\prime} .{ }^{87}$ However, a $3^{\prime}, 4^{\prime}$-elimination reaction promoted by the 
basic fluoride ion with concomitant cleavage of the 2',3'-O-cyclohexylidene during work-up cannot be excluded. Due to this discouraging result, a different approach was adopted. Compound $\mathbf{1 7 0}$ was treated sequentially with phenylmethanesulfonyl chloride, $80 \%$ aqueous acetic acid and $0.1 \mathrm{M}$ sodium methoxide solution in methanol to afford epoxide (173). The treatment of 173 with $\mathrm{KHF}_{2}$ in ethylene glycol afforded fluorinated derivatives 174 and $\mathbf{1 7 5}$ as a 1:5 mixture of inseparable compounds. This reaction also afforded non-fluorinated by-products as a result of nucleophilic attacks by ethylene glycol and water (not shown). A mixture 174 and 175 was deprotected under Birch conditions, and then the compounds were separated using ionic exchange chromatography, allowing the isolation of 176.

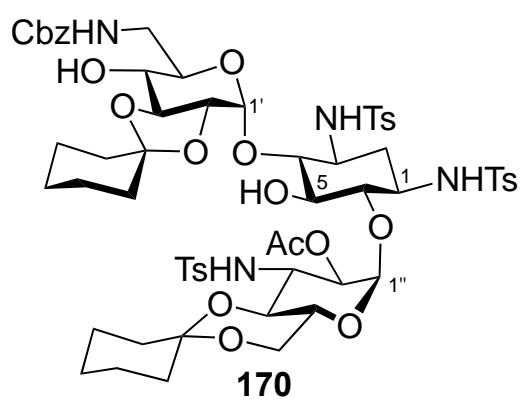

$$
\begin{aligned}
& \begin{array}{l}
\text { 1. } \mathrm{Tf}_{2} \mathrm{O}, \mathrm{CH}_{2} \mathrm{Cl}_{2} \\
-20{ }^{\circ} \mathrm{C}
\end{array} \\
& \begin{array}{l}
\text { 2. } \mathrm{NaNO}_{2}, \mathrm{DMF} \\
\text { rt, overnight } \\
\text { 32\% }
\end{array}
\end{aligned}
$$
2. $\mathrm{NaNO}_{2}, \mathrm{DMF}$ rt, overnight $32 \%$

170

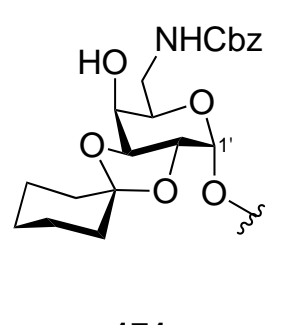

171

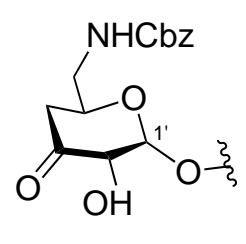

172

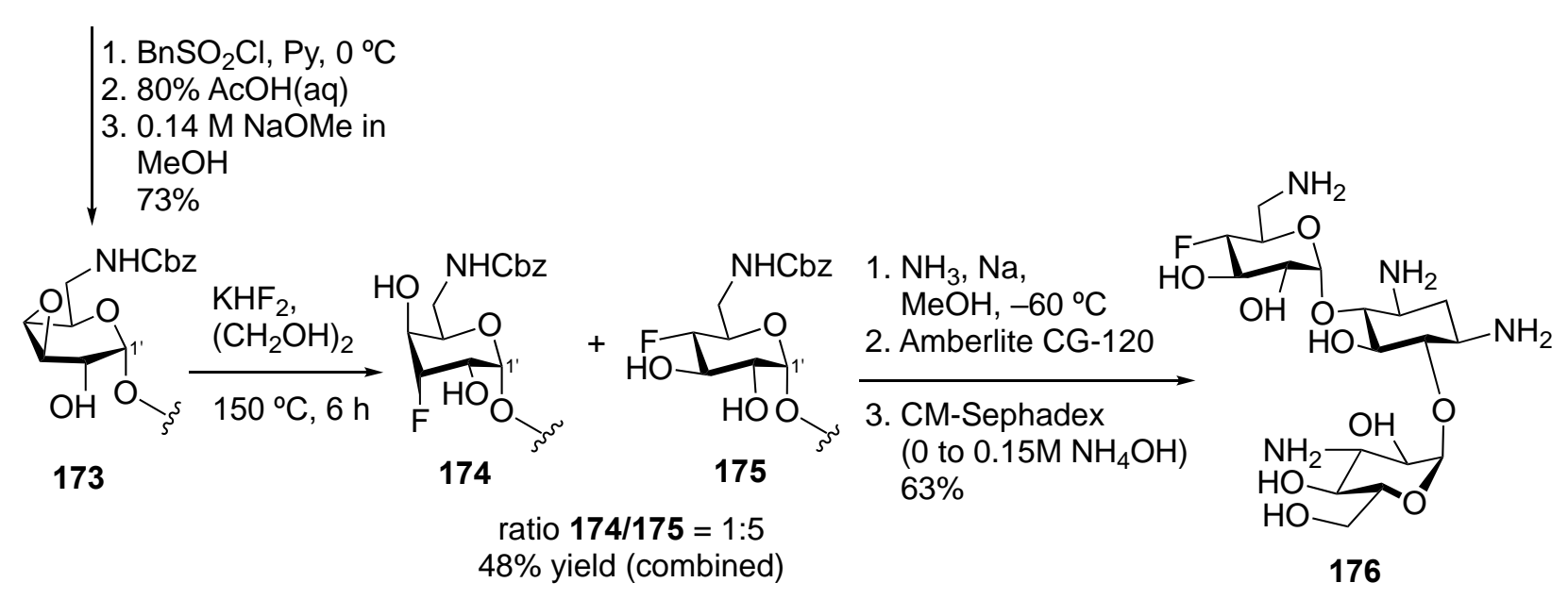

Scheme 27. Synthesis of 4'-deoxy-4'-fluorokanamycin A (176).

3.3.12. Synthesis of 4'-deoxy-4'-fluorokanamycin B (182). ${ }^{87}$ Compound 177 was first reacted with phenylmethanesulfonyl chloride in pyridine and then treated with sodium methoxide to afford 178 (Scheme 28). The reaction of $\mathbf{1 7 8}$ with $\mathrm{KHF}_{2}$ in ethylene glycol resulted in a complex mixture of products, of which only three were identified. The major product was bicyclic compound 180 (52\% yield), followed by the desired 4' deoxy-4'-fluoro derivative (179), which was obtained in $24 \%$. Traces of 3'-deoxy-3'-fluoro-4'-epi kanamycin B derivative (181) were also isolated. Several attempts to improve the yield of $\mathbf{1 7 9}$ by running the reaction in various protic and polar aprotic high-boiling solvents resulted only in the formation of compound $\mathbf{1 8 0}$. Compound $\mathbf{1 7 8}$ preferentially adopts an ${ }^{\mathrm{O}} \mathrm{H}_{1}$ conformation that exists in rapid equilibrium with a higher energy

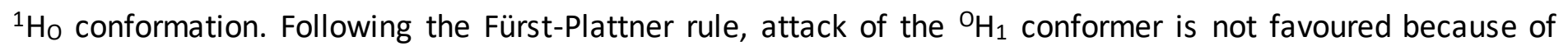
the stereoelectronic effects of the lone pair orbital on the oxygen of the glycosidic bond hindering the approach of the nucleophile from the bottom face. Fluoride attack at C-4' occurs on the highest energy ${ }^{1} \mathrm{H}_{\mathrm{O}}$ energy conformer of 178, affording desired isomer (179). Attack at C-4' by fluorine is highly solventdependent, and only ethylene glycol was suitable for this transformation. Neighbouring group participation of 
the C-2 tosylamino moiety affords $2^{\prime}, 3^{\prime}-N$-tosylepimine compound 183 , which can be attacked intramolecularly at C-3' by the C-6' tosylamino group, affording bicyclic intermediate 180 , or intermolecularly by a fluoride anion, affording compound $\mathbf{1 8 1}$. The attack at $\mathrm{C}-3^{\prime}$ is reversible and favours the formation of bicyclic intermediate 180 based on the Curtin-Hammett principle. ${ }^{89}$ Fluorinated kanamycin B analogue 182 was obtained after cleavage of the $N$-tosyl protecting groups under Birch conditions and purification by ion exchange chromatography. ${ }^{87}$

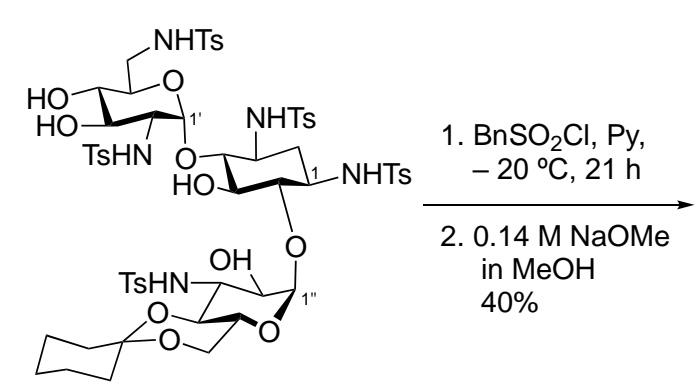

177
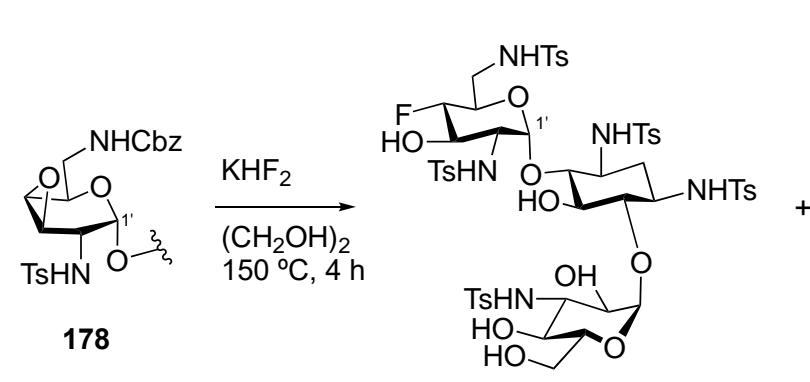

$179(24 \%)$

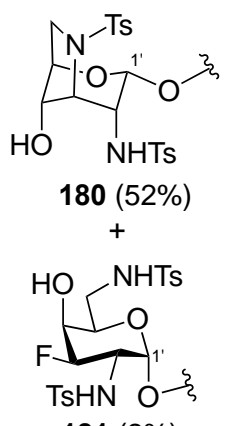

$181(2 \%)$

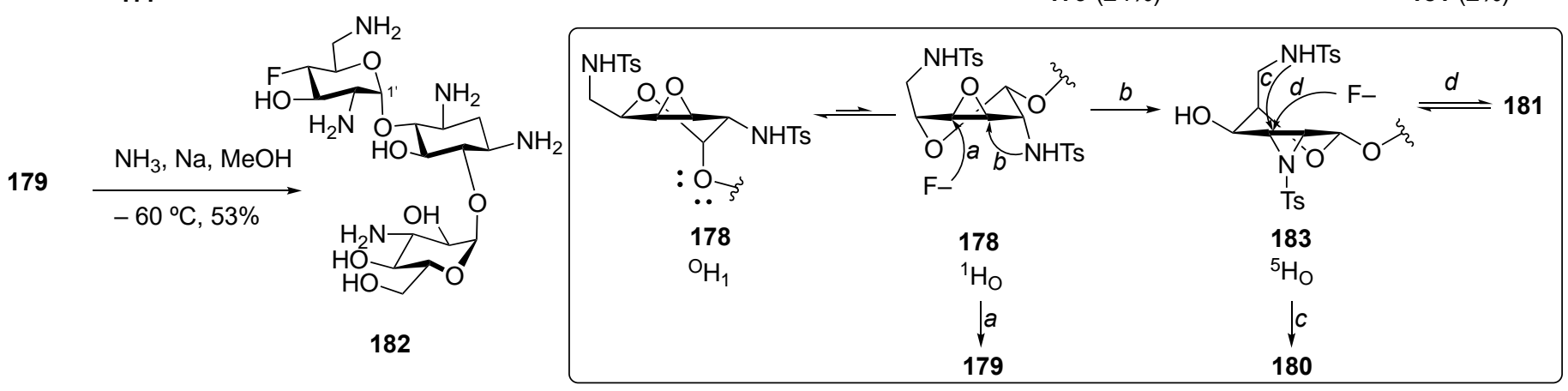

Scheme 28. Synthesis of 4'-deoxy-4'-fluorokanamycin B (182).

Compounds 176 and 182 were slightly less potent than kanamycins $A(\mathbf{1})$ and $B$, but they showed broader activity. Bacteria expressing $A A D\left(4^{\prime}\right)$ enzyme were susceptible to 176 and 182, but bacteria expressing $A P H\left(3^{\prime}\right)$ were resistant to the fluorinated AGs, indicating that the presence of an equatorial fluorine at $\mathrm{C}-4^{\prime}$ does not influence enzymes modifying the $\mathrm{C}-3^{\prime}$ position. ${ }^{87}$

3.3.13. Synthesis of 5-deoxy-5-fluoro derivatives of kanamycin B (91), tobramycin (2), and dibekacin (3). ${ }^{26}$ The syntheses of $\mathbf{1 8 6 - 1 8 8}$ have been described elsewhere. ${ }^{53}$ The synthesis of 5-deoxy-5-fluorokanamycin B (186) is described herein as an example (Scheme 29). Treatment of kanamycin B (91) with $p$-TsCl followed by $\mathrm{AcCl}$ in pyridine afforded 184. The inversion of the $\mathrm{C}-5$ stereocenter of $\mathbf{1 8 4}$ was performed under Mitsunobu conditions using DEAD, triphenylphosphine and benzoic acid, and subsequent treatment with sodium methoxide and reacetylation with $\mathrm{AcCl}$ in pyridine afforded intermediate (185). Treatment of 185 with DAST inverted the configuration, and compound (186) was obtained after deprotection. A similar approach was used for the syntheses of 187 and 188. 


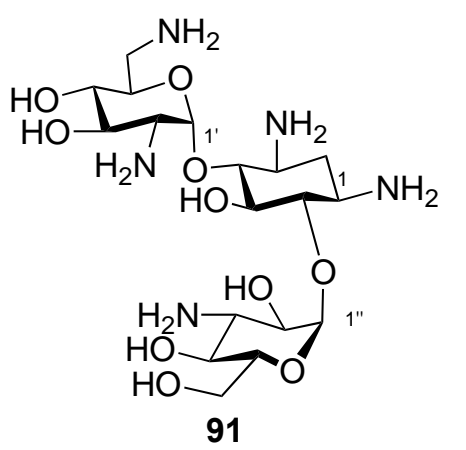

1. DEAD, $\mathrm{PPH}_{3}$, $\mathrm{PhCOOH}$

2. $\mathrm{MeONa}, \mathrm{MeOH}$

3. AcCl, py

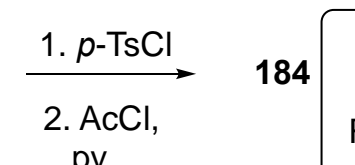

py

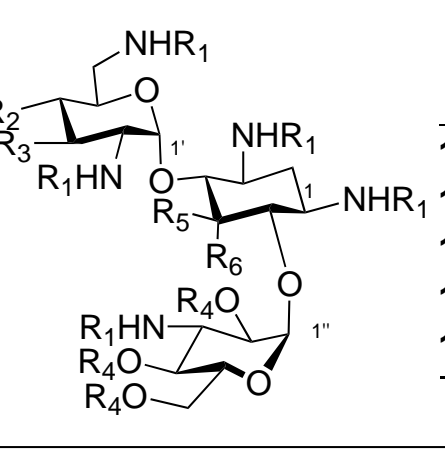

\begin{tabular}{lllllll}
\cline { 2 - 6 } & $\mathrm{R}_{1}$ & $\mathrm{R}_{2}$ & $\mathrm{R}_{3}$ & $\mathrm{R}_{4}$ & $\mathrm{R}_{5}$ & $\mathrm{R}_{6}$ \\
\hline 184 & $\mathrm{Ts}$ & $\mathrm{OAc}$ & $\mathrm{OAc}$ & $\mathrm{Ac}$ & $\mathrm{OH}$ & $\mathrm{H}$ \\
185 & $\mathrm{Ts}$ & $\mathrm{OAc}$ & $\mathrm{OAc}$ & $\mathrm{Ac}$ & $\mathrm{H}$ & $\mathrm{OH}$ \\
186 & $\mathrm{H}$ & $\mathrm{OH}$ & $\mathrm{OH}$ & $\mathrm{H}$ & $\mathrm{F}$ & $\mathrm{H}$ \\
187 & $\mathrm{H}$ & $\mathrm{OH}$ & $\mathrm{H}$ & $\mathrm{H}$ & $\mathrm{F}$ & $\mathrm{H}$ \\
188 & $\mathrm{H}$ & $\mathrm{H}$ & $\mathrm{H}$ & $\mathrm{H}$ & $\mathrm{F}$ & $\mathrm{H}$ \\
\hline
\end{tabular}

Scheme 29. Synthesis of 5-deoxy-5-fluorokanamycin B (186), 5-deoxy-5-fluorotobramycin (187), and 5-deoxy5-fluorodibekacin (188).

The synthesis of 5-deoxy-5,5-difluorotobramycin (192) is described as a second example (Scheme 30). The treatment of suitably protected tobramycin derivative (189) with pyridinium chlorochromate (PCC) in dichloromethane afforded the 5-oxo derivative (190). The treatment of 190 with DAST gave a difluorinated analogue (191) that afforded 192 after deprotection. A similar approach afforded 5-deoxy-5,5-difluorodibekacin (193).
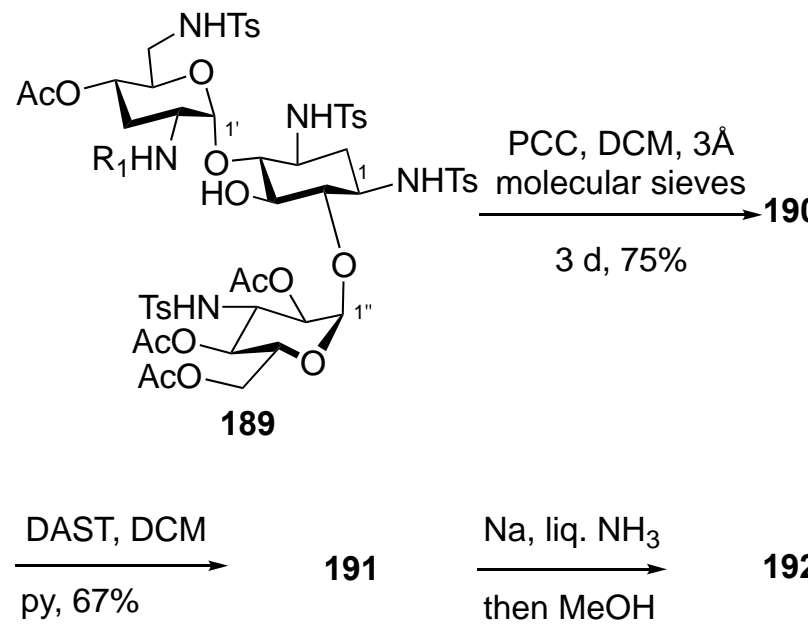

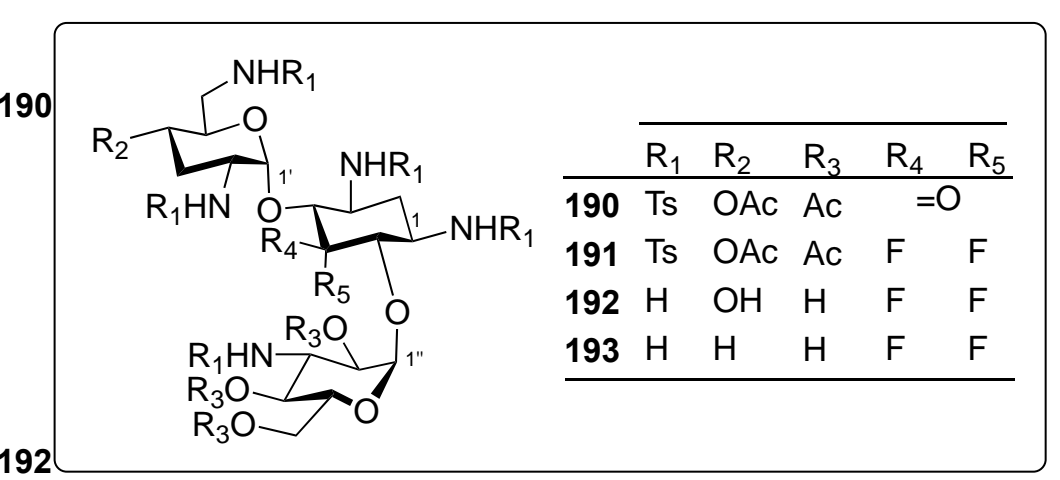

192

\begin{tabular}{|c|c|c|c|c|c|}
\hline & $\mathrm{R}_{1}$ & $\mathrm{R}_{2}$ & $\mathrm{R}_{3}$ & $\mathrm{R}_{L}$ & $R_{5}$ \\
\hline 190 & Ts & OAc & Ac & \multicolumn{2}{|c|}{$=\mathrm{O}$} \\
\hline 191 & Ts & OAc & Ac & $F$ & $F$ \\
\hline 192 & $\mathrm{H}$ & $\mathrm{OH}$ & $\mathrm{H}$ & $F$ & $\mathrm{~F}$ \\
\hline 193 & $\mathrm{H}$ & $\mathrm{H}$ & $\mathrm{H}$ & $F$ & $F$ \\
\hline
\end{tabular}

Scheme 30. Synthesis of 5-deoxy-5,5-difluorotobramycin (192) and 5-deoxy-5,5-difluorodibekacin (193).

The results of the antibacterial test suggested that the potencies of fluorinated analogues 186-188, 192 and 193 were comparable to those of their parent un-fluorinated counterparts, but depending on their deoxygenation pattern, they exhibit different behaviours against resistant bacteria. Compound (186) was inactive against bacteria expressing the enzyme $\operatorname{APH}\left(3^{\prime}\right)$ I and II, while compounds $(187,188,192$ and 193) evaded resistance from bacteria expressing the enzymes $\operatorname{APH}\left(3^{\prime}\right), \operatorname{ANT}\left(2^{\prime \prime}\right), \operatorname{AAC}(3)$, and AAC $\left(2^{\prime}\right)$. Their ability to evade AAC was attributed to the decreased basicity of the C-3 and C-2' amine groups, but the source of their ability to evade the enzyme ANT( $\left.2^{\prime \prime}\right)$ is not clear. The authors proposed that the presence of the fluorine 
atom at C-5 could alter the glycosidic bond angles, impairing the fit of the AG in ANT( $\left.2^{\prime \prime}\right)$ but not in the ribosome A-site. ${ }^{26}$ The fluorine atom can also alter the affinity of the AG towards the ANT(2") enzyme due to the reduction of the nucleophilicity of the $2^{\prime \prime}$-hydroxy group, as demonstrated by $4^{\prime}$-deoxy-4', $4^{\prime}$ difluoroneamine (40) and $4^{\prime}$-deoxy-4',4'-difluorokanamycin A (223) (refer to Section 3.3.18). ${ }^{47}$ The acute toxicity tests showed that the fluorinated derivatives are less toxic than their parent oxygenated AGs in mice. In general, 5-deoxy-5-fluoro derivatives 187 and 188 presented LD 50 values approximately two-fold higher than those of their difluorinated counterparts (192 and 193). These results strongly suggest that the basicity of the $\mathrm{C}-1$ and $\mathrm{C}-3$ amines contributes to the toxicity of the AGs.

3.3.14. Synthesis of 1-N-HABA-5-deoxy-5-fluoro analogues of kanamycin B (91), tobramycin (2), arbekacin (93). ${ }^{27}$ The synthesis of 1-N-HABA- derivatives 194-198 started from previously described fluorinated derivatives 186-188, 192 and $193^{26}$ and was performed in a manner similar to what was described previously (Scheme 19). The synthesis of 195 has been described elsewhere. ${ }^{53}$
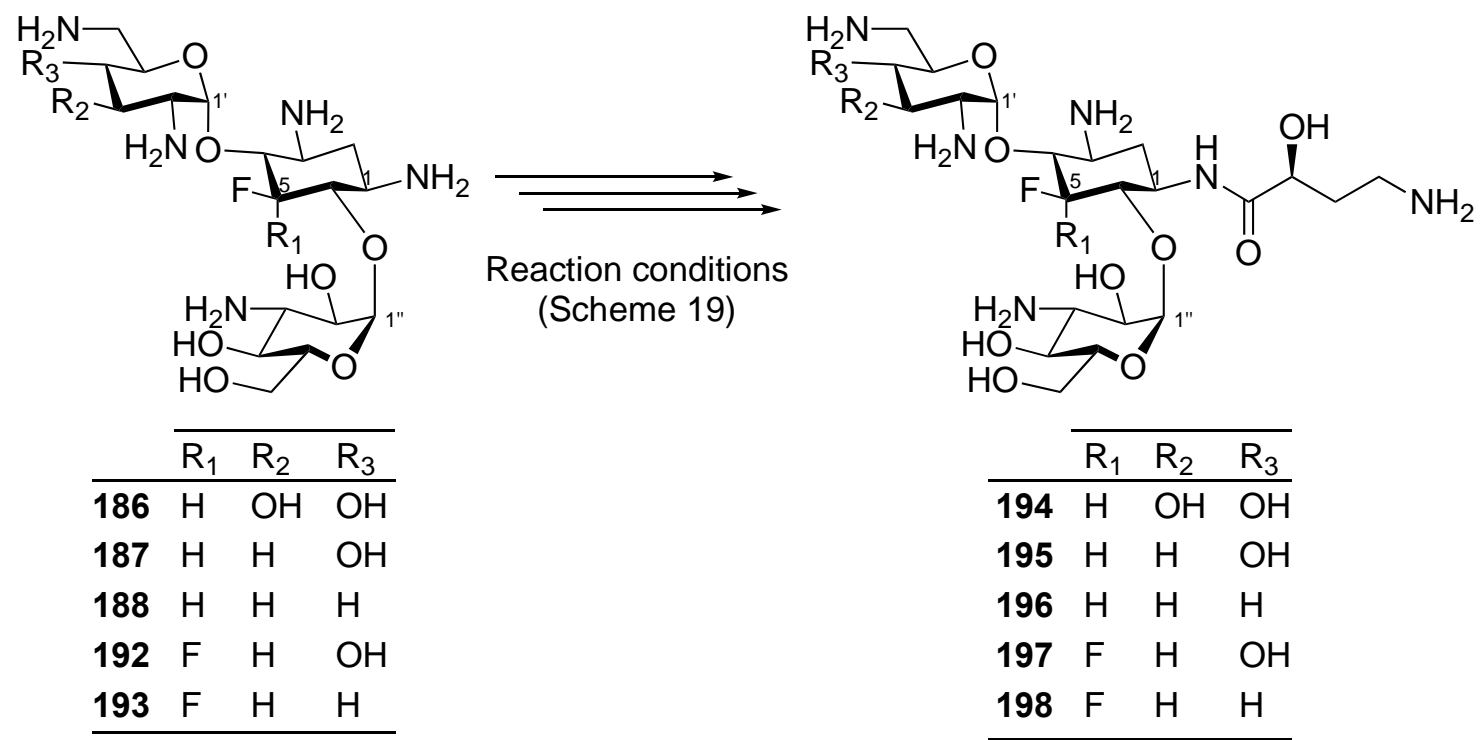

Scheme 31. Synthesis of 1-HABA-5-deoxy-5-fluorokanamycin B (194), 1-HABA-5-deoxy-5-fluorotobramycin (195), 1-HABA-5-deoxy-5-fluorodibekacin (196), 1-HABA-5-deoxy-5,5-difluorotobramycin (197) and 1-HABA-5deoxy-5,5-difluorodibekacin (198).

The toxicities of the AGs were in the order $5-\mathrm{OH}>5-\mathrm{F}>5-\mathrm{F}, \mathrm{F}$, and based on these results, the 1-N-HABA group had no appreciable effect on the toxicity of this series of compounds, again suggesting that the toxicity is a consequence of the basicity of the amine groups on the deoxystreptamine core. ${ }^{27}$

3.3.15. 5-Deoxy-5-epi- derivatives of amikacin (4), tobramycin (2), dibekacin (3), 1-N-HABA tobramycin, a nd arbekacin (93). ${ }^{90}$ The same strategy that was used for the synthesis of compound 201 was used for the synthesis of 5-deoxy-5-fluoro-5-epi derivatives 202 and 203 (Scheme 32). The treatment of suitably protected intermediate 199 with DAST afforded 200 with inversion of the configuration at C-5 in 65\% yield. Compound (201) was obtained following standard deprotection procedures. The installation of the 1-N-HABA side chain in compounds 204 and 205 started from 5-deoxy-5-fluoro-5-epi fluorinated derivatives (202 and 203) and followed the strategy described previously (Scheme 19). 

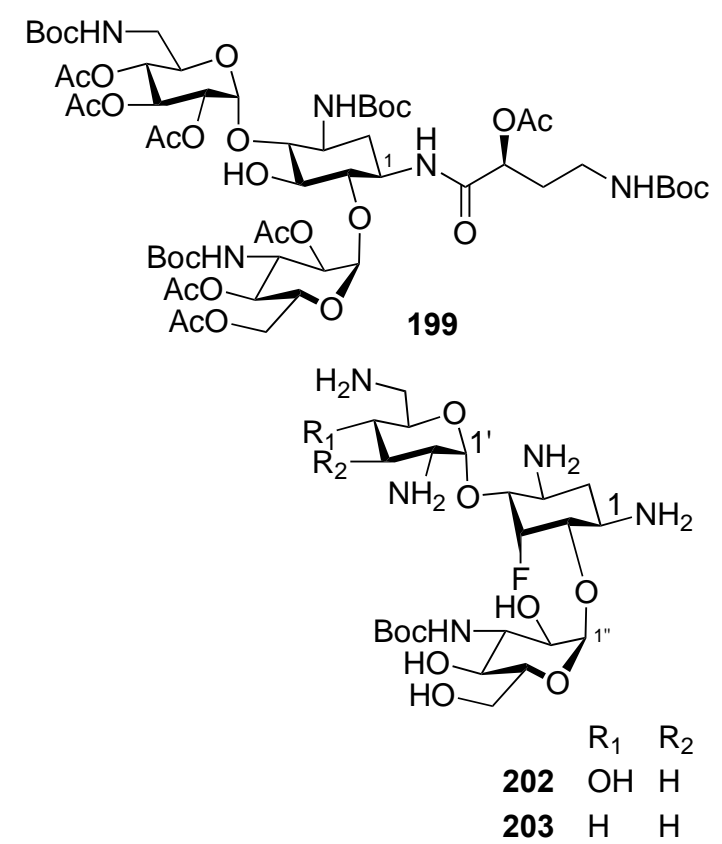
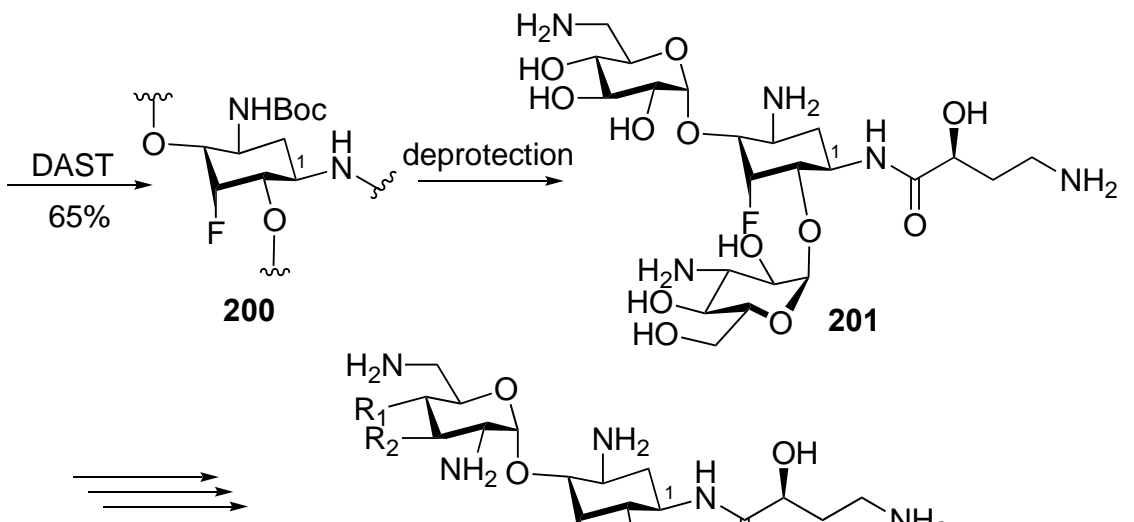

Reaction conditions (Scheme 19)

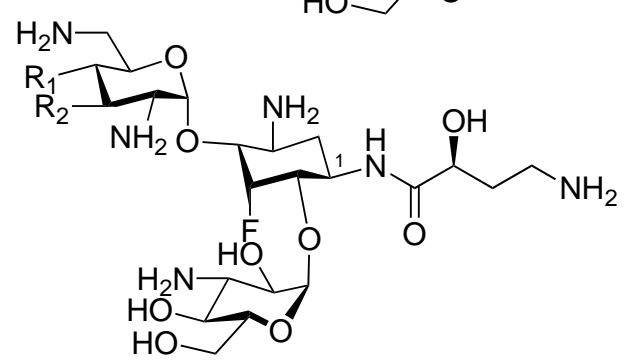

$\begin{array}{lll} & \mathrm{R}_{1} & \mathrm{R}_{2} \\ 204 & \mathrm{OH} & \mathrm{H} \\ 205 & \mathrm{H} & \mathrm{H}\end{array}$

Scheme 32. 5-Deoxy-5-epi-5-fluoroamikacin (201), 5-deoxy-5-epi-5-fluorotobramycin (202), 5-deoxy-5-epi-5fluorodibekacin (203), 1-N-[(S)-4-amino-2-hydroxybutanoyl]-5-deoxy-5-epi-5-fluorotobramycin (204), 5-deoxy5-epi-5-fluoroarbekacin (205).

All the 5-deoxy-5-epi-5-fluoro analogues retained the antibacterial activity of the 5-deoxy-5-fluoroanalogues and were as potent as AGs arbekacin (93), amikacin (4) and 1-N-HABA tobramycin (not shown). AGs 201-205 were all active against bacteria expressing the AAC(2') enzyme, and 1-N-HABA AGs 204-205 showed the strongest antibacterial potency against clinically isolated methicillin-resistant $S$. aureus. Surprisingly, the toxicities of 5-deoxy-5-fluoro-5-epi AGs (201-205) were the same as those of their parent compounds; this is unlike the results of 5-deoxy-5-epi-5-fluorosisomicin (73), which is less toxic than sisomicin (65). ${ }^{55}$

The relationship between the orientation of the 5 -fluoro substituent and the basicity of the amino groups at C-1 and C-3 in the 5-deoxy-5-fluoro and 5-deoxy-5-fluoro-5-epi series was studied with a model system. Three compounds, namely, 2-deoxystreptamine (69), 2,5-dideoxy-5-fluoro-2-deoxystreptamine (70) and 2,5dideoxy-5-epi-5-fluoro-2-deoxystreptamine (71), were prepared, and the $\mathrm{p} K_{\mathrm{a}}$ values of the 1,3-amino groups were determined by ${ }^{13} \mathrm{C}$ NMR spectroscopy and by classic titration methods (Figure 11). The obtained $\mathrm{p} K_{\mathrm{a}}$ values showed that the equatorial $\mathbf{5}$-fluoro atom of $\mathbf{7 0}$ significantly reduced the basicity of the amino groups $(\Delta=0.35)$ when compared to the value obtained for 2-deoxystreptamine (70). The axial 5-fluoro of 71, however, reduced the basicity only slightly $(\Delta=0.09)$. This difference in basicity correlates well with the difference in acute toxicity found between the 5-deoxy-5-fluoro and 5-deoxy-5-fluoro-5-epi series. ${ }^{90}$ The effect of the difluorination at $\mathrm{C}-5$ still needs to be assessed. 


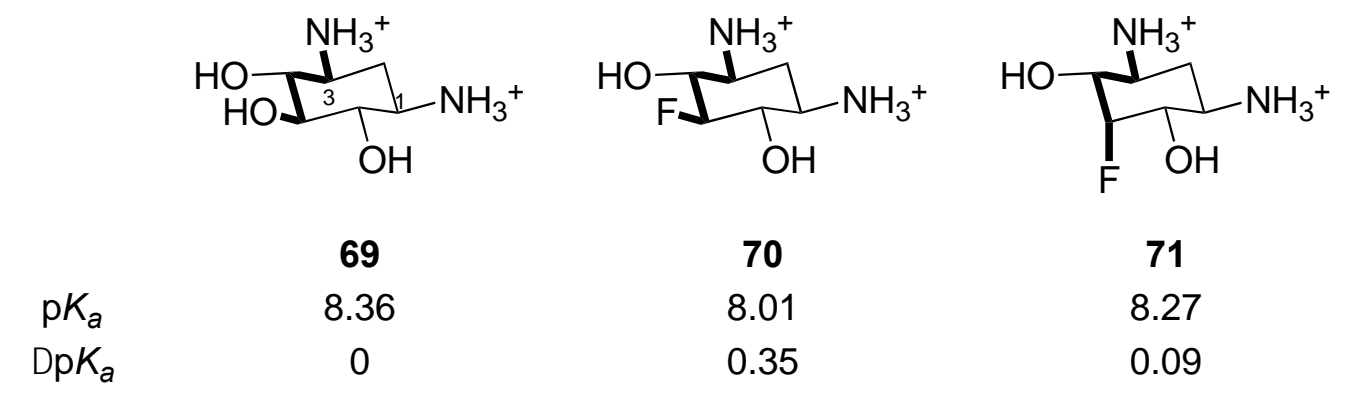

Figure 11. Influence of fluorination on $\mathrm{p} K$ a.

3.3.16. Synthesis of 2"-amino-5,2"-dideoxy-5-epi-5-fluorodibekacin (208) and 2"-amino-5,2"'-dideoxy-5,2"'diepi-5-fluorodibekacin (210). ${ }^{91}$ As part of a study on the effect of 5-fluorination on the ${ }^{13} \mathrm{C}$ NMR chemical shifts of C-4 and C-6, several 2"-amino-2"-deoxy and 2"-acylamino-2"-deoxy derivatives of 5-deoxy-5-fluoro5-epi-dibekacin (203) were prepared. The syntheses of 208 and 210 are described as examples (Scheme 33). A suitably protected derivative (206) was treated with DMSO and acetic anhydride to give the 2 " -oxo derivative, which was the reacted with methoxyamine hydrochloride and reduced with $\mathrm{LiBH}_{4}-\mathrm{TMSCl}^{92}$ to afford a diastereomeric mixture of $\mathbf{2 0 7}$ and $\mathbf{2 0 9}$ that was separated by flash chromatography. The deprotection of 207 and 209 afforded AGs (208 and 210).

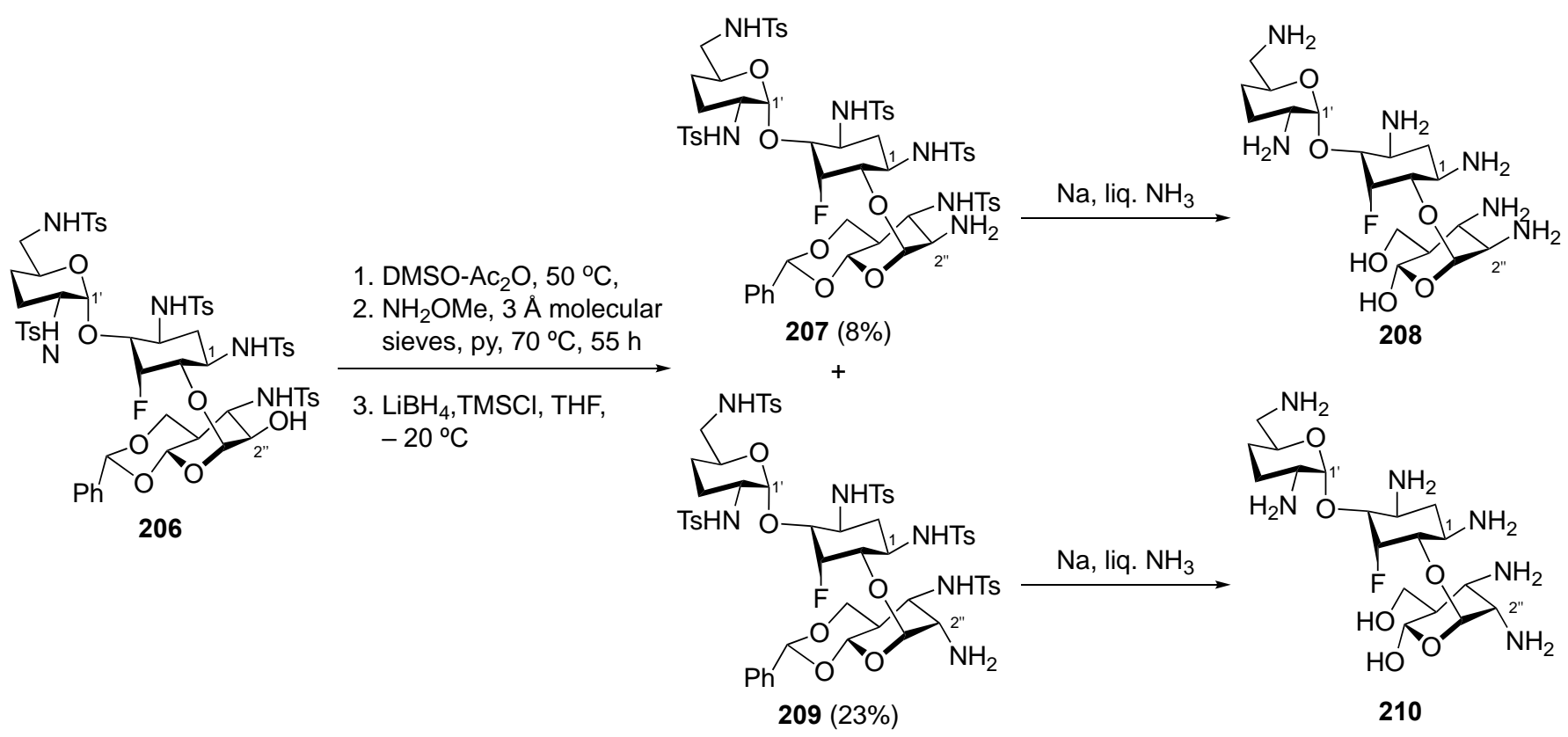

Scheme 33. Synthesis of 2"-amino-5,2"-dideoxy-5-epi-5-fluorodibekacin (208) and 2"'-amino-5,2"-dideoxy5,2"-diepi-5-fluorodibekacin (210).

Intermediates (207 and 209) were acylated at 2"-N with HABA, $\beta$-alanine or 4-butanoic acid (not shown), and the compounds were analysed by NMR spectroscopy. Deoxyfluorination at C-5 causes an upfield shift in the ${ }^{13} \mathrm{C}$ NMR signals of $\mathrm{C}-4$ and $\mathrm{C}-6$ relative to the values determined for the non-fluorinated AG. The effect is more significant at $\mathrm{C}-4$, indicating that despite both carbons being vicinal to the halogen atom, the electronwithdrawing effect is more pronounced at this position than at C-6. These results, together with MM2UEC 
refined by MOPAC93/MP3 calculations, revealed that this difference can be explained by a through-space interaction between the 5-fluoro atom and the 4-O and 6-O species (Figure 12) that shield the vicinal C-4 and C-6 atoms. ${ }^{91}$

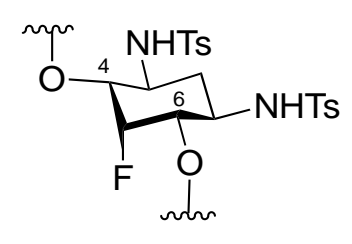

\section{Figure 12}

With the exception of 208, which showed some potency, the $\mathbf{2 1 0}$ and the 2"-acylamino-2"-deoxy derivatives (not shown) exhibited lower potencies or a complete absence of antibacterial activity, indicating that $\mathrm{N}$-acylation at $\mathrm{C}-2^{\prime \prime}$ is detrimental to the bacteriotoxic nature of these molecules. ${ }^{91}$

3.3.17. Synthesis of 5-deoxy-5,2"-diepi-5-fluorodibekacin (216), 5-deoxy-5-epi-5-fluoro-2"-hydroxy dibekacin (218) and 5-deoxy-5-epi-5-fluoro-2"'-hydroxyarbekacin (219).93 A suitably protected dibekacin analogue (211) was treated with DAST in dichloromethane to afford 212 in $80 \%$ yield (Scheme 34). Deacetylation of $\mathbf{2 1 2}$ followed by triflation gave $\mathbf{2 1 4}$ in a high yield. Treatment of $\mathbf{2 1 4}$ with sodium acetate in DMF afforded cyclic carbamate (215) with inversion of the configuration at C-2". Finally, deprotection under standard procedures afforded 216. Treatment of $\mathbf{2 1 3}$ with PCC in dichloromethane gave compound $\mathbf{2 1 7}$ in $80 \%$ yield, and deprotection of this compound gave 2"-oxo derivative $\mathbf{2 1 8}$ in the form of a hydrate. Arbekacin analogue (219) was prepared in a similar manner starting from a suitably protected arbekacin analogue (not shown). 


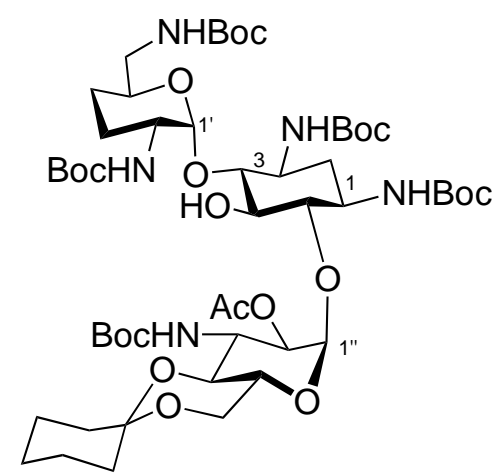

211
DAST, $\mathrm{CH}_{2} \mathrm{Cl}_{2}$, $-20^{\circ} \mathrm{C}, 6 \mathrm{~h}$ 212
214
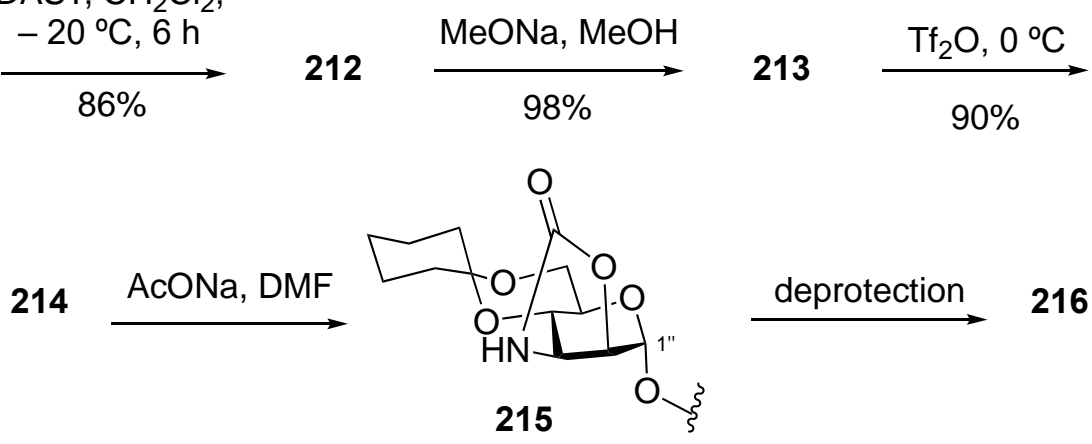

$213 \underset{90 \%}{\stackrel{\mathrm{Tf}_{2} \mathrm{O}, 0^{\circ} \mathrm{C}}{\longrightarrow}}$
213

$$
\underset{80 \%}{\stackrel{\text { PCC, } \mathrm{CH}_{2} \mathrm{Cl}_{2}}{\longrightarrow}}
$$

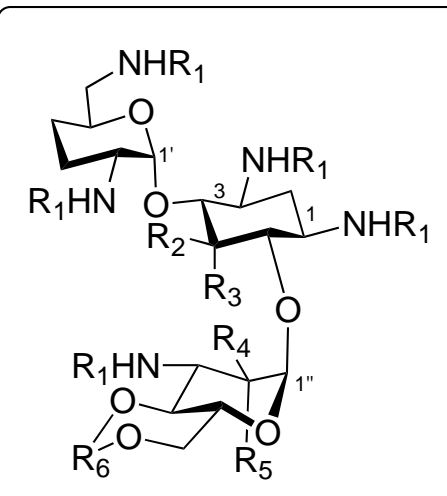

217

\begin{tabular}{lllllll}
\cline { 2 - 7 } & $\mathrm{R}_{1}$ & $\mathrm{R}_{2}$ & $\mathrm{R}_{3}$ & $\mathrm{R}_{4}$ & $\mathrm{R}_{5}$ & $\mathrm{R}_{6}$ \\
\hline $\mathbf{2 1 2}$ & Boc & $\mathrm{H}$ & $\mathrm{F}$ & $\mathrm{OAc}$ & $\mathrm{H}$ & $\mathrm{C}_{6} \mathrm{H}_{10}$ \\
$\mathbf{2 1 3}$ & Boc & $\mathrm{H}$ & $\mathrm{F}$ & $\mathrm{OH}$ & $\mathrm{H}$ & $\mathrm{C}_{6} \mathrm{H}_{10}$ \\
$\mathbf{2 1 4}$ & Boc & $\mathrm{H}$ & $\mathrm{F}$ & $\mathrm{OTf}$ & $\mathrm{H}$ & $\mathrm{C}_{6} \mathrm{H}_{10}$ \\
$\mathbf{2 1 6}$ & $\mathrm{H}$ & $\mathrm{H}$ & $\mathrm{F}$ & $\mathrm{H}$ & $\mathrm{OH}$ & $\mathrm{H}, \mathrm{H}$ \\
$\mathbf{2 1 7}$ & Boc & $\mathrm{H}$ & $\mathrm{F}$ & \multicolumn{2}{c}{$\mathrm{C}=\mathrm{O}$} & $\mathrm{C}_{6} \mathrm{H}_{10}$ \\
$\mathbf{2 1 8}$ & $\mathrm{H}$ & $\mathrm{H}$ & $\mathrm{H}$ & $\mathrm{OH}$ & $\mathrm{OH}$ & $\mathrm{H}, \mathrm{H}$ \\
\hline
\end{tabular}

deprotection

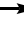

218

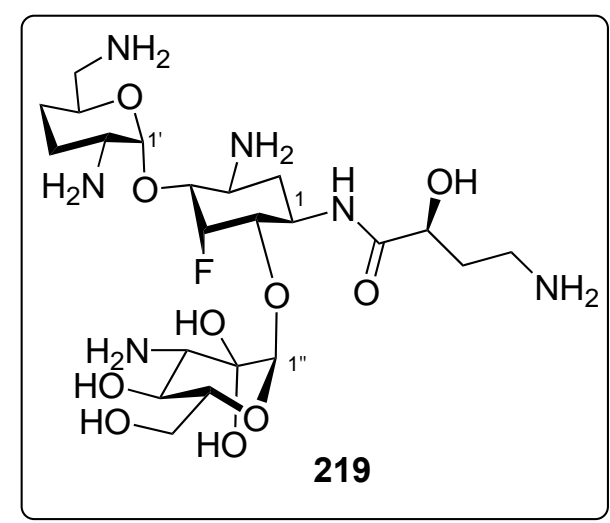

Scheme 34. Synthesis of 5-deoxy-5,2"-diepi-5-fluorodibekacin (216), 5-deoxy-5-epi-5-fluoro-2"hydroxydibekacin (218) and 5-deoxy-5-epi-5-fluoro-2"'-hydroxyarbekacin (219).

The antibacterial activity potencies of 216-219 were considerably diminished compared with that of arbekacin (93); this effect was attributed to the absence of the equatorial $\mathrm{OH}-2$ " of the AG when in the oxo form.

3.3.18. Synthesis of 4'-deoxy-4',4'-difluorokanamycin A (223). 47 $^{4}$ '-Deoxy-4', 4'-difluorokanamycin A (223) was synthesized to determine the importance of the nucleophilicity $\mathrm{C}-3$ ' $\mathrm{OH}$ group in the phosphorylation mechanism of the enzyme $\mathrm{APH}\left(3^{\prime}\right)$. The synthesis started from compound 220, which was obtained in six steps from kanamycin A (1) ${ }^{94}$ (Scheme 35). Treatment of 220 with $p$-methoxybenzyl chloromethyl ether (PMBMCl) followed by base-promoted hydrolysis of the $5^{\prime}, 6^{\prime}-N, O$-carbonyl moiety afforded 221 . The reaction of 221 with Dess-Martin periodinane (DMP) gave the 4'-oxo derivative, which was treated with Morpho-DAST to afford 222. Difluorinated kanamycin A derivative (223) was obtained after protecting group cleavage under standard conditions. 


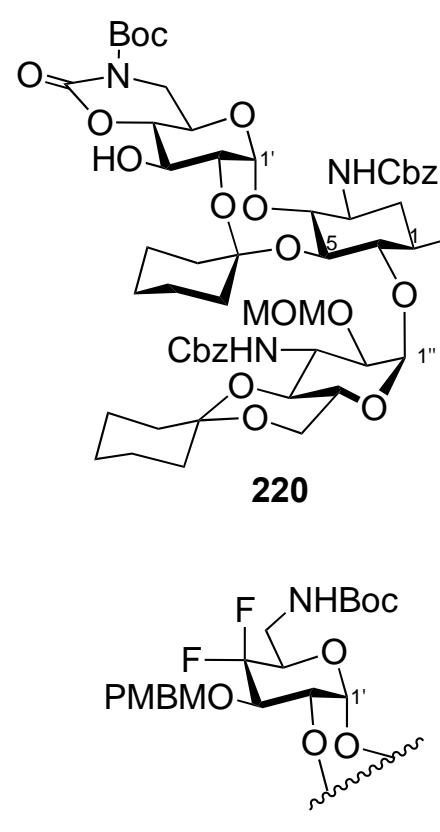

222
1. DDQ, $\mathrm{CH}_{2} \mathrm{Cl}_{2}$, phosphate buffer, rt, $8 \mathrm{~h}$

2. TFA $/ \mathrm{CH}_{2} \mathrm{Cl}_{2} 1: 14 \mathrm{~h}$

3. $\mathrm{Pd} / \mathrm{C}, \mathrm{H}_{2}, p$-dioxane/ $\mathrm{H}_{2} \mathrm{O} 1: 1$ overnight $31 \%$
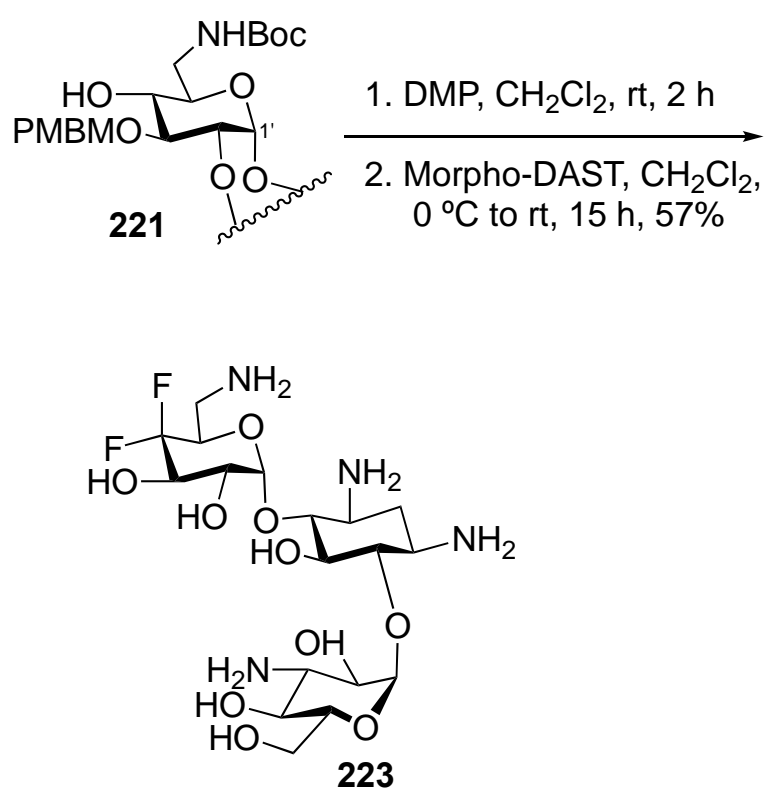

Scheme 35. Synthesis of $4^{\prime}$-deoxy-4', $4^{\prime}$-difluorokanamycin A (223).

4'-Deoxy-4',4'-difluorokanamycin A (223) and 4'-deoxy-4',4'-difluoroneamine (40) (Scheme 5, Section 2.2.3) presented moderate antibacterial potencies. Remarkably, the MIC determined for a resistant $E$. coli strain that expresses the APH(3')lla enzyme was the same as that determined for the wild-type bacteria when $\mathbf{2 2 3}$ and $\mathbf{4 0}$ were used for testing. Enzyme kinetics analysis also demonstrated that $\mathbf{4 0}$ and $\mathbf{2 2 3}$ were impaired substrates for the $\mathrm{APH}\left(3^{\prime}\right)$ Ila enzyme. These results show that the reduction in the nucleophilicity of $\mathrm{C}-3^{\prime} \mathrm{OH}$ caused by the electronegativity of the adjacent fluoride atom renders these compounds poor substrates for phosphorylation by the APH( $\left.3^{\prime}\right)$ Ila enzyme. ${ }^{47}$

3.3.19. Synthesis of 6"-deoxy-6",6"'-difluorokanamycin A (227). ${ }^{35}$ A diazo transfer reaction afforded perazido derivative 224 from kanamycin A (1) in 64\% yield (Scheme 36). The regioselective protection of the primary $\mathrm{OH}$ of 224 as a trityl ether followed by per-O-benzylation and removal of the trityl protecting group with $\mathrm{BF}_{3} \cdot \mathrm{Et}_{2} \mathrm{O}$ afforded compound $\mathbf{2 2 5}$ in $65 \%$ overall yield. A Swern oxidation followed by treatment with DAST afforded difluorinated analogue 226, which was fully deprotected to afford 227. 


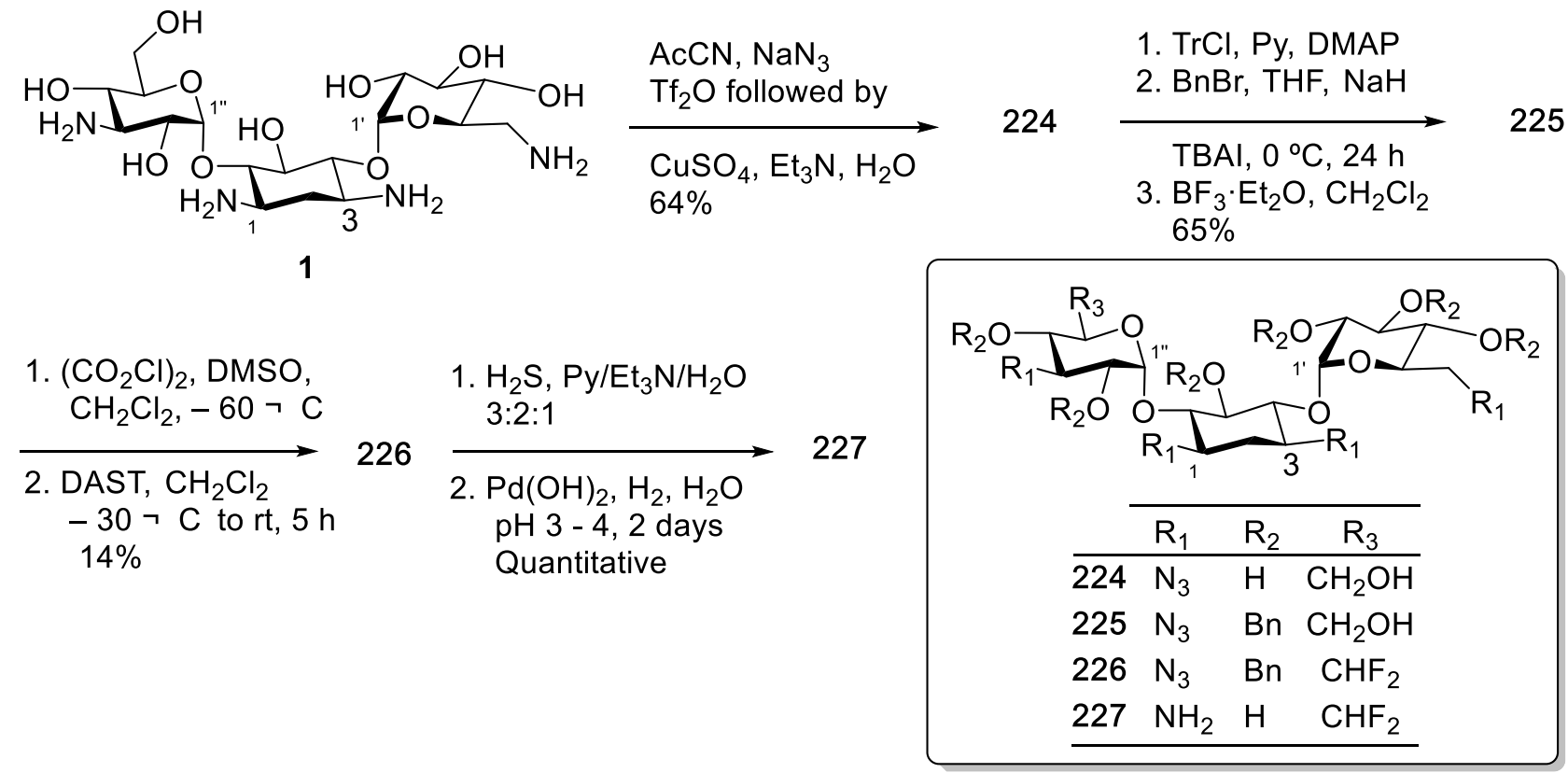

Scheme 36. Synthesis of 6"-deoxy-6", 6"-difluorokanamycin A (227).

Compound $\mathbf{2 2 7}$ was two-fold more active against AG-sensitive bacteria but was practically inactive against the tested AG-resistant bacteria.

\section{Fluorinated 4,5-Disubstituted 2-Deoxystreptamine AGs}

Fluorinations of the 4,5-disustituted-2-deoxystreptamine family of AGs are rare. Examples of this family of AGs include paromomycin (7), neomycin (8), and lividomycin (228) (Figure 13).

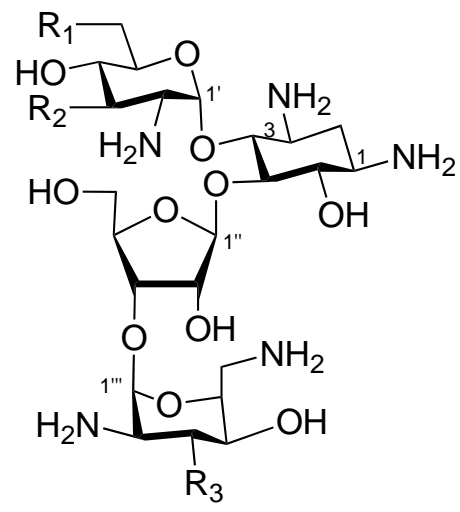

\begin{tabular}{clll}
\cline { 2 - 4 } & $\mathrm{R}_{1}$ & $\mathrm{R}_{2}$ & $\mathrm{R}_{3}$ \\
\hline $\mathbf{2 2 8}$ lividomycin & $\mathrm{OH}$ & $\mathrm{H}$ & -mannopyranoside \\
$\mathbf{7}$ paromomycin & $\mathrm{OH}$ & $\mathrm{OH}$ & $\mathrm{H}$ \\
$\mathbf{8}$ neomycin $\mathrm{B}$ & $\mathrm{NH}_{2}$ & $\mathrm{OH}$ & $\mathrm{H}$ \\
\hline
\end{tabular}

Figure 13. The neomycin family of AGs.

\subsection{Synthesis of 5"-deoxy-5"-fluorolividomycin B (234) 55 $^{25}$}

The selective tritylation of the $\mathrm{C}-5^{\prime \prime} \mathrm{OH}$ of $\mathbf{2 3 0}$ with phenyl boronate and trityl chloride followed by peracetylation afforded 231 (Scheme 37). The removal of the C-5" trityl group under acidic conditions followed by reaction with DAST produced 232 ( $59 \%$ yield) as the major component and desired 5" -deoxy-5"fluoro derivative $\mathbf{2 3 3}$ in $\mathbf{2 7 \%}$ yield. Standard protecting group removal afforded 234. 


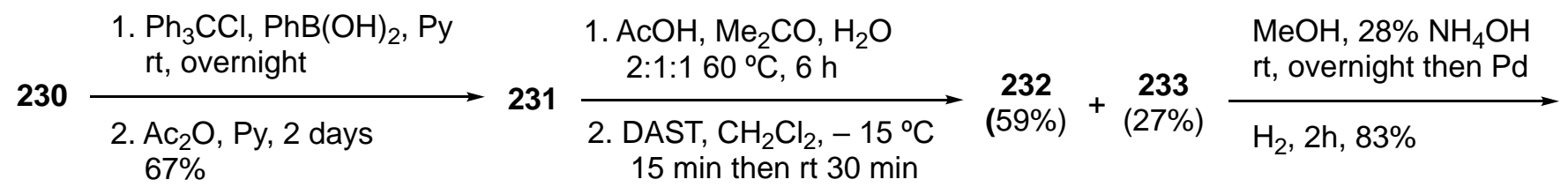

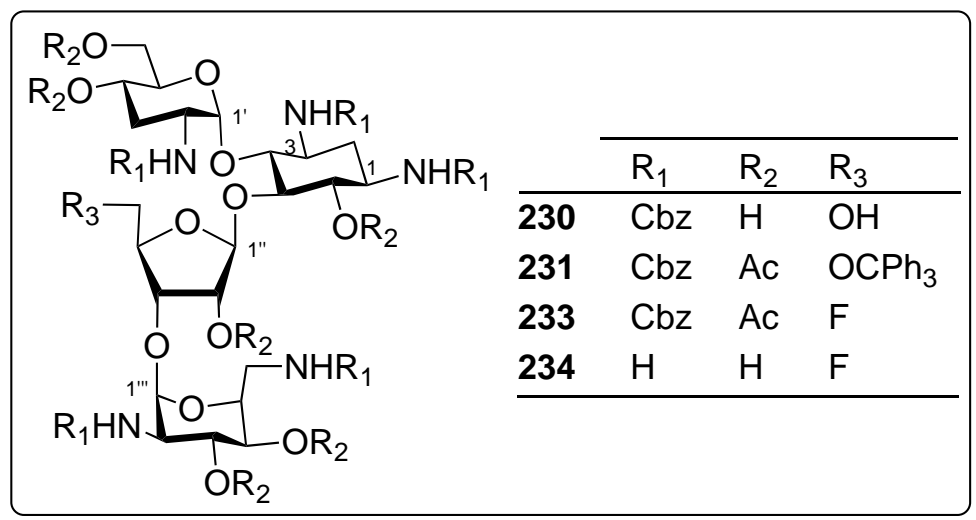

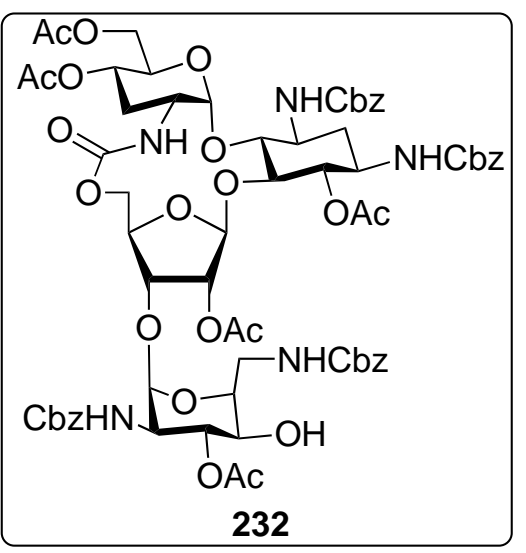

Scheme 37. Synthesis of 5"-deoxy-5"'-fluorolividomycin B (234).

Deoxyfluorination at C -5 " was detrimental to the antibacterial potency of lividomycin B. The antibacterial potency of compound (234) is comparable to the potency of $5^{\prime \prime}$-deoxylividomycin $\mathrm{B}$, indicating that $\mathrm{C}-5^{\prime \prime} \mathrm{OH}$ moiety is important for biological activity. ${ }^{95}$

\subsection{Fluorination of paromomycin (7) and neomycin (8)}

4.2.1. Synthesis of $6^{\prime}$-deoxy-6'-fluoroparomomycin (238). ${ }^{96}$ Hydrogenolysis of the benzylidene protecting group of compound 235 afforded 236 (Scheme 38). A selective deoxyfluorination with DAST in dichloromethane followed by cleavage of the protecting groups using standard procedures afforded 238.

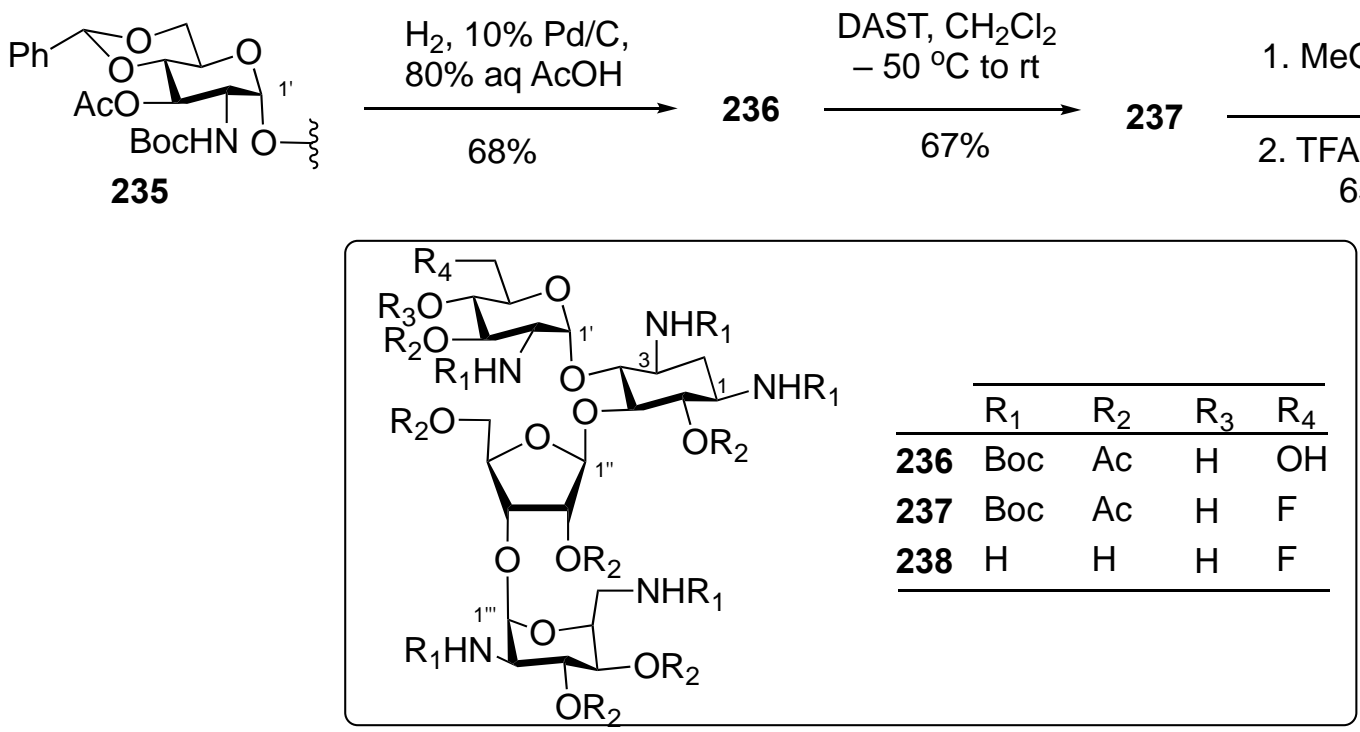

Scheme 38. Synthesis of 6'-deoxy-6'-fluoroparomomycin (238). 
Compared with paromomycin (7), 6'-deoxy-6'-fluoro analogue (238) showed a lower potency against both wild-type $1408 \mathrm{~A}$ and $1408 \mathrm{G}$ mutant ribosomes ${ }^{96}$ and against methicillin-resistant strains of $S$. aureus, E. coli and $P$. aeruginosa. ${ }^{97}$ Compound $\mathbf{2 3 8}$ was also screened in cell-free assays for its ability to inhibit translation by bacterial wild-type and recombinant hybrid ribosomes carrying complete A site cassettes of the human mitochondrial (Mit13), mitochondrial A1555G, and cytoplasmic ribosomes (Cyt14), and it showed no significant potency. ${ }^{97}$

4.2.2. Synthesis of 4'-deoxy-4'-epi-4'-fluoro- (241), 4'-deoxy-4'-fluoro- (243), and 1-N-HABA-4'-deoxy-4'-e pi4'-fluoroneomycin B (246). ${ }^{25}$ The synthesis started with a suitably protected neomycin B analogue (239, Scheme 39). Treatment of $\mathbf{2 3 9}$ with DAST gave a complex mixture of products (not shown). Compound 239 was then reacted with triflic anhydride in dichloromethane and then treated with TBAF in THF to give 240. Cleavage of the protecting groups under standard conditions afforded $\mathbf{2 4 1}$. To synthesize $\mathbf{2 4 3}$, the alcohol at $4^{\prime}-C$ was epimerized by sequential oxidation with Dess-Martin periodinane in dichloromethane followed by stereoselective reduction using L-Selectride ${ }^{\circledR}$, affording 4-epi derivative 242 . The reaction of 242 with triflic anhydride followed by treatment with fluoride using TBAF in THF and deprotection gave compound (243).
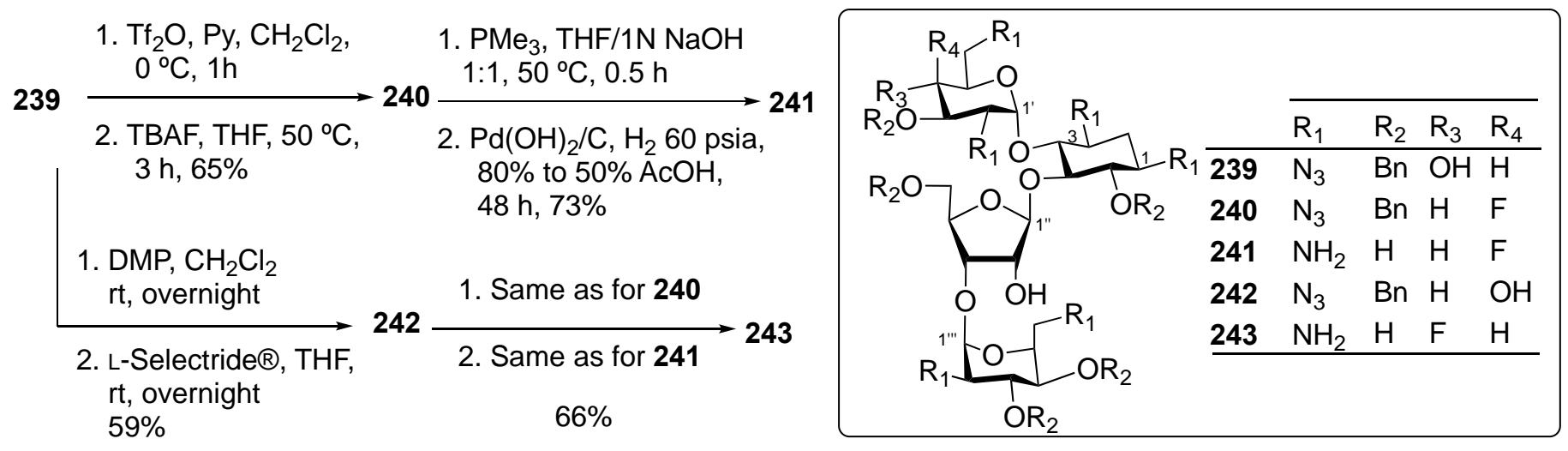

Scheme 39. Synthesis of 4'-deoxy-4'-epi-4'-fluoroneomycin B (241), 4'-deoxy-4'-fluoroneomycin B (243).

The selective reduction of the C-1 and C-3 azides of $\mathbf{2 4 0}$ under Staudinger conditions ${ }^{98-99}$ followed by acylation with $\mathrm{N}$-Cbz-HABA-OSu afforded compounds 244 and 245 (Scheme 40). The reaction gave a 1:0.8 ratio of 244:245. The regioselectivity of the Staudinger reduction correlates with the electron density at the corresponding $\alpha$-nitrogen atoms as determined by natural abundance ${ }^{15} \mathrm{~N} \mathrm{NMR}$; the azide bearing the most electron-deficient $\alpha$-nitrogen was preferentially reduced. ${ }^{100}$ Compound 244 was deprotected under standard conditions, affording 246.

Isomeric 4'-fluoro analogues 241 and 243 showed potencies similar to those of their parent compound, neomycin B (8), when tested against susceptible isolates of S. aureus, $K$. pneumoniae and E. coli strains. Both compounds were also active towards bacterial isolates expressing the ANT(4')-I and ANT(4')-II enzymes. Remarkably, 4'-deoxy-4'fluoro-4'-epi derivative $\mathbf{2 4 3}$ was also active towards two $P$. aeruginosa strains expressing chromosomal APH(3')-Ilb enzymes. Similarly, these properties were also observed in its analogue, 1-N-HABA-4'-deoxy-4'-fluoro-4'-epi-neomycin (246), which is active against $P$. aeruginosa expressing the $\mathrm{APH}\left(3^{\prime}\right)$-IIb enzyme. ${ }^{25}$ Similar behaviour was observed in the kanamycin series in which $4^{\prime}$-deoxy-4', $4^{\prime}$ difluorokanamycin $A(223)$ and $4^{\prime}$-deoxy-4',4'-difluoroneamine (40) were found to be impaired substrates for the $\mathrm{APH}\left(3^{\prime}\right)$ lla enzyme. ${ }^{47}$ On the other hand, 4'-deoxy-4'-fluorokanamycin $A$ (176) and 4'-deoxy-4'fluorokanamycin $B(\mathbf{1 8 2})$ are susceptible to inactivation by $\mathrm{APH}\left(3^{\prime}\right)$ enzyme. ${ }^{87}$ These results, together with 
those obtained for compounds 241,243 and 246, seem to indicate that an axial fluorine atom at C-4' is required to impair binding with the $\mathrm{APH}\left(3^{\prime}\right)$ lla enzyme.

A co-crystal of $\mathbf{2 4 6}$ with A-site rRNA showed that the compound is accommodated inside the A-site and the fluorine atom at C-4' stacks with a guanine residue inside the receptor. ${ }^{25}$

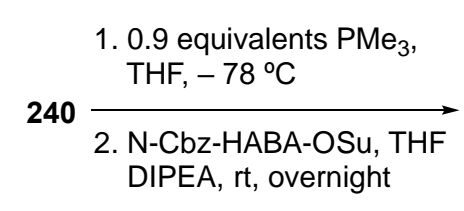

0.9 equivalents $\mathrm{PMe}_{3}$

N-Cbz-HABA-OSu, THF

DIPEA, rt, overnight

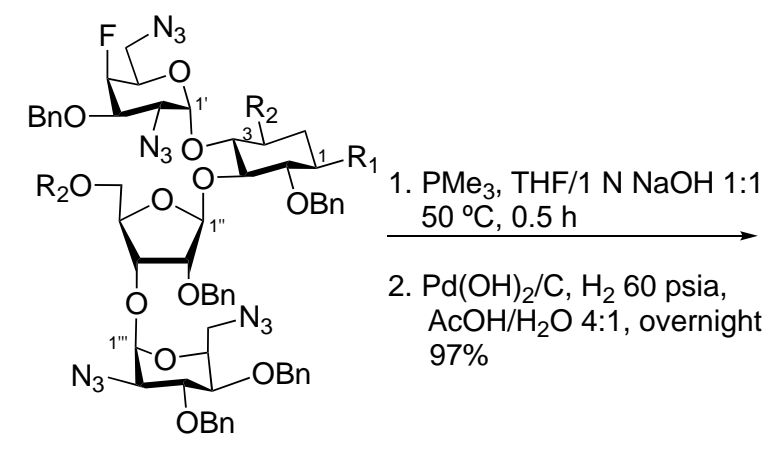

$244 \mathrm{R}_{1}=\mathrm{NH}-\mathrm{HABACbz}, \mathrm{R}_{2}=\mathrm{N}_{3}(21 \%)$

$245 R_{1}=N_{3}, R_{2}=N H-H A B A C b z(10 \%)$

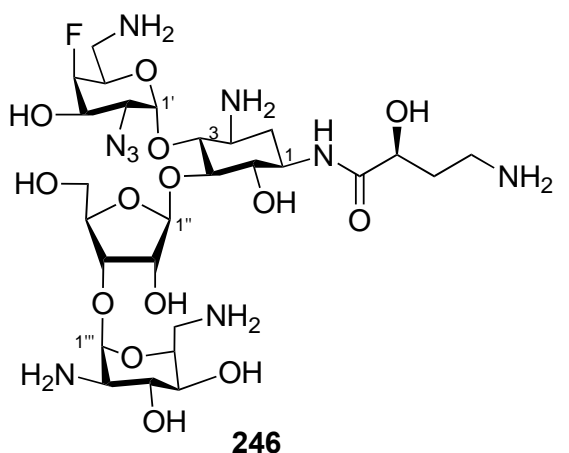

Scheme 40. Synthesis of 1-N-HABA-4'-deoxy-4'-epi-4'-fluoroneomycin B (246).

\section{AGs with Fluorinated $\omega$-Amino Acid Lateral Chains at Position 1}

\subsection{Synthesis of amikacin analogues with a $\omega$-amino- $\alpha$-fluoroalkanoyl side chain ${ }^{23}$}

Kanamycin A (1) was $1-N$-acylated with a series of $\omega$-amino- $\alpha$-fluoro amino acids to determine their impact on the antibacterial activity (Figure 14). The fluorinated amino acids required for the side chains were synthesized by deoxyfluorination of suitably protected $\alpha$-hydroxy or $\alpha$-oxo esters with DAST. The $1-N$-acylation was performed following the zinc-chelate ethyl trifluoroacetate method (see Scheme 19). ${ }^{71}$

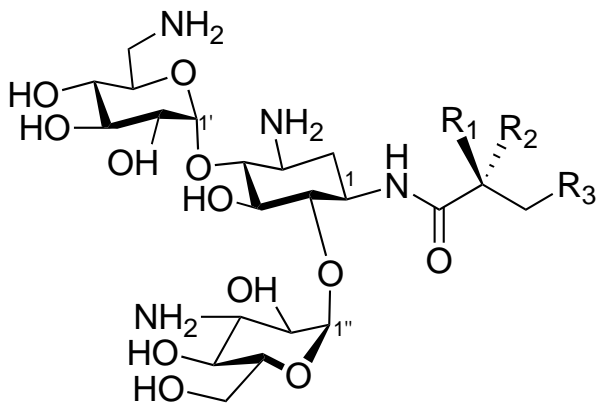

\begin{tabular}{lllcl}
\cline { 2 - 5 } & $\mathrm{R}_{1}$ & $\mathrm{R}_{2}$ & Configuration & \multicolumn{1}{c}{$\mathrm{R}_{3}$} \\
\hline $\mathbf{2 4 7}$ & $\mathrm{F}$ & $\mathrm{H}$ & $(\mathrm{S})$ & $\mathrm{NH}_{2}$ \\
$\mathbf{2 4 8}$ & $\mathrm{F}$ & $\mathrm{H}$ & $(\mathrm{S})$ & $\mathrm{CH}_{2} \mathrm{NH}_{2}$ \\
$\mathbf{2 4 9}$ & $\mathrm{H}$ & $\mathrm{F}$ & $(R)$ & $\mathrm{CH}_{2} \mathrm{NH}_{2}$ \\
$\mathbf{2 5 0}$ & $\mathrm{F}$ & $\mathrm{F}$ & & $\mathrm{CH}_{2} \mathrm{NH}_{2}$ \\
$\mathbf{2 5 1}$ & $\mathrm{F}$ & $\mathrm{H}$ & $(\mathrm{S})$ & $\mathrm{CH}_{2} \mathrm{CH}_{2} \mathrm{NH}_{2}$ \\
\hline
\end{tabular}

Figure 14. Kanamycin $\omega$-amino- $\alpha$-fluoro analogues: 1- $N$-[(S)-3-amino-2-fluoropropanoyl]kanamycin A (247),

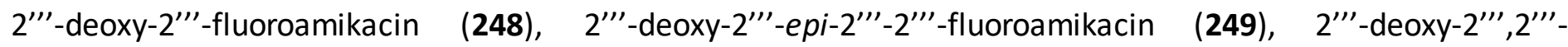
difluoroamikacin (250) and 1-N-[(S)-5-amino-2-fluorovaleryl]kanamycin A (251).

The most promising chain in terms of biological activity, the (S)-4-amino-2-fluorobutyric acid moiety, was also introduced to other AGs, to get acylated derivatives of kanamycin B (252), tobramycin (253), dibekacin (254), and gentamycin B (not shown) (Figure 15).

Of all the $\omega$-amino-2-fluoro amino acids coupled with kanamycin A, 2'"-deoxy-2"'-fluoroamikacin (248) showed the best biological activity profile (similar to that of kanamycin). The other analogues showed 
dramatically lower antibacterial potencies. It was also noted that the antibacterial potency of the fluorinated analogues parallel the potencies of the corresponding 2-hydroxybutyryl analogues, leading to the conclusion that the 2-fluoro group may play the same role as the 2-hydroxy group when present in the side chain. The acute toxicity of 248 ( $L D_{50} 280 \mathrm{mg} / \mathrm{kg}$, iv mice) was found to be the same as that reported for amikacin (4, LD50 $280 \mathrm{mg} / \mathrm{kg}) \cdot{ }^{23}$

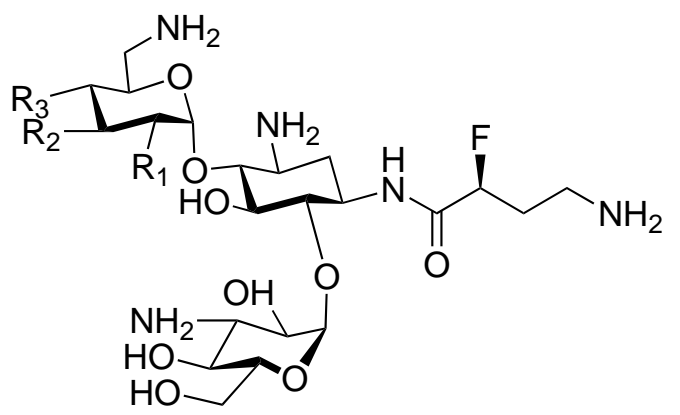

\begin{tabular}{llll} 
& $\mathrm{R}_{1}$ & $\mathrm{R}_{2}$ & $\mathrm{R}_{3}$ \\
\hline $\mathbf{2 4 8}$ & $\mathrm{OH}$ & $\mathrm{OH}$ & $\mathrm{OH}$ \\
$\mathbf{2 5 2}$ & $\mathrm{NH}_{2}$ & $\mathrm{OH}$ & $\mathrm{OH}$ \\
$\mathbf{2 5 3}$ & $\mathrm{NH}_{2}$ & $\mathrm{H}$ & $\mathrm{OH}$ \\
$\mathbf{2 5 4}$ & $\mathrm{NH}_{2}$ & $\mathrm{H}$ & $\mathrm{H}$ \\
\hline
\end{tabular}

Figure 15. 1- $N-[(S)-4-A m i n o-2-f l u o r o b u t a n o y l]$ series: 2"' -deoxy-2'"'-fluoroamikacin (248), 1-N-[(S)-4-amino-2fluorobutanoyl]kanamycin B (252), 1-N-[(S)-4-amino-2-fluorobutanoyl]tobramycin (253), 1-N-[(S)-4-amino-2fluorobutanoyl]dibekacin (254).

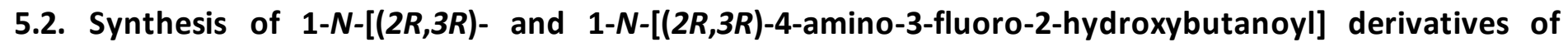 kanamycin $\mathrm{A}^{101}$}

The required (2R,3R)-4-amino-3-fluoro-2-hydroxybutanoic acids were synthesized from the appropriate carbohydrate precursors ${ }^{101}$ and were coupled to the $\mathrm{N}-1$ group of suitably protected kanamycin $A$ and kanamycin B analogues to give compounds 255 - 258 (Figure 16).

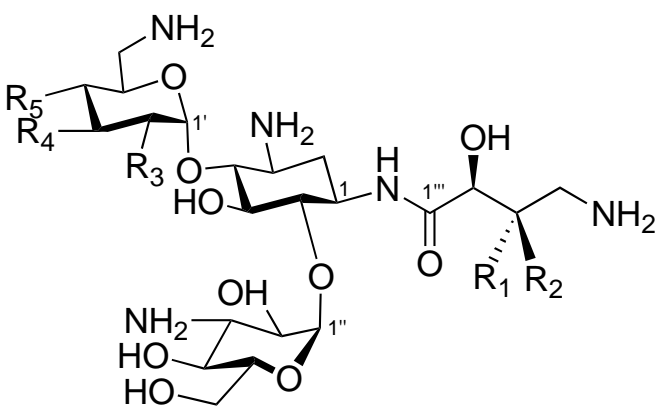

\begin{tabular}{cccclll}
\cline { 2 - 6 } & $\mathrm{R}_{1}$ & $\mathrm{R}_{2}$ & Configuration & $\mathrm{R}_{3}$ & $\mathrm{R}_{4}$ & $\mathrm{R}_{5}$ \\
\hline $\mathbf{2 5 5}$ & $\mathrm{F}$ & $\mathrm{H}$ & $(R)$ & $\mathrm{OH}$ & $\mathrm{OH}$ & $\mathrm{OH}$ \\
$\mathbf{2 5 6}$ & $\mathrm{F}$ & $\mathrm{H}$ & $(R)$ & $\mathrm{NH}_{2}$ & $\mathrm{H}$ & $\mathrm{OH}$ \\
$\mathbf{2 5 7}$ & $\mathrm{F}$ & $\mathrm{H}$ & $(R)$ & $\mathrm{NH}_{2}$ & $\mathrm{H}$ & $\mathrm{H}$ \\
$\mathbf{2 5 8}$ & $\mathrm{H}$ & $\mathrm{F}$ & $(S)$ & $\mathrm{NH}_{2}$ & $\mathrm{H}$ & $\mathrm{H}$ \\
\hline
\end{tabular}

Figure 16. 1- $N$-[(2R,3R)-4-amino-3-fluoro-2-hydroxybutanoyl]kanamycin A (255), 1- $N$-[(2R,3R)-4-amino-3fluoro-2-hydroxybutanoyl]tobramycin (256), 1-N-[(2R,3R)-4-amino-3-fluoro-2-hydroxybutanoyl]dibekacin (257) and 1-N-[(2R,3S)-4-amino-3-fluoro-2-hydroxybutanoyl]dibekacin (258).

The antibacterial tests showed that the $(2 R, 3 R)$-analogues (255-258) were slightly more potent as antibacterial agents compared with amikacin (4), arbekacin (93) and 1-N-HABA tobramycin, while the (2R,3S) diastereomer (258) was less potent. Additionally, compounds 255-258 were slightly more potent against bacteria producing $A A C(3)$ enzyme and remarkably also against $A A C\left(2^{\prime}\right)$ and $A A C\left(6^{\prime}\right)$, which are located far from the fluorine atom.

The $\mathrm{p} K_{\mathrm{a}}$ values of the C-4"' amino groups of amikacin (4) and arbekacin (93) were measured by ${ }^{13} \mathrm{C}$ NMR spectroscopy and were approximately two units higher than the $p K_{a}$ values determined for compounds 255 
and 257 (10.2 vs 8.7). The acute toxicity values determined for 255 (LD $50250 \mathrm{mg} / \mathrm{kg}$ ) and 257 (LD50 $80 \mathrm{mg} / \mathrm{kg})$, on the other hand, were quite similar to those of the reference compounds (4, LD $50220 \mathrm{mg} / \mathrm{kg}$ and $93, \mathrm{LD}_{50} 80$ $\mathrm{mg} / \mathrm{kg}$ ), indicating that the toxicity was not influenced by the presence of the fluorine atom. It was postulated that the toxicity may be largely influenced by the ratio of $\mathrm{C}-4$ "' $\mathrm{NH}_{2}$ present as the free base or as the ammonium salt and not simply by the basicity and that a $p K_{a}$ value of $\sim 8$ is required for a meaningful reduction in the toxicity by analogy with compounds 201-205 (refer to Section 3.3.15.). ${ }^{101}$

\subsection{Synthesis of $1-\mathrm{N}-\left[\left(2^{\prime \prime \prime} S, 4^{\prime \prime \prime} S\right)\right.$ and $\left(2^{\prime \prime} S, 4^{\prime \prime \prime} R\right)$-5-amino-4-fluoro-2-hydroxypentanoyl] derivatives of dibekacin $^{102}$}

The homologous $(2 S, 4 S)$ and $(2 R, 4 R)$-5-amino-4-fluoro-2-hydroxypentanoic acids (prepared from malic acid) were coupled to 1-N of the aminoglycoside dibekacin (3) to obtain compounds 259 and 260 (Figure 17). Compounds 259 and $\mathbf{2 6 0}$ had the same potency as arbekacin (93). The acute toxicities in mice determined for $259(\sim 130 \mathrm{mg} / \mathrm{kg})$ and $260(\sim 125 \mathrm{mg} / \mathrm{kg})$ were approximately 1.7-fold weaker than that of arbekacin (93) ( 75 $\mathrm{mg} / \mathrm{kg}$ ). This decrease in toxicity was attributed to the length of the chain attached to the AG. To further test this hypothesis, compounds 93, 261, 262 and 263 were synthesized (Figure 17), and a direct relationship between the chain length and the toxicity was found. The acute toxicities of these compounds were in the order 261>93>262>263. The $L_{50}$ for $\mathbf{2 6 2}(\sim 120 \mathrm{mg} / \mathrm{kg}$ ), which possesses a 5-carbon chain, is similar to that of $259(\sim 130 \mathrm{mg} / \mathrm{kg})$, indicating that the chain length and not the presence of the fluorine atom at C-4"' controls the toxicity. With respect to antibacterial activity, 263 was less potent than arbekacin (93), while 261 and 260 are almost equipotent to the aforementioned $A G,{ }^{102}$ indicating that a butanoic derivative presents the best balance between high antibacterial potency and low acute toxicity.
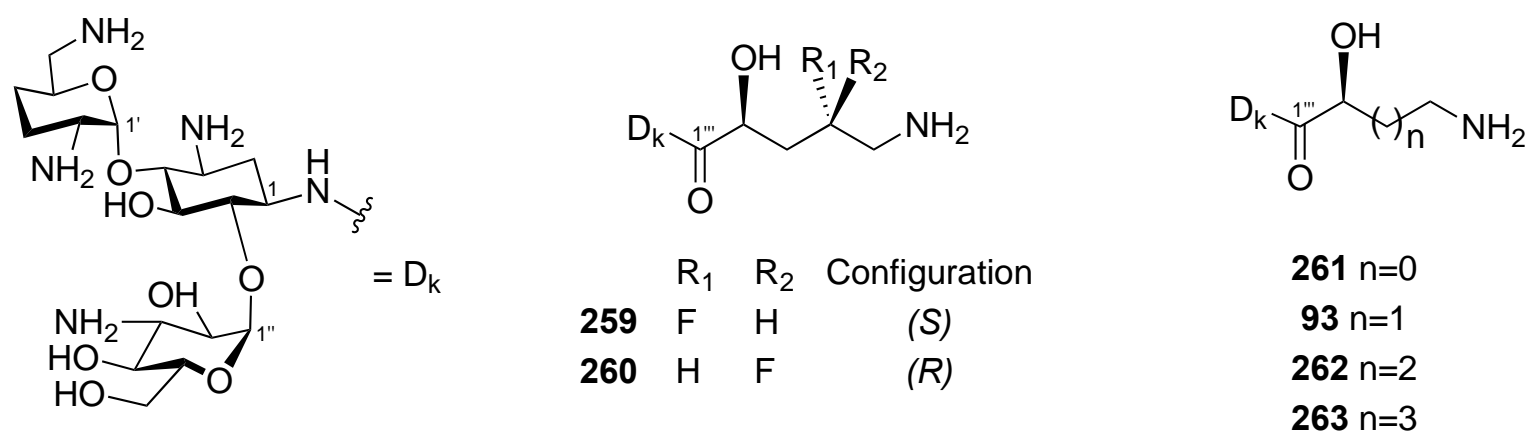

Figure 17. 1-N-[(2'"'S,4"'SS)-5-amino-4-fluoro-2-hydroxypentanoyl]dibekacin (259) and 1- $N$-[(2'"'S,4'” $R)-5$ amino-4-fluoro-2-hydroxypentanoyl] (260) and homologous $\omega$-amino- $\alpha$-hydroxyalkanoyl analogues.

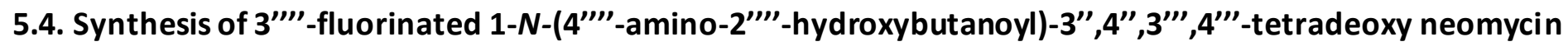 B analogues 28}

Suitably protected fluorinated acids (exemplified by 268 and 270, Scheme 41) were synthesized and coupled to a tetradeoxy neomycin precursor $(\mathbf{2 7 1})^{103}$ to afford a series AGs that were tested for biological activity. Divinyl-carbinol 264 was treated with (-)-diisopropyl-tartrate (DIPT), $\mathrm{Ti}(\mathrm{iOPr})_{4}$ and $\mathrm{PhCMe} 2 \mathrm{OOH}$ and then benzylated to afford optically pure epoxide 265. Treatment of 265 with sodium azide gave 266. Further treatment of $\mathbf{2 6 6}$ with DAST gave a deoxyfluorinated analogue (267). Ozonolysis followed by a Pinnick oxidation afforded 268. The oxidation of $\mathbf{2 6 6}$ under Swern conditions followed by deoxyfluorination with DAST gave difluorinated compound 269, which was then converted to $\mathbf{2 7 0}$. Compounds $\mathbf{2 6 8}$ and $\mathbf{2 7 0}$ were coupled 
to $\mathbf{2 7 1}$, and subsequent reduction of the azides and olefins by catalytic hydrogenation afforded $\mathbf{2 7 3}$ and $\mathbf{2 7 4}$. A similar procedure was used to prepare $\mathbf{2 7 6}$ and 277. Diols $\mathbf{2 7 5}$ and $\mathbf{2 7 8}$ were also synthesized.

Compounds 272-275, which have the natural L-HABA configuration at C-2'"', and unnatural D-HABA analogues (276-278) were tested against a broad panel of susceptible and resistant strains of ESKAPE pathogens to examine the effects of $\mathrm{Y}-N \mathrm{p} K \mathrm{a}$ modulation on their antibacterial potencies. The L-HABA analogues (273-275) were as potent as the parent compound (272) against wild-type strains and retained the activity of the parent compound through a panel of AG-resistant strains. The D-HABA analogues (276-278) were generally less potent than the analogues in the L-series but much more potent than the reference compounds. ${ }^{28}$ A strong correlation between the $\mathrm{p}-N \mathrm{p} K_{\mathrm{a}}$ and the antibiotic potency was observed in the $\mathrm{D}$ HABA series.

Compound $\mathbf{2 7 3}$ was co-crystallized with the A-site decoding rRNA region. The data showed that the fluorinated acyl groups adopt the same conformation inside the A-site as the HABA chain as was observed for amikacin (4), and the $\left(3^{\prime \prime \prime \prime \prime} R\right)$ fluorine atom forms hydrogen bonds to two cytosine residues inside the A-site rRNA.

Dose-response caspase-3/7 activation on the human kidney cell line HK2 triggered by compounds 272-278 revealed that apoptosis induction depends on the $\mathrm{p} K_{\mathrm{a}}$ of the derivative. Compounds with higher $\mathrm{\gamma}-\mathrm{N} \mathrm{p} K_{\mathrm{a}}$ values elicited apoptosis with an average $\mathrm{EC}_{50}=26 \mathrm{mg} / \mathrm{mL}$, which is equal to that of the parent compound (272) (EC50 $=27 \mathrm{mg} / \mathrm{mL}$ ) within assay error. Difluorinated analogues 274 and 277 were less toxic, requiring a 2-fold higher concentration to elicit apoptosis ( $E_{50}=47$ and $58 \mathrm{mg} / \mathrm{mL}$, respectively).

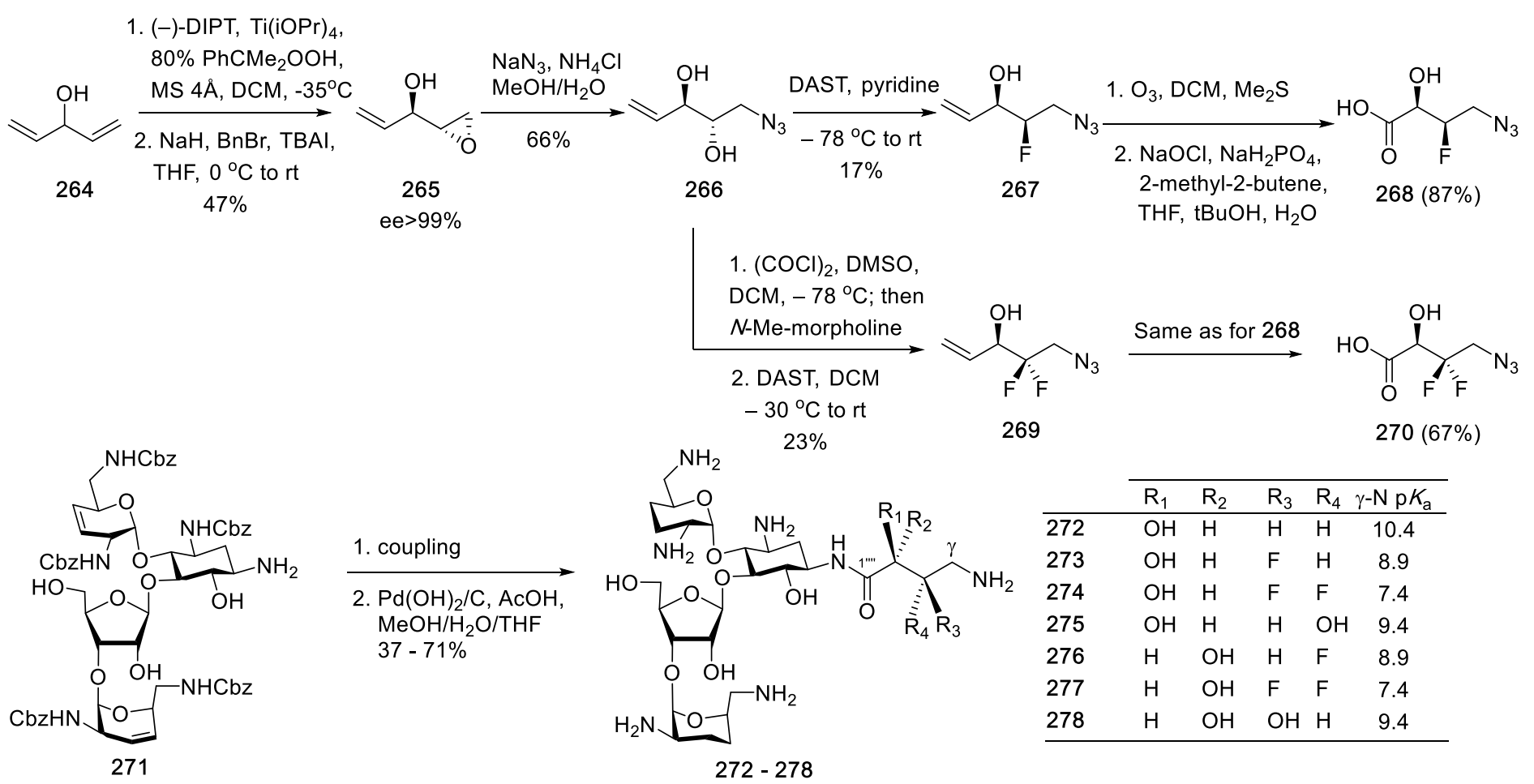

Scheme 41. $3^{\prime \prime}, 4^{\prime \prime}, 3^{\prime \prime \prime}, 4^{\prime \prime \prime}-$ Tetradeoxy neomycin B analogues. 


\section{Conclusions}

The present review provides an overview of the methods used for the incorporation of fluorine into AGs. It can be seen that the major synthetic challenge continues to be the somewhat cumbersome protecting-group strategies employed herein. The development of milder and more selective fluorinating agents, e.g., PhenoFluor $^{\circledast}$, which allows the fluorination of unprotected complex molecules, will undoubtedly simplify this process in the future. The biological importance of the fluorination of AGs parallels the importance of the introduction of fluorine into biologically active molecules and remains an active field of research given the importance of AGs as antibiotics.

Additionally, current progress in the biosynthetic pathways of aminoglycosides ${ }^{104-105}$ could furnish tools to access fluorinated aminoglycosides by designed mutasynthesis.

\section{References}

1. Davis, J. In Aminoglycoside antibiotics: from chemical biology to drug discovery, Ayra, D. P., Ed. WileyInterscience: Hoboken: N.J., 2007; pp 1-13.

2. Wimberly, B. T.; Brodersen, D. E.; Clemons Jr, W. M.; Morgan-Warren, R. J.; Carter, A. P.; Vonrhein, C.; Hartsch, T.; Ramakrishnan, V. Nature 2000, 407, 327.

https://doi.org/10.1038/35030006

3. Ogle, J. M.; Ramakrishnan, V. Annu. Rev. Biochem 2005, 74 (1), 129-177.

https://doi.org/10.1146/annurev.biochem.74.061903.155440

4. Masquida, B.; François, B.; Westhof, E.; Aboul-ela, F.; Murray, J. B.; Vicens, Q.; Russell, R. J. M. Nucleic Acids Res. 2005, 33 (17), 5677-5690.

https://doi.org/10.1093/nar/gki862

5. Wilson, D. N. Crit. Rev. Biochem. Mol. Biol. 2009, 44 (6), 393-433.

6. Mingeot-Leclercq, M. P.; Glupczynski, Y.; Tulkens, P. M. Antimicrob. Agents Chemother. 1999, 43 (4), 727737.

https://doi.org/10.1128/AAC.43.4.727

7. Davidson, R. N.; den Boer, M.; Ritmeijer, K. Trans. R. Soc. Trop. Med. Hyg. 2009, 103 (7), 653-660. https://doi.org/10.1016/j.trstmh.2008.09.008

8. Kikuchi, T.; Koga, M.; Shimizu, S.; Miura, T.; Maruyama, H.; Kimura, M. Parasitol. Int. 2013, 62 (6), 497501.

https://doi.org/10.1016/j.parint.2013.07.004

9. Waksman, S. A.; Lechevalier, H. A.; Harris, D. A. J. Clin. Invest. 1949, 28 (5 Pt 1), 934-939. https://doi.org/10.1172/JCI102182

10. Shaw, K. J.; Rather, P. N.; Hare, R. S.; Miller, G. H. Microbiol. Rev. 1993, 57 (1), 138-163.

11. Azucena, E.; Mobashery, S. Drug Resist. Updat. 2001, 4 (2), 106-117.

https://doi.org/10.1054/drup.2001.0197

12. Paulsen, I. T.; Brown, M. H.; Skurray, R. A. Microbiol. Rev. 1996, 60 (4), 575-608.

13. Umezawa, H.; Umezawa, S.; Tsuchiya, T.; Okazaki, Y. J. Antibiotics 1971, 24 (7), 485-487. https://doi.org/10.7164/antibiotics.24.485

14. Takahashi, Y.; Tsuchiya, T.; Umezawa, S.; Umezawa, H. Carbohydr. Res. 1991, 210, 221-232. https://doi.org/10.1016/0008-6215(91)80124-6 
15. Mingeot-Leclercq, M.-P.; Tulkens, P. M. Antimicrob. Agents Chemother. 1999, 43 (5), 1003. https://doi.org/10.1128/AAC.43.5.1003

16. Hutchin, T.; Cortopassi, G. Antimicrob. Agents Chemother. 1994, 38 (11), 2517-2520. https://doi.org/10.1128/AAC.38.11.2517

17. Erol, S. Curr. Pharm. Des. 2007, 13 (1), 119-126. https://doi.org/10.2174/138161207779313731

18. Perletti, G.; Vral, A.; Patrosso, M.; Marras, E.; Ceriani, I.; Willems, P.; Fasano, M.; Magri, V. Mol. Med. Rep. 2008, 1 (1).

19. Destache, C. J. J. Pharm. Pract. 2014, $27(6)$, 562-566.

https://doi.org/10.1177/0897190014546102

20. Chen, L.; Hainrichson, M.; Bourdetsky, D.; Mor, A.; Yaron, S.; Baasov, T. Biorg. Med. Chem. 2008, 16 (19), 8940-8951.

https://doi.org/10.1016/j.bmc.2008.08.053

21. Müller, K.; Faeh, C.; Diederich, F. Science 2007, 317 (5846), 1881.

https://doi.org/10.1126/science.1131943

22. Purser, S.; Moore, P. R.; Swallow, S.; Gouverneur, V. Chem. Soc. Rev. 2008, 37 (2), 320-330. https://doi.org/10.1039/B610213C

23. Hoshi, H.; Aburaki, S.; limura, S.; Yamasaki, T.; Naito, T.; Kawaguchi, H. J. Antibiot. 1990, 43 (7), 858-872. https://doi.org/10.7164/antibiotics.43.858

24. Tsuchiya, T.; Takahashi, Y.; Kobayashi, Y.; Umezawa, S.; Umezawa, H. J. Antibiot. 1985, 38 (9), $1287-1290$. https://doi.org/10.7164/antibiotics.38.1287

25. Hanessian, S.; Saavedra, O. M.; Vilchis-Reyes, M. A.; Maianti, J. P.; Kanazawa, H.; Dozzo, P.; Matias, R. D.; Serio, A.; Kondo, J. Chem. Sci. 2014, 5 (12), 4621-4632.

https://doi.org/10.1039/C4SC01626B

26. Shitara, T.; Kobayashi, Y.; Tsuchiya, T.; Umezawa, S. Carbohydr. Res. 1992, 232 (2), 273-290. https://doi.org/10.1016/0008-6215(92)80060-E

27. Tsuchiya, T.; Shitara, T.; Umezawa, S.; Takeuchi, T.; Hamada, M.; Tomono, N.; Umemura, E. Carbohydr. Res. 1993, 240, 307-312. https://doi.org/10.1016/0008-6215(93)84194-B

28. Maianti, J. P.; Kanazawa, H.; Dozzo, P.; Matias, R. D.; Feeney, L. A.; Armstrong, E. S.; Hildebrandt, D. J.; Kane, T. R.; Gliedt, M. J.; Goldblum, A. A.; Linsell, M. S.; Aggen, J. B.; Kondo, J.; Hanessian, S. ACS Chem. Biol. 2014, 9 (9), 2067-2073. https://doi.org/10.1021/cb5003416

29. Dax, K.; Albert, M.; Ortner, J.; Paul, B. J. Carbohydr. Res. 2000, 327 (1-2), 47-86. https://doi.org/10.1016/S0008-6215(00)00022-7

30. Ferret, H.; Déchamps, I.; Gomez-Pardo, D.; Van Hijfte, L.; Cossy, J. Arkivoc 2010, 2010 (8), 126-158.

31. Vass, G.; Rolland, A.; Cleophax, J.; Mercier, D.; Quiclet, B.; Gero, S. D. J. Antibiot. 1979, 32 (6), 670-672. https://doi.org/10.7164/antibiotics.32.670

32. Daum, S. J.; Lemke, J. R. Annu. Rev. Microbiol. 1979, 33 (1), 241-265. https://doi.org/10.1146/annurev.mi.33.100179.001325

33. Kanazawa, H.; Saavedra, O. M.; Maianti, J. P.; Young, S. A.; Izquierdo, L.; Smith, T. K.; Hanessian, S.; Kondo, J. Chemmedchem 2018, 13 (15), 1541-1548.

https://doi.org/10.1002/cmdc.201800166

34. Takahashi, Y.; Umemura, E.; Ida, T.; Igarashi, M. U.S. Patent 0,214,470 A1, 2018. 
35. Zhang, W.; Li, Z.; Fan, Y.; Meng, X. Chinese Patent 10, 1481, 397 (B), 2018.

https://doi.org/10.2174/2212797610666171114150458

36. Umemura, E. Meiji Seika Kenku Nenpo 2008, 46, 17-32.

37. Tsuchiya, T.; Torii, T.; Umezawa, S.; Umezawa, H. J. Antibiot. 1982, 35 (9), 1245-1247. https://doi.org/10.7164/antibiotics.35.1245

38. Tsuchiya, T.; Torii, T.; Suzuki, Y.; Umezawa, S. Carbohydr. Res. 1983, 116 (2), 277-287. https://doi.org/10.1016/0008-6215(83)88117-8

39. Fauq, A. H.; Singh, R. P.; Meshri, D. T. Diethylaminosulfurtrifluoride. In Encyclopedia of Reagents for Organic Synthesis.

40. Hudlický, M., Fluorination with Diethylaminosulfur Trifluoride and Related Aminofluorosulfuranes. In Organic Reactions 2004.

41. Tsuchiya, T., Chemistry and Developments of Fluorinated Carbohydrates. In Adv. Carbohydr. Chem. Biochem., Tipson, R. S.; Horton, D. Eds. Academic Press: 1990; Vol. 48, pp 91-277.

https://doi.org/10.1016/S0065-2318(08)60032-3

42. Lombès, T.; Moumné, R.; Larue, V.; Prost, E.; Catala, M.; Lecourt, T.; Dardel, F.; Micouin, L.; Tisné, C. Angew. Chem. Int. Ed. 2012, 51 (38), 9530-9534.

https://doi.org/10.1002/anie.201204083

43. Hanessian, S.; Saavedra, O. M.; Vilchis-Reyes, M. A.; Llaguno-Rueda, A. M. MedChemComm 2014, 5 (8), 1166-1171.

https://doi.org/10.1039/C4MD00072B

44. Hanessian, S.; Plessas, N. R. Chem. Commun. 1968, (12), 706b-708.

https://doi.org/10.1039/c1968000706b

45. PDBID:5BWS; Kondo, J., Hanessian, S., Kanazawa, H. Crystal structure of the bacterial ribosomal decoding site in complex with 4'-deoxy-4'-fluoro neamine analog (axial 4'-F).

46. PDBID:5BXK; Kondo, J., Hanessian, S., Kanazawa, H. Crystal structure of the bacterial ribosomal decoding site in complex with 4'-deoxy-4'-fluoro neamine analog (equatorial 4'-F).

47. Kim, C.; Haddad, J.; Vakulenko, S. B.; Meroueh, S. O.; Wu, Y.; Yan, H.; Mobashery, S. Biochemistry (Mosc.) 2004, 43 (9), 2373-2383.

https://doi.org/10.1021/bi036095+

48. Messina, P. A.; Mange, K. C.; Middleton, W. J. J. Fluorine Chem. 1989, 42 (1), 137-143. https://doi.org/10.1016/S0022-1139(00)83974-3

49. Adamson, J.; Foster, A. B.; Westwood, J. H. Carbohydr. Res. 1971, 18 (2), 345-347. https://doi.org/10.1016/S0008-6215(00)80363-8

50. Adamson, J.; Foster, A. B.; Hall, L. D.; Johnson, R. N.; Heese, R. H. Carbohydr. Res. 1970, 15 (3), $351-359$.

51. Livermore, D. M.; Mushtaq, S.; Warner, M.; Zhang, J.-C.; Maharjan, S.; Doumith, M.; Woodford, N. J. Antimicrob. Chemother. 2010, 66 (1), 48-53.

https://doi.org/10.1093/jac/dkq408

52. Boettger, E.; Vasella, A. U.S. Patent 2013/016,539,7 A1, 2013.

53. Daniels, P. J. L.; Rane, D. U.S. Patent 4,284,764, 1981.

54. Daniels, P. J. L.; Rane, D. F.; McCombie, S. W.; Testa, R. T.; Wright, J. J.; Nagabhushan, T. L., Chemical and Biological Modification of Antibiotics of the Gentamicin Group. In Aminocyclitol Antibiotics, ACS Symp. Ser.: 1980; Vol. 125, pp 371-392. https://doi.org/10.1021/bk-1980-0125.ch020

55. Daniels, P. J. L.; Rane, D. F. S. African Patent 78 06, 385, 1978. 
https://doi.org/10.1016/0008-6215(93)87010-P

56. Umemura, E.; Tsuchiya, T.; Koyama, Y.; Umezawa, S. Carbohydr. Res. 1993, 238, 147-162.

https://doi.org/10.1039/C1SC00538C

57. Hanessian, S.; Maianti, J. P.; Ly, V. L.; Deschênes-Simard, B. Chem. Sci. 2012, 3 (1), 249-256. https://doi.org/10.1039/C1SC00538C

58. Sladojevich, F.; Arlow, S. I.; Tang, P.; Ritter, T. J. Am. Chem. Soc. 2013, 135 (7), 2470-2473. https://doi.org/10.1021/ja3125405

59. Daum, S. J.; Clarke, R. L. U.S. Patent 3,972,930, 1976.

60. Albert, R.; Dax, K.; Stutz, A. E.; Weidmann, H. J. Carbohydr. Chem. 1982, 1 (3), 289-299. https://doi.org/10.1080/07328308208085101

61. Dax, K.; Wolflehner, W.; Weidmann, H. Carbohydr. Res. 1978, 65 (1), 132-138. https://doi.org/10.1016/S0008-6215(00)84220-2

62. Agami, C.; Couty, F. Tetrahedron 2002, 58 (14), 2701-2724. https://doi.org/10.1016/S0040-4020(02)00131-X

63. Albert, R.; Dax, K.; Stütz, A. E. Tetrahedron Lett. 1983, 24 (17), 1763-1766. https://doi.org/10.1016/S0040-4039(00)81764-5

64. Takagi, Y.; Tsuchiya, T.; Umezawa, S. Nippon Kagaku Kaishi 1985, 1985 (10), 2001-2009. https://doi.org/10.1246/nikkashi.1985.2001

65. Albert, R.; Dax, K.; Stütz, A. E. J. Carbohydr. Chem. 1984, 3 (2), 267-278. https://doi.org/10.1080/07328308408058820

66. Lipshutz, B. H.; Harvey, D. F. Synth. Commun. 1982, 12 (4), 267-277. https://doi.org/10.1080/00397918209409233

67. Albert, R.; Dax, K.; Stütz, A. E. Carbohydr. Res. 1984, 132 (1), 162-167. https://doi.org/10.1016/0008-6215(84)85075-2

68. Lattrell, R.; Lohaus, G. Justus Liebigs Ann. Chem. 1974, 1974 (6), 901-920. https://doi.org/10.1002/jlac.197419740606

69. Albert, R.; Dax, K.; Link, R. W.; Stütz, A. E. Carbohydr. Res. 1983, 118, C5-C6. https://doi.org/10.1016/0008-6215(83)88062-8

70. Umemura, E.; Tsuchiya, T.; Umezawa, S. Bull. Chem. Soc. Jpn. 1990, 63 (12), 3583-3589. https://doi.org/10.1246/bcsj.63.3583

71. Tsuchiya, T.; Takagi, Y.; Umezawa, S. Tetrahedron Lett. 1979, 20 (51), 4951-4954. https://doi.org/10.1016/S0040-4039(01)86759-9

72. Umemura, E.; Tsuchiya, T.; Kobayashi, Y.; Tanaka, K. Carbohydr. Res. 1992, 224, 141-163. https://doi.org/10.1016/0008-6215(92)84101-W

73. Nagabhushan, T. L.; Cooper, A. B.; Turner, W. N.; Tsai, H.; McCombie, S.; Mallams, A. K.; Rane, D.; Wright, J. J.; Reichert, P. J. Am. Chem. Soc. 1978, 100 (16), 5253-5254.

https://doi.org/10.1021/ja00484a081

74. Hanessian, S.; Patil, G. Tetrahedron Lett. 1978, 19 (12), 1031-1034.

https://doi.org/10.1016/S0040-4039(01)85444-7

75. Hanessian, S.; Patil, G. Tetrahedron Lett. 1978, 19 (12), 1035-1038. https://doi.org/10.1016/S0040-4039(01)85445-9

76. Carney, R. E.; Hanessian, S. U.S. Patent 4,214,077A, 1980.

77. Jikihara, T.; Tsuchiya, T.; Umezawa, H.; Umezawa, S. Carbohydr. Res. 1981, 89 (1), 91-101. https://doi.org/10.1016/S0008-6215(00)85232-5 
78. Umezawa, H.; Umezawa, S.; Tsuchiya, O.; Umemura, E. Japan Patent 61,140,596, 1986.

79. Tsuchiya, T.; Takahashi, Y.; Endo, M.; Umezawa, S.; Umezawa, H. J. Carbohydr. Chem. 1985, 4 (4), 587611.

https://doi.org/10.1080/07328308508082678

80. Umezawa, H.; Umezawa, S.; Tsuchiya, T.; Takahashi, Y. U.S. Patent 4,661,474, 1987.

81. Jennings, H. J.; Jones, J. K. N. Can. J. Chem. 1965, 43 (8), 2372-2386.

https://doi.org/10.1139/v65-319

82. Hanessian, S. Carbohydr. Res. 1966, 2 (1), 86-88.

https://doi.org/10.1016/S0008-6215(00)81783-8

83. Failla, D. L.; Hullar, T. L.; Siskin, S. B. Chem. Commun. 1966, (20), 716-717. https://doi.org/10.1039/C19660000716

84. Kobayashi, Y.; Tsuchiya, T.; Ohgi, T.; Taneichi, N.; Koyama, Y. Carbohydr. Res. 1992, 230 (1), 89-105. https://doi.org/10.1016/S0008-6215(00)90515-9

85. Umezawa, H.; Umezawa, S.; Tsuchiya, O.; Furubayashi, Y. Japan Patent 61,140,597, 1986.

86. Wang, H.; Houk, K. N. Chem. Sci. 2014, 5 (2), 462-470.

https://doi.org/10.1039/C3SC52538D

87. Takahashi, Y.; Tsuneda, S.; Tsuchiya, T.; Koyama, Y.; Umezawa, S. Carbohydr. Res. 1992, 232 (1), 89-105. https://doi.org/10.1016/S0008-6215(00)90996-0

88. Kobayashi, Y.; Tsuchiya, T.; Umezawa, S.; Yoneta, T.; Fukatsu, S.; Umezawa, H. Bull. Chem. Soc. Jpn. 1987, 60 (2), 713-720.

https://doi.org/10.1246/bcsj.60.713

89. Seeman, J. I. Chem. Rev. 1983, 83 (2), 83-134.

https://doi.org/10.1021/cr00054a001

90. Shitara, T.; Umemura, E.; Tsuchiya, T.; Matsuno, T. Carbohydr. Res. 1995, 276 (1), 75-89.

https://doi.org/10.1016/0008-6215(95)00123-B

91. Kuwahara, R.; Tsuchiya, T. Carbohydr. Res. 1997, 299 (4), 271-279.

https://doi.org/10.1016/S0008-6215(97)00031-1

92. Giannis, A.; Sandhoff, K. Angew. Chem. Int. Ed. 1989, 28 (2), 218-220.

https://doi.org/10.1002/anie.198902181

93. Kobayashi, Y.; Tsuchiya, T. Carbohydr. Res. 1997, 298 (4), 261-277.

https://doi.org/10.1016/S0008-6215(96)00318-7

94. Haddad, J.; Vakulenko, S.; Mobashery, S. J. Am. Chem. Soc. 1999, 121 (50), 11922-11923.

https://doi.org/10.1021/ja9934520

95. Torii, T.; Tsuchiya, T.; Umezawa, S.; Umezawa, H. Bull. Chem. Soc. Jpn. 1983, 56 (5), 1522-1526.

https://doi.org/10.1246/bcsj.56.1522

96. Pathak, R.; Böttger, E. C.; Vasella, A. Helv. Chim. Acta 2005, 88 (11), 2967-2985.

https://doi.org/10.1002/hlca.200590240

97. Mandhapati, A. R.; Yang, G.; Kato, T.; Shcherbakov, D.; Hobbie, S. N.; Vasella, A.; Bottger, E. C.; Crich, D. J. Am. Chem. Soc. 2017, 139 (41), 14611-14619.

https://doi.org/10.1021/jacs.7b07754

98. Bayley, H.; Standring, D. N.; Knowles, J. R. Tetrahedron Lett. 1978, 19 (39), 3633-3634.

https://doi.org/10.1016/S0040-4039(01)95015-4

99. Li, J.; Chen, H. N.; Chang, H.; Wang, J.; Chang, C. W. Org. Lett. 2005, 7 (14), 3061-3064. https://doi.org/10.1021/ol051045d 
100. Nyffeler, P. T.; Liang, C.-H.; Koeller, K. M.; Wong, C.-H. J. Am. Chem. Soc. 2002, 124 (36), 10773-10778. https://doi.org/10.1021/ja0264605

101. Takahashi, Y.; ueda, C.; Tsuchiya, T.; Kobayashi, Y. Carbohydr. Res. 1993, 249 (1), 57-76. https://doi.org/10.1016/0008-6215(93)84060-J

102. Takahashi, Y.; Kohno, J.; Tsuchiya, T. Carbohydr. Res. 1998, 306 (3), 349-360. https://doi.org/10.1016/S0008-6215(97)10080-5

103. Hanessian, S.; Giguère, A.; Grzyb, J.; Maianti, J. P.; Saavedra, O. M.; Aggen, J. B.; Linsell, M. S.; Goldblum, A. A.; Hildebrandt, D. J.; Kane, T. R.; Dozzo, P.; Gliedt, M. J.; Matias, R. D.; Feeney, L. A.; Armstrong, E. S. ACS Med. Chem. Lett. 2011, 2 (12), 924-928.

https://doi.org/10.1021/ml200202y

104. Kudo, F.; Eguchi, T. Chem. Rec. 2016, 16 (1), 4-18.

https://doi.org/10.1002/tcr.201500210

105. Kudo, F.; Eguchi, T. J. Antibiot. 2009, 62 (9), 471-481.

https://doi.org/10.1038/ja.2009.76

\section{Authors' Biographies}

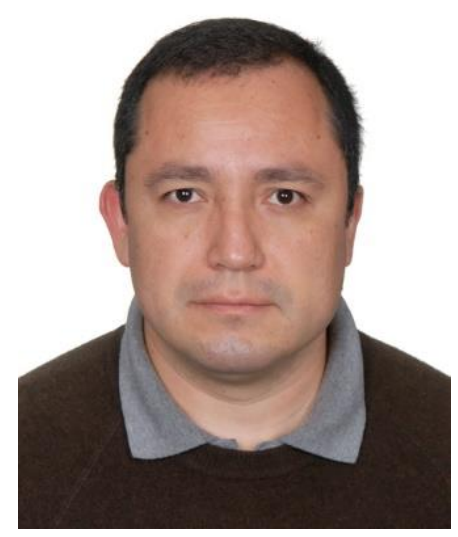

Dr. Miguel A. Vilchis-Reyes was awarded his MSc (2004) and Ph.D. (2010) at the National Autonomous University of Mexico (UNAM), the latter under the supervision of Prof. Eduardo Diaz. This was followed by a postdoctoral position at the University of Montreal in Stephen Hanessian group (2011-2015). In 2015, he relocated to Universidad Juarez Autonoma de Tabasco and was promoted to full professor in 2017. His research interests lie in the discovery of compounds with cytotoxic activity and organocatalysis. 


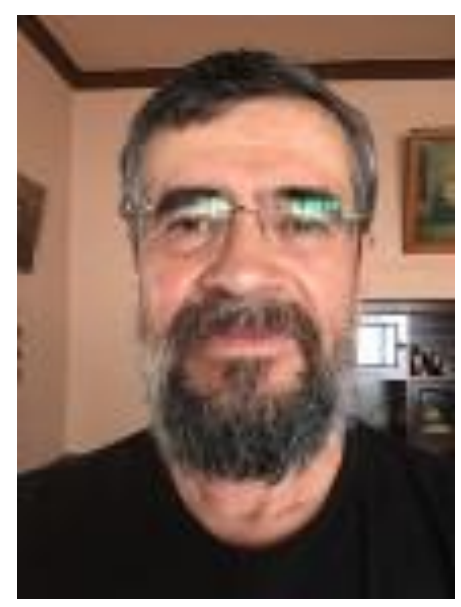

Oscar M. Saavedra studied Chemical Engineering at the University of San Francisco Xavier (Sucre, Bolivia) where he graduated with a B.Sc. degree, and Organic Chemistry at the Institut Quimic de Sarria (Barcelona, Spain) where he graduated with a MS degree. In 1997 he received his Ph.D. in Organic Chemistry under the supervision of Professor Olivier Martin at the State University of New York, Binghamton. After a postdoctoral stay in Professor Steve Hanessian's laboratory, he joined MethylGene Inc. (Montreal, Canada) were he worked for several years as Research Scientist. In 2010 he returned to Professor Hanessian's group as a Research Assistant where he worked in the Synthesis of Fluorinated Aminoglycosides. He currently works as Senior Research Scientist at NuChem Therapeutics (Montreal, Canada). 